\title{
ESTIMATIVA DIÁRIA DA EVAPOTRANSPIRAÇÃO DE REFERÊNCIA COM DADOS DE ESTAÇÃO METEOROLÓGICA CONVENCIONAL E AUTOMÁTICA
}

\section{Paulo Cesar Sentelhas}

Engenheiro Agrônomo

\section{Orientador: Prof. Dr. MARCOS VINíCIUS FOLEGATTI Co-orientador: Prof. Dr. ANTONIO ROBERTO PEREIRA}

Tese apresentada à Escola Superior de Agricultura "Luiz de Queiroz", Universidade de São Paulo, para a obtenção do título de Doutor em Agronomia, Área de concentração em Irrigação e Drenagem

PIRACICABA

Estado de São Paulo - Brasil

Outubro - 1998 
Dados Internacionais de Catalogação na Publicação (CIP) DIVISĀO DE BIBLIOTECA E DOCUMENTAÇÃO - Campus "Luiz de Queiroz"/USP

Sentelhas, Paulo Cesar

Estimativa diária da evapotranspiraçăo de referência com dados de estaçăo

meteorológica convencional e automática / Paulo Cesar Sentelhas. - - Piracicaba, 1998.

97 p. : il.

Tese (doutorado) - - Escola Superior de Agricultura Luiz de Queiroz, 1998.

Bibliografia.

1. Agrometerologia 2. Estação meteorológica 3. Evapotranspiraçăo 4. Modelo de Penman-Monteith I. Título

CDD 551.572 
Dedico este trabalho à

\section{Rô, Babi e Bebel,}

pela compreensão, apoio e,

principalmente, pelo amor que

sentimos uns pelos outros 


\author{
Ofereço este trabalho ao \\ Dr. Angelo Paes de Camargo, \\ pioneiro nos estudos de evapotranspiração \\ no Brasil, com quem tive o prazer \\ de trabalhar e aprender muito.
}




\section{AGRADECIMENTOS}

À Escola Superior de Agricultura "Luiz de Queiroz", da Universidade de São Paulo, especialmente aos Departamentos de Engenharia Rural, e de Física e Meteorologia, pela oportunidade e facilidades oferecidas para a realização deste trabalho.

Aos Professores Dr. Marcos Vinícius Folegatti e Dr. Antonio Roberto Pereira pela orientação, amizade e estímulo.

Ao Perinho, Giló, Valtão e Nilsão, por terem apostado em mim e por estarem constantemente me ensinando coisas.

Aos inúmeros colegas do curso de pós-graduação em Irrigação e Drenagem, que ao longo desses anos compartilharam dos bons momentos dessa empreitada.

Aos meus alunos e amigos desses primeiros anos de ESALQ/USP, que me ensinaram mais do que eu a eles. 


\section{SUMÁRIO}

Página

LISTA DE FIGURAS ...................................................................... vii

LISTA DE TABELAS ….....................................................................

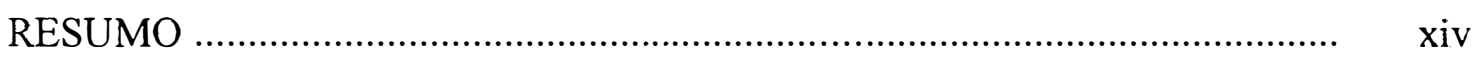

SUMMARY .................................................................................... $\quad$ xvii

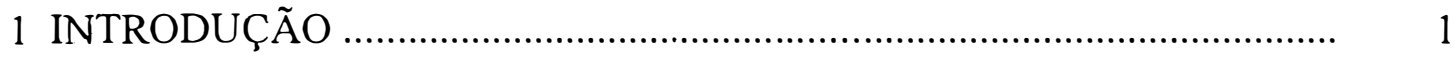

2 REVISÃO DE LITERATURA _........................................................... 4

2.1 Importância da evapotranspiração .......................................................... 4

2.2 Conceitos e definições de evapotranspiração ............................................ 5

2.3 Medida da evapotranspiração .......................................................... 8

2.4 Estimativa da evapotranspiração de referência ......................................... 11

2.5 Utilização de estações meteorológicas na estimativa da evapotranspiração de referência ............................................................................... 17

2.6 Estimativa da radiação líquida a partir de dados meteorológicos ................ 20

3 MATERIAL E MÉTODOS .................................................................. 22

3.1 Caracterização do local do experimento ................................................ 22

3.2 Área experimental e equipamentos ........................................................ 23

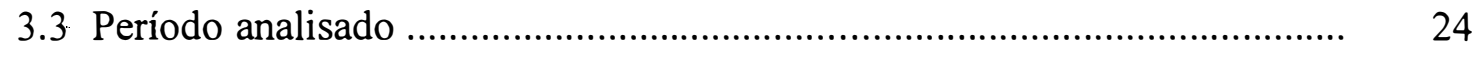

3.4 Estimativa da radiação líquida ............................................................. 24

3.5 Estimativa da evapotranspiração de referência ......................................... 26

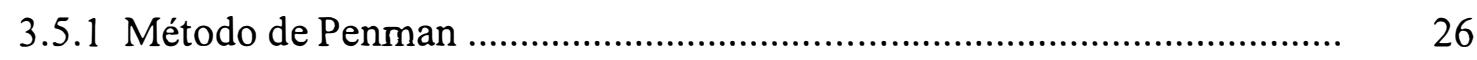

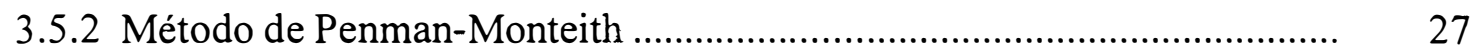

3.5.3 Método de Priestley-Taylor .............................................................. 29

3.6 Análise dos resultados ................................................................... 30

4 RESULTADOS E DISCUSSÃO …..................................................... 31 
4.1 Comparação de dados meteorológicos obtidos por estação meteorológica convencional (EMC) e automática (EMA)

4.2 Estimativa da radiação líquida a partir de elementos meteorológicos observados na EMC e na EMA

4.3 Estimativa da evapotranspiração de referência a partir de elementos meteorológicos observados na EMC e na EMA 40

4.3.1 Método de Penman ............................................................................. 40

4.3.1.1 Com Rn estimada pelas equações de Angström e Brunt ......................... $\quad 40$

4.3.1.2 Com Rn estimada pelos métodos de regressão linear .............................. 44

4.3.2 Método de Priestley-Taylor ................................................................... 47

4.3.2.1 Com Rn estimada pelas equações de Angström e Brunt ......................... 47

4.3.2.2 Com Rn estimada pelos métodos de regressão linear .............................. 50

4.3.3 Método de Penman-Monteith .................................................................. 53

4.3.3.1 Com Rn estimada pelas equações de Angström e Brunt .......................... 53

4.3.3.2 Com Rn estimada pelos métodos de regressão linear ............................... 56

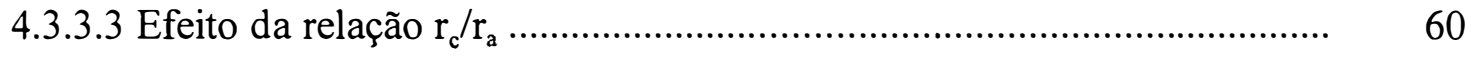

4.3.4 Análise global dos métodos de estimativa da ETo ................................... 65

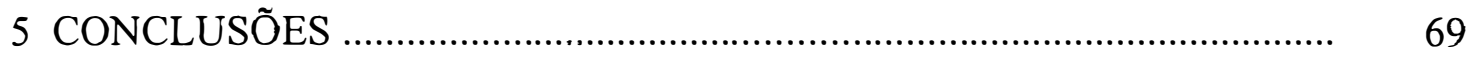

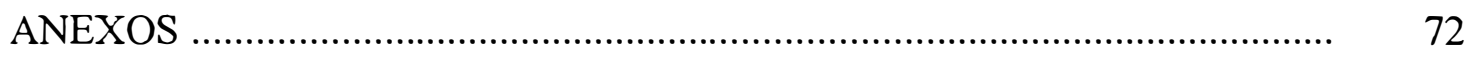

REFERÊNCIAS BIBLIOGRÁFICAS _............................................................. 85 


\section{LISTA DE FIGURAS}

1 Representação esquemática do efeito da advecção de calor sensível sobre a curva de evapotranspiração. Adaptado de Camargo \& Pereira (1990) e Pereira et al. (1997a)

2 Representação esquemática dos fluxos do balanço de água no solo ..

Página

3 Extrato do balanço hídrico climatológico normal decendial, Thornthwaite \& Mather (1955), CAD =100mm, de Piracicaba, SP, no período de 1917 a 1997

4 Extrato do balanço hídrico climatológico decendial (Thornthwaite \& Mather, 1955), em Piracicaba, SP, em 1995 e 1996

5 Relação entre dados meteorológicos diários: a) temperatura média do ar; b) umidade relativa média do ar; e desvio: c) temperatura média do ar; e d) umidade relativa média do ar, observados na EMC e na EMA, em Piracicaba, SP

6 Relação entre dados meteorológicos diários: a) velocidade média do vento a $2 \mathrm{~m}$; e b) radiação líquida; e desvio: c) velocidade média do vento a $2 \mathrm{~m}$; e d) radiação líquida, observados na EMC e na EMA, em Piracicaba, SP

7 Relação entre a radiação líquida $(\mathrm{Rn})$ medida e estimada a partir de dados da EMC: a) temperatura, pressão parcial de vapor e razão de insolação; b) temperatura e razão de insolação; c) razão de insolação, em Piracicaba, SP

8 Relação entre a radiação líquida $(\mathrm{Rn})$ medida e estimada pelas equações de Angström e Brunt, utilizando-se dados da EMC, em Piracicaba, SP

9 Relação entre a radiação líquida $(\mathrm{Rn})$ medida e estimada a partir de dados da EMA: a) temperatura, pressão parcial de vapor e radiação solar global; b) temperatura e radiação solar global; c) radiação solar global, com $\mathrm{a}=-1,74$; d) radiação solar global, com $\mathrm{a}=0$, em Piracicaba, SP 
10 Relação e desvio entre a radiação líquida $(\mathrm{Rn})$ medida na EMA e estimada a partir de dados da EMC (a e c) e da EMA (b e d), utilizando-se equações de regressão em função da temperatura $e$ razão de insolação, na EMC, e da radiação solar global, na EMA, no período de observações lisimétricas de ETo, em Piracicaba, SP

11 Relação entre a ETo estimada pelo método de Penman com dados da EMC e medida em lisímetro (a) e desvio relativo da ETo (b), com Rn estimada por Angström-Brunt, em Piracicaba, SP

12 Relação entre a ETo estimada pelo método de Penman com dados da EMA e medida em lisímetro (a) e desvio relativo da ETo (b), em Piracicaba, SP

13 Relação entre a ETo estimada pelo método de Penman, com dados da EMC e da EMA (a) e desvio relativo da ETo (b), com Rn na EMC estimada por Angström-Brunt, em Piracicaba, SP

14 Relação entre a ETo medida em lisímetro e a Rn medida na EMA, para os períodos úmido e seco, em Piracicaba, SP

15 Relação entre a ETo estimada pelo método de Penman, com dados da EMC (a) e da EMA (b), e medida em lisímetro, para o período úmido e seco, com dados de Rn na EMC estimados pela equação de Angström-Brunt, em Piracicaba, SP

16 Relação entre a ETo estimada pelo método de Penman com dados da EMC e medida em lisímetro (a) e desvio relativo da ETo (b), com Rn estimada pela equação 22, em Piracicaba, SP

17 Relação entre a ETo estimada pelo método de Penman com dados da EMA e medida em lisímetro (a) e desvio relativo da ETo (b), com Rn estimada pela equação 23, em Piracicaba, SP

18 Relação entre a ETo estimada pelo método de Penman, com dados da EMC e da EMA (a) e desvio relativo da ETo (b), com Rn estimada pelas equações 22 e 23, respectivamente, em Piracicaba, SP

19 Relação entre a ETo estimada pelo método de Penman, com dados da EMC (a) e da EMA (b), e medida em lisímetro, para o período úmido e seco, com dados de Rn estimados pelas equações 22 e 23, em Piracicaba, SP 
20 Relação entre a ETo estimada pelo método de Priestley-Taylor $(\alpha=1,26)$, com dados da EMC (a) e da EMA (b), e medida em lisímetro, para o período úmido e seco, com dados de Rn na EMC estimados pela equação de Angström-Brunt, em Piracicaba, SP .

21 Valores diários e médios do parâmetro de Priestley-Taylor nos períodos úmido e seco, utilizando-se dados provenientes da EMC (a) e da EMA (b), sendo Rn estimada por Angström-Brunt e medida, respectivamente, em Piracicaba, SP

22 Relação entre a ETo estimada pelo método de Priestley-Taylor, com dados da EMC (a) e da EMA (b), e medida em lisímetro, para o período úmido e seco, com dados de Rn estimados pelas equações 22 e 23 , respectivamente

23 Valores diários e médios do parâmetro de Priestley-Taylor nos períodos úmido e seco, utilizando-se dados provenientes da EMC (a) e da EMA (b), sendo Rn estimada pelas equações 22 e 23, respectivamente

24 Relação entre a ETo estimada pelo método de Priestley-Taylor e medida em lisímetro, utilizando-se $\alpha$ igual a 1,00 no período úmido e igual a 1,33 no período seco, a partir dos dados meteorológicos obtidos na EMA, em Piracicaba, SP

25 Relação entre a ETo estimada pelo método de Penman-Monteith com dados da EMC e medida em lisímetro (a) e desvio relativo da ETo (b), com Rn estimada por Angström-Brunt, em Piracicaba, SP..

26 Relação entre a ETo estimada pelo método de Penman-Monteith com dados da EMA e medida em lisímetro (a) e desvio relativo da ETo (b), em Piracicaba, SP

27 Relação entre a ETo estimada pelo método de Penmam-Monteith, com dados da EMC e da EMA (a) e desvio relativo da ETo (b), com Rn estimado na EMC por Angström-Brunt, em Piracicaba, SP

28 Relação entre a ETo estimada pelo método de Penman-Monteith, com dados da EMC (a) e da EMA (b), e medida em lisímetro, para o período úmido e seco, com dados de Rn estimados na EMC por Angström-Brunt, em Piracicaba, SP 
29 Relação entre a ETo estimada pelo método de Penman-Monteith com dados da EMC e medida em lisímetro (a) e desvio relativo da ETo (b), com Rn estimada pela equação 22, em Piracicaba, SP .........

30 Relação entre a ETo estimada pelo método de Penman-Monteith com dados da EMA e medida em lisímetro (a) e desvio relativo da ETo (b), com Rn estimada pela equação 23, em Piracicaba, SP ........

31 Relação entre a ETo estimada pelo método de Penmam-Monteith, com dados da EMC e da EMA (a) e desvio relativo da ETo (b), com $\mathrm{Rn}$ estimada, respectivamente, pelas equações 22 e 23 , em Piracicaba, SP

32 Relação entre a ETo estimada pelo método de Penman-Monteith, com dados da EMC (a) e da EMA (b), e medida em lisímetro, para o período úmido e seco, com dados de Rn estimados pelas equações 22 e 23, respectivamente, na EMC e na EMA, em Piracicaba, SP .....

33 Relação entre a ETo estimada pelo método de Penman-Monteith com dados da EMC e medida em lisímetro (a) e desvio relativo da ETo (b), com Rn estimada por Angström-Brunt e $r_{c} / r_{a}$ por Pereira et al. (1998), em Piracicaba, SP

34 Relação entre a ETo estimada pelo método de Penman-Monteith com dados da EMA e medida em lisímetro (a) e desvio relativo da ETo (b), com Rn medida e $r_{c} / r_{a}$ por Pereira et al. (1998), em Piracicaba, SP

35 Relação entre a ETo estimada pelo método de Penmam-Monteith, com dados da EMC e da EMA (a) e desvio relativo da ETo (b), com Rn estimada por Angström-Brunt na EMC e $r_{c} / r_{a}$ por Pereira et al. (1998), em Piracicaba, SP

36 Relação entre a ETo estimada pelo método de Penman-Monteith, com dados da EMC (a) e da EMA (b), e medida em lisímetro, para o período úmido e seco, com dados de Rn estimado por AngströmBrunt na EMC e $r_{c} / r_{a}$ por Pereira et al. (1998), em Piracicaba, SP .....

37 Relação entre a ETo estimada pelo método de Penman-Monteith com dados da EMC e medida em lisímetro (a) e desvio relativo da ETo (b), com Rn estimada pela equação 22 e $r_{c} / r_{a}$ por Pereira et al. (1998), em Piracicaba, SP 
38 Relação entre a ETo estimada pelo método de Penman-Monteith com dados da EMA e medida em lisímetro (a) e desvio relativo da ETo (b), com Rn estimada pela equação 23 e $r_{c} / r_{a}$ por Pereira et al. (1998), em Piracicaba, SP

39 Relação entre a ETo estimada pelo método de Penmam-Monteith, com dados da EMC e da EMA (a) e desvio relativo da ETo (b), com $\mathrm{Rn}$ estimada, respectivamente, pelas equações 22 e 23 e $r_{c} / r_{a}$ por Pereira et al. (1998), em Piracicaba, SP

40 Relação entre a ETo estimada pelo método de Penman-Monteith, com dados da EMC (a) e da EMA (b), e medida em lisímetro, para o período úmido e seco, com dados de Rn estimado, respectivamente, pelas equações 22 e 23 e $r_{c} / r_{a}$ por Pereira et al. (1998), em Piracicaba, SP 


\section{LISTA DE TABELAS}

1 Especificação dos equipamentos das estações meteorológicas convencional (EMC) e automática (EMA)

Página 23

2 Equações de regressão linear de estimativa da radiação líquida ( $R n)$, expressa em $\mathrm{MJ} \cdot \mathrm{m}^{-2} \cdot \mathrm{d}^{-1}$, em função dos elementos meteorológicos obtidos na estação meteorológica convencional (EMC)

3 Equações de regressão linear de estimativa da radiação líquida (Rn), expressa em MJ.m.-2. $\mathrm{d}^{-1}$, em função dos elementos meteorológicos obtidos na estação meteorológica automática (EMA)

4 Coeficiente angular (b) e de determinação $\left(\mathrm{r}^{2}\right)$ da relação entre a ETo estimada pelo método de Penman e medida em lisímetro, nos períodos integral, úmido e seco, utilizando-se dados da EMC e da EMA, em Piracicaba, SP

5 Coeficiente angular (b) e de determinação $\left(\mathrm{r}^{2}\right)$ da relação entre a ETo estimada pelo método de Priestley-Taylor e medida em lisímetro, nos períodos integral, úmido e seco, utilizando-se dados da EMC e da EMA, em Piracicaba, SP

6 Coeficiente angular (b) e de determinação $\left(\mathrm{r}^{2}\right)$ da relação entre a ETo estimada pelo método de Penman-Monteith e medida em lisímetro, nos períodos integral, úmido e seco, utilizando-se dados da EMC e da EMA, em Piracicaba, SP

7 Média diária dos dados meteorológicos observados na Estação Meteorológica Convencional (EMC): temperatura do ar (T); umidade relativa do ar (UR); velocidade do vento a $2 \mathrm{~m}\left(\mathrm{U}_{2 \mathrm{~m}}\right)$; e número de horas de brilho solar (n), em Piracicaba, SP

8 Média diária dos dados meteorológicos observados na Estação Meteorológica Automática (EMA): temperatura do ar (T); umidade relativa do ar (UR); velocidade do vento a $2 \mathrm{~m}\left(\mathrm{U}_{2 \mathrm{~m}}\right)$; e radiação líquida (MJ.m-2.d-1), em Piracicaba, SP 
9 Evapotranspiração de referência medida em lisímetro (ETo-Lis) e estimada pelos métodos de Penman (ETo-P), Priestley-Taylor (ETo-PT) e Penman-Monteith (ETo-PM), com dados medidos na estação meteorológica convencional (EMC), em Piracicaba, SP ............................

10 Evapotranspiração de referência medida em lisímetro (ETo-Lis) e estimada pelos métodos de Penman (ETo-P), Priestley-Taylor (ETo-PT) e Penman-Monteith (ETo-PM), com dados medidos na estação meteorológica automática (EMA), em Piracicaba, SP ............................... 


\title{
ESTIMATIVA DIÁRIA DA EVAPOTRANSPIRAÇÃO DE REFERÊNCIA COM DADOS DE ESTAÇÃO METEOROLÓGICA CONVENCIONAL E AUTOMÁTICA
}

\author{
Autor: PAUlo CESAR SENTELHAS \\ Orientador: Prof. Dr. MARCOS VINÍCIUS FOLEGATTI \\ Co-Orientador: Prof. Dr. ANTONIO ROBERTO PEREIRA
}

\section{RESUMO}

Foram avaliados os efeitos da utilização de dados meteorológicos obtidos com estações convencional (EMC) e automática (EMA) na estimativa diária da evapotranspiração de referência (ETo), pelos métodos de Penman (P), Priestley-Taylor (P-T) e Penman-Monteith (P-M), padrão FAO, em Piracicaba, SP (Lat.: 2242'30" S; Long.: $47^{\circ} 30^{\prime} 00^{\prime \prime}$ W; e $546 \mathrm{~m}$ de altitude). Para tanto foram utilizadas medidas de ETo obtidas em lisímetro de pesagem automatizada com célula de carga, em dois períodos: 1) úmido - entre dezembro de 1995 e maio de 1996; e 2) seco - de agosto a dezembro de 1996.

Primeiro, comparou-se os dados meteorológicos provenientes da EMC e da EMA, observando-se boa concordância para temperatura média $(\mathrm{T})$ e umidade relativa média do ar (UR), com coeficiente angular (b) de 0,97 e 0,99, e o coeficiente de determinação $\left(\mathrm{r}^{2}\right)$ igual a 0,97 e 0,81 , repectivamente. Para velocidade média do vento $\left(\mathrm{U}_{2 \mathrm{~m}}\right)$ e radiação líquida $(\mathrm{Rn})$, não houve boa concordância entre os dados das duas estações, em razão da estimativa desses elementos na EMC, o que proporcionou baixa precisão para $U_{2 m}\left(r^{2}=0,57\right)$ e baixa exatidão para $R n(b=1,23)$. Com o objetivo de minimizar as diferenças de Rn entre a EMC e a EMA, foram desenvolvidos, testados e 
validados modelos de regressão linear de estimativa desse elemento a partir de temperatura (T), pressão parcial de vapor (ea), razão de insolação (n/N), e radiação solar global (Qg), tanto para a EMC como para a EMA. Os resultados indicaram estimativas mais precisas e exatas da $\mathrm{Rn}$ do que aquelas obtidas pela associação das equações de Angström e de Brunt. Para dados obtidos na EMC, pode-se estimar a $\mathrm{Rn}$ com boa confiabilidade $\left(b=1,0043\right.$ e $\left.\mathrm{r}^{2}=0,88\right)$ a partir de $\mathrm{T}$ e de $\mathrm{n} / \mathrm{N}$. Para dados da EMA, essa estimativa pode ser obtida a partir da $\mathrm{Qg}$, com a relação $\mathrm{Rn}=0,574 \mathrm{Qg}$, que na validação

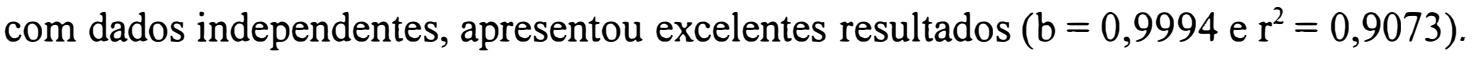

Segundo, após essas análises preliminares, efetuou-se a estimativa da ETo a partir dos dados das duas estações, empregando-se os três métodos. De modo geral, foi observada tendência de melhores estimativas da ETo a partir de dados da EMA em relação à EMC, por qualquer dos métodos, com valores menores (@18\%) nas estimativas a partir da EMC. Essa tendência foi reduzida quando se utilizou estimativa da $\mathrm{Rn}$ pelos modelos de regressão linear. Tomando-se como referência os dados da EMA, o método de Penman estimou bem a ETo no período seco $\left(\mathrm{b}=1,0589\right.$ e $\mathrm{r}^{2}=$ 0,9013). No entanto, no período úmido a superestimativa média foi de $31 \%(b=1,3108$ e $\mathrm{r}^{2}=0,9143$ ). O método de P-T, apresentou resultados semelhantes aos de Penman quando utilizou-se $\alpha=1,26$, sugerido como padrão. Porém, com $\alpha=1$, no período úmido, e igual a 1,33, no período seco, houve excelente estimativa de ETo, com b= 1,028 e $\mathrm{r}^{2}=0,91$. O método de P-M foi o que apresentou as melhores estimativas de ETo, considerando-se o período integral da análise. Porém, analisando-se distintamente os períodos úmido e seco, observou-se resultados diferentes aos demais métodos, ou seja, superestimativa no período úmido de $14 \%$ e subestimativa de $10 \%$ no período seco. Empregando-se a este método a estimativa da relação $r_{c} / r_{a}$ sugerida por Pereira et al. (1998), observou-se melhoria nas estimativas de ETo no período úmido ( $b=0,9977$ e $\mathrm{r}^{2}$ $=0,90$ ); porém, piora no período seco, que passou a ter subestimativas da ordem de $27 \%$.

Terceiro, para a estimativa da ETo a partir da EMC, os melhores resultados foram obtidos estimando-se a Rn pelo método da regressão linear e a ETo pelo método de Penman, para o período integral; pelo método de P-M com $r_{c} / r_{a}$ por Pereira et al. 
(1998), para o período úmido; e pelo método de Penman, para o período seco. Para as estimativas a partir de dados da EMA, os melhores ajustes aos dados de ETo medidos foram com o método de P-M com $r_{c} / r_{a}$ segundo Smith (1991), para o período integral; com o método de P-M com $r_{c} / r_{a}$ segundo Pereira et al. (1998), para o período úmido; e com o método de P-T $(\alpha=1,26)$ ou Penman, para o período seco. 


\title{
ESTIMATING DAILY REFERENCE EVAPOTRANSPIRATION WITH DATA FROM CONVENTIONAL AND AUTOMATIC WEATHER STATIONS
}

\author{
Author: PaUlo CeSAR Sentelhas \\ Adviser: Prof. Dr. MARCos VINÍCIUS FOLEGATTI \\ Co-Adviser: Prof. Dr. ANTONIO ROBERTO PEREIRA
}

\section{SUMMARY}

Daily estimatives of reference evapotranspiration (ETo) by Penman (P), Priestley-Taylor (P-T) and Penman-Monteith (P-M) methods, utilizing data obtained with conventional (EMC) and with automatic (EMA) weather stations were evaluated at

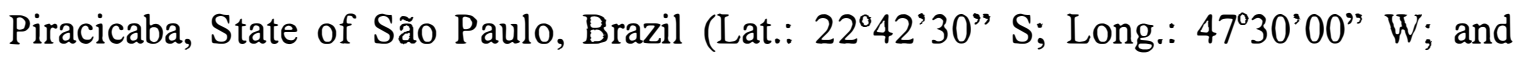
Altitude of $546 \mathrm{~m}$ ). For such, it was used 127 data points from an automatic weight lysimeter in two periods: 1) wet season - from December 1995 to May 1996; and, 2) dry season - from August to December 1996.

First, meteorological data from the EMC and EMA were compaired and the results showed small discrepancies for average air temperature $(\mathrm{T})$ and relative humidity (UR), with angular coefficient (b) being, respectivelly, 0.97 and 0.99 , and determination coefficient $\left(\mathrm{r}^{2}\right)$ equal to 0.97 and 0.81 . For average wind speed $\left(\mathrm{U}_{2 \mathrm{~m}}\right)$ and net radiation $(\mathrm{Rn})$, the agreement between the two stations was not good, because the estimatives of these elements in EMC resulted in low precision for $U_{2 m}\left(r^{2}=0.57\right)$ and high overestimation for $\mathrm{Rn}(\mathrm{b}=1.23)$. Aiming to minimize the $\mathrm{Rn}$ differences between EMC and EMA linear regression models were developed, tested, and validated for estimating $\mathrm{Rn}$ from air temperature $(\mathrm{T})$, partial water vapor pressure (ea), insolation ratio $(\mathrm{n} / \mathrm{N})$, and 
global solar radiation data. The results indicated better $\mathrm{Rn}$ estimatives from linear regression models than from the association of the Angström's and Brunt's equations. With EMC data, Rn can be well estimated $\left(b=1.0043\right.$ and $\left.r^{2}=0.88\right)$ with $T$ and $n / N$. For the EMA, Rn can be obtained from global solar radiation $(\mathrm{Qg})$ through the relation $\mathrm{Rn}=0,574 \mathrm{Qg}$, which gave very good validation $\left(\mathrm{b}=0.9994\right.$ and $\left.\mathrm{r}^{2}=0.9073\right)$.

Second, after these preliminary analysis of the raw data, ETo was estimated for the two stations using the three above mentioned methods. In general, there was a tendency of better ETo estimatives with EMA data in relation to the EMC, with lower (around 18\%) values given by the EMC data. This tendency was reduced when Rn was estimated by the linear regression model for EMC. Taking EMA data as reference, the Penman method showed good ETo estimatives during the dry season, but during the wet season this method overestimate ETo by $31 \%$. The P-T method showed the same results when $\alpha=1.26$; however, when $\alpha=1$, for wet season, and $\alpha=1.33$, for dry season, were used this method produce very good estimatives, with $b=1.028$ and $r^{2}=0.91$. The P-M was the best method to estimate ETo for the total period (wet + dry). But when the two seasons were separeted, it was observed different results in relation to the others methods. There was method overestimation $(\cong 14 \%)$ in the wet season and underestimation $(\cong 10 \%)$ in the dry season. Using the relation $r_{c} / r_{a}$ sugested by Pereira et al. (1998), it was observed a better estimative in the wet season $\left(b=0.9977\right.$ and $r^{2}=$

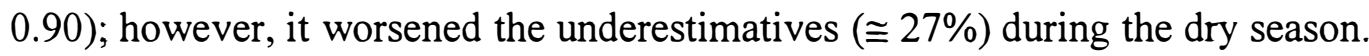

Third, to estimate ETo with EMC data, the best results were obtained with Rn estimated by linear regression model and by Penman for total period, by P-M with $r_{c} / r_{a}$ by Pereira et al. (1998) for the wet season, and by Penman for the dry season. To estimate ETo with EMA data, the best adjust with lisymeter data were with P-M using $r_{c} / r_{a}$ sugested by Smith (1991) for the total period, with P-M method using $r_{c} / r_{a}$ sugested by Pereira et al. (1998) for the wet season, and with P-T or Penman for the dry season. 


\section{INTRODUÇÃO}

O planejamento e a operação de um projeto de irrigação em que se vise a máxima produção e boa qualidade do produto, usando de maneira eficiente a água, requer conhecimentos das interrelações entre as diversas fases do sistema solo-plantaatmosfera.

A irrigação é, basicamente, uma operação agrícola para atendimento das necessidades de água das culturas, sendo fundamental nos sistemas de produção de regiões com ocorrências de secas regulares, onde torna-se operação fundamental, tão importante quanto a fertilização, controle de pragas e doenças, e tratos culturais, provendo importante grau de estabilidade para a produção de alimentos. A possibilidade de estimar corretamente a evapotranspiração e, a partir delas, determinar a quantidade de água a ser suprida ao solo é importante para o monitoramento da irrigação, pois tanto sub como super-irrigações resultam em baixas produções (Camargo \& Pereira, 1990). Além disso, o custo cada vez maior de energia de bombeamento, a crescente disputa pela água com o setor industrial e as cidades, e a eminente cobrança pelo uso da água, tem nos levado a buscar alternativas que racionalizem seu uso, visando a redução nos custos da irrigação.

Desse modo, a determinação da necessidade hídrica da cultura, ou seja, da evapotranspiração da cultura, torna-se um dos dados básicos que se precisa conhecer, tanto a nível de planejamento como a nível de manejo da irrigação, haja visto que o objetivo da irrigação é manter a água facilmente disponível no solo para as plantas, entre as umidades de capacidade de campo e crítica, intervalo no qual a cultura evapotranspira na sua taxa máxima. 
A evapotranspiração de uma cultura (ETc), varia com seu estádio de desenvolvimento e com as condições atmosféricas, variáveis que irão condicionar a freqüência de irrigação, juntamente com a chuva e a água disponível no solo.

Vários trabalhos vêm demonstrando a importância e a necessidade de se estimar corretamente a ETc, visando o manejo da irrigação (Jensen \& Wright, 1978; Fuchs et al., 1987; Mohammad \& Al-Amoud, 1993), especialmente onde a água é um recurso pouco disponível, como nas regiões de clima árido e semi-árido. A estimativa mais comum é a que se utiliza da evapotranspiração de referência (ETo) e do coeficiente de cultura (Kc), metodologia preconizada pela FAO (Doorenbos \& Pruitt, 1977; Doorenbos \& Kassam, 1994), em razão da sua praticidade. Assim, a estimativa da ETc fica sendo dependente da estimativa da ETo, que pode ser obtida por diferentes métodos.

Dentre os vários métodos de estimativa da evapotranspiração de referência, na escala diária, a FAO adotou o de Penman-Monteith como padrão (Smith, 1991), embora seu uso exija informações meteorológicas nem sempre disponíveis, limitando-o principalmente a projetos de pesquisas (Pereira et al., 1997a). Porém, a evolução tecnológica das estações meteorológicas automáticas e a sua popularização atual, têm facilitado a aquisição e a organização dos dados, e o uso desse método (Bausch, 1990; Tanner, 1990). Apesar das estações automáticas fornecerem dados com melhor caracterização das condições meteorológicas, em razão da aquisição contínua dos dados, elas nem sempre são disponíveis, havendo necessidade de utilização de dados meteorológicos provenientes de estações convencionais com menor representatividade, especialmente das condições médias.

Em função do exposto, o objetivo deste trabalho é:

a) comparar dados meteorológicos obtidos por estação meteorológica convencional e automática visando detectar possíveis fontes de erros nas estimativas provenientes dos dados da estação convencional, assumindo que a estação automática representa melhor a verdadeira condição atmosférica; 
b) elaborar e testar métodos de estimativa da radiação líquida, a partir de dados meteorológicos obtidos na estação convencional e na automática, visto que ela não é normalmente medida em estações convencionais e em algumas estações automáticas, e que sua estimativa é fundamental na determinação de ETo;

c) avaliar o efeito da utilização de dados provenientes de estação meteorológica convencional e automática na estimativa da evapotranspiração de referência, utilizando-se os métodos de Penman, Penman-Monteith e Priestley-Taylor, e compará-las aos dados medidos em lisímetro de pesagem cultivado com grama;

d) testar a utilização dos diferentes métodos de estimativa da radiação líquida e também da relação entre resistência da cobertura e aerodinâmica na determinação da evapotranspiração de referência utilizando-se os métodos de Penman, PenmanMonteith e Priestley-Taylor, em período seco e úmido. 


\section{REVISÃO DE LITERATURA}

\subsection{Importância da evapotranspiração}

O crescente aumento na adoção da técnica de irrigação, na busca da estabilização da produção de alimentos, fez com que a necessidade de informações nessa área de conhecimento das ciências agronômicas aumentasse rapidamente nas últimas décadas, especialmente, com relação às informações agroclimáticas, no intuito de torná-la uma atividade mais eficiente, tanto sob o ponto de vista econômico como ambiental.

A prática da irrigação, que tem por objetivo fornecer água às plantas para que elas evapotranspirem em sua taxa máxima, ou seja, manter a disponibilidade de água no solo entre a umidade da capacidade de campo e a umidade crítica para a cultura, nem sempre traz os resultados esperados, haja visto que quando empregada de forma inadequada, ou seja, irrigação deficiente ou excessiva, pode resultar em redução da produção (Camargo \& Pereira, 1990), quer seja pela deficiência hídrica que irá afetar o metabolismo fotossintético das plantas, ou pela redução da aeração do solo, lixiviação de nutrientes, alteração microclimática, e favorecimento da ocorrência de doenças fúngicas (Sentelhas, 1992).

Assim, a determinação do consumo de água pelas culturas torna-se requisito fundamental ao sucesso da irrigação. Vários trabalhos demonstram a importância e a necessidade de se estimar corretamente a evapotranspiração das culturas, visando o manejo racional da irrigação e a otimização da eficiência do uso da água (Jensen \& Wright, 1978; Fuchs et al., 1987; Mohammad \& Al-Amoud, 1993), especialmente onde o recurso hídrico é pouco disponível, como nas regiões de clima semi-árido e árido.

Existem diversas maneiras de se determinar a evapotranspiração de uma cultura. No entanto, a multiplicidade de termos, existentes na literatura, relacionados à 
evapotranspiração, e que são, muitas vezes, vagos e dúbios, tem dificultado a sua utilização e, especialmente, a transposição e comparação de resultados (Pereira et al., 1997a), mostrando a necessidade de padronização de conceitos e definições.

\subsection{Conceitos e definições de evapotranspiração}

Apesar de bastante estudado desde os anos 40 deste século, e mais intensamente nessas três últimas décadas (Alves et al., 1998), o processo conjunto de transferência de água para a atmosfera pela evaporação da água do solo e pela transpiração da vegetação, denominado de evapotranspiração, tem sido apresentado na literatura com diferentes denominações, o que dificulta o seu entendimento e utilização correta (Pereira et al., 1997a).

O conceito de evapotranspiração foi introduzido pela primeira vez por Thornthwaite et al. (1944), citado por Camargo (1962), nos Estados Unidos, como sendo a ocorrência simultâneados processos de evaporação e de transpiração, numa superfície vegetada. Alguns anos mais tarde, Thornthwaite $(1946,1948)$ definiu como potencial (ETP) a evapotranspiração que ocorre nas seguintes condições de contorno: extensa superfície vegetada; em crescimento ativo; cobrindo totalmente o solo; e sem restrição de ordem hídrica, de modo que somente o balanço vertical de energia interfira no processo. Quase que simultâneamente, Penman (1948, 1956), na Inglaterra, também definiu a ETP, ressaltando que a vegetação deveria ser baixa e com altura uniforme. De uma modo geral, a grama foi tomada como padrão, em razão da sua utilização nos postos meteorológicos (Pereira et al., 1997a).

Essa definição de ETP apesar de largamente utilizada, especialmente na elaboração do balanço hídrico climatológico proposto por Thornthwaite \& Mather (1955), apresenta pontos que geram incompreensão. O principal, de acordo com Pereira et al. (1997a), é com relação ao tamanho da área vegetada, que não é estipulada de modo a se atingir as condições de contorno exigidas, ou seja, eliminar as trocas laterais de energia. Assim, tal condição de contorno somente seria satisfeita após período de chuva, 
quando extensa área se encontra úmida, minimizando a advecção de energia (Pereira et al., 1997a). Segundo Stanhill (1973), citado por Pereira et al. (1997a), em regiões áridas essa definição não se aplicaria à maioria dos campos irrigados. Trabalhos realizados por Goltz \& Pruitt (1970), citado por Pereira et al. (1997a), na Califómia, e por Stanhill (1961) em Israel, indicaram que o tamanho da área tampão, para se minimizar os efeitos da advecção, deveria ser da ordem de 100 a 300m de extensão.

Nas condições de clima árido, a evapotranspiração que predomina é aquela oriunda tanto do balanço horizontal (radiação líquida), como do vertical de energia (advecção de calor sensível), resultando em valores maiores do que os que ocorreriam na condição potencial. Penman (1956) denominou essa evapotranspiração como aquela que ocorreria no meio-do-deserto, sendo por isso definida como de oásis (ETO) por Camargo \& Pereira (1990). De acordo com Pereira et al. (1997a), a ETO, normalmente, ocorre quando a área tampão é insuficiente para eliminar os efeitos advectivos do calor sensível, situação normalmente observada em pequenas áreas irrigadas circundadas por áreas secas. A Figura 1 ilustra o efeito da adveção sobre a curva de evapotranspiração, indicando a área tampão, e as áreas de ocorrência de ETP e de ETO.

Observa-se também na Figura 1, a evapotranspiração na área seca, denominada de real (ETR), que é aquela que ocorre numa superfície vegetada, independente de sua área, de seu porte e das condições de disponibilidade de água no solo, portanto, sem imposição de qualquer condição de contorno (Pereira et al., 1997a).

A evapotranspiração de referência (ETo) foi introduzida no início dos anos 70, sendo definida por Jensen (1973) como aquela que ocorre numa cultura padrão, no caso a alfafa, com uma altura entre 0,3 e 0,5m, numa dada condição climática, e com cerca de $100 \mathrm{~m}$ de área tampão na direção dos ventos predominates. Posteriormente, Doorenbos \& Pruitt (1977), definiram como ETo a evapotranspiração que ocorre em uma extensa área de grama com altura de 0,08 a $0,15 \mathrm{~m}$, em crescimento ativo, cobrindo totalmente o solo e sem deficiência de água. Essa definição vai ao encontro à definição de ETP postulada por Thornthwaite (1946) e por Penman (1948). De acordo com Smith (1991), a ETo é definida como aquela que ocorre de uma cultura hipotética, com altura fixa de $0,12 \mathrm{~m}$, 
albedo igual a 0,23 e resistência da cobertura ao transporte de vapor d'água igual a $69 \mathrm{~s} \cdot \mathrm{m}^{-1}$, que representaria a evapotranspiração de um gramado verde, de altura uniforme, em crescimento ativo, cobrindo totalmente a superficie do solo e sem falta de água (Sediyama, 1996; Pereira et al., 1997a). A definição de ETo, de acordo com Sediyama (1996), foi adotada para evitar conflitos entre as definições existentes.

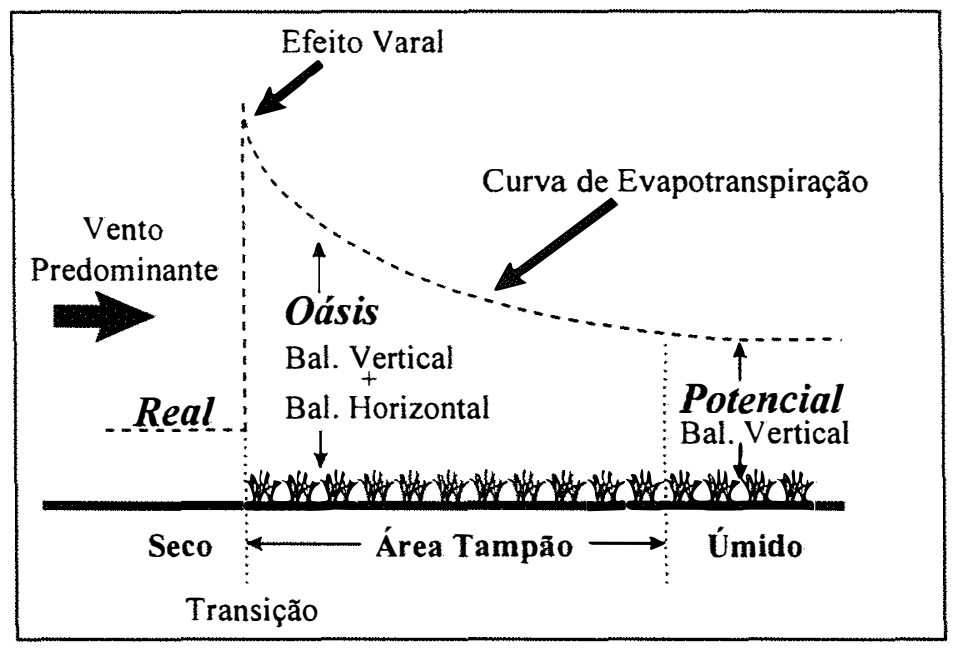

Figura 1. Representação esquemática do efeito da advecção de calor sensível sobre a curva de evapotranspiração. Adaptado de Camargo \& Pereira (1990) e Pereira et al. (1997a).

A evapotranspiração da cultura (ETc), também conhecida como máxima (ETm), é definida como aquela que ocorre de uma superfície vegetada com a cultura de interesse em qualquer fase de seu desenvolvimento e sem restrição hídrica (Doorenbos \& Kassam, 1994). O conhecimento da ETc é fundamental em projetos e no manejo da irrigação (Alves et al., 1998), pois ela representa a quantidade de água que deve ser reposta ao solo para manter o crescimento e a produção em condições ideais. A metodologia preconizada pela FAO, em seu boletim número 24 (Doorenbos \& Pruitt, 1977), sugere a estimativa de ETc a partir da ETo e do coeficiente de cultura (Kc), utilizando-se como padrão o método de Penman (1948). Essa metodologia, denominada de dois passos, ainda é bastante empregada, porém, atualmente, o novo método estabelecido como 
padrão pela FAO (Smith, 1991) para se estimar a ETo é o de Penman-Monteith (Monteith, 1965), apesar de alguns problemas relacionados à sua aplicação prática (Alves et al., 1998).

\subsection{Medida da evapotranspiração}

A medida direta da evapotranspiração é extremamente difícil e onerosa, exigindo a instalação de equipamentos especiais, o que limita sua utilização às condições experimentais (Pereira et al., 1997a). Nessas condições, a medida da evapotranspiração pode ser obtida pelo balanço hídrico do solo ou através de lisímetros.

O balanço hídrico nada mais é do que a contabilização da água do solo, resultante da aplicação do Princípio de Conservação de Massa num volume de solo vegetado. A variação de armazenamento de água no solo $(\triangle \mathrm{ARM})$ por unidade de tempo representa o balanço entre a água que entrou e a que saiu do volume de controle. Considerando-se um volume de controle delimitado por uma área superficial unitária e uma profundidade L, o balanço hídrico nessa camada de solo pode ser representado pelos seguintes fluxos: chuva (P); irrigação (I); orvalho (O); escorrimento superficial (Run-in - Ri, e Run-off Ro); drenagem lateral (DLi e DLo); ascensão capilar (AC); evapotranspiração (ET); e drenagem profunda (DP) (Figura 2). Considerando-se que o orvalho (O) representa uma contribuição com ordem de magnitude muito pequena (no máximo $0,5 \mathrm{~mm} / \mathrm{d}$ ), que as entradas e saídas por escorrimento superficial (Ri e Ro) e drenagem lateral (DLi e DLo) tendem a se compensar, o balanço hídrico pode ser expresso da seguinte forma:

$\triangle \mathrm{ARM}=\mathrm{P}+\mathrm{I}-\mathrm{ET}+\mathrm{AC}-\mathrm{DP}$ 


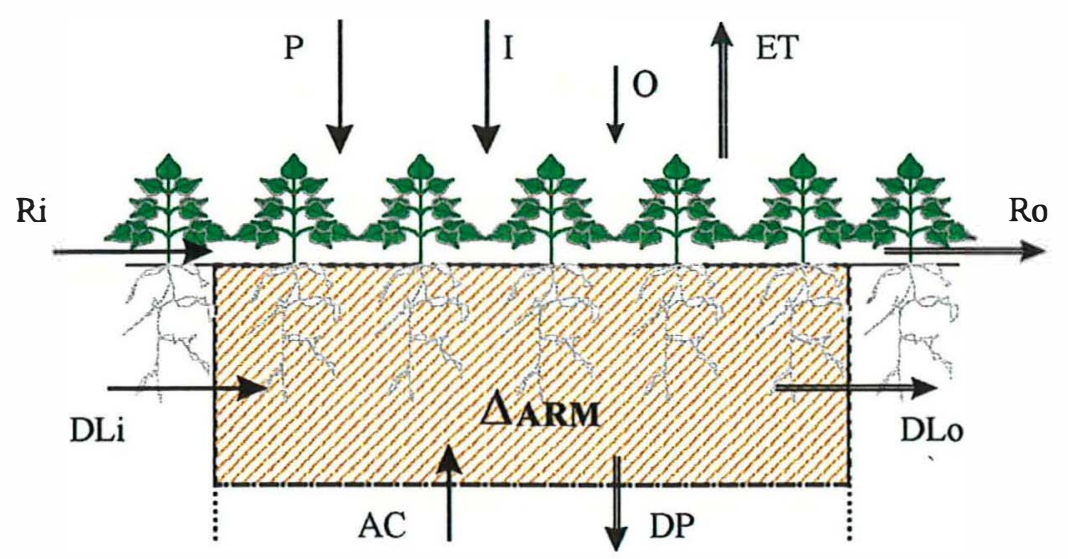

Figura 2. Representação esquemática dos fluxos do balanço de água no solo.

Nesse caso, a precipitação e a irrigação podem ser medidas mais facilmente. A ascensão capilar, que ocorre em períodos secos, a drenagem profunda, que ocorre em períodos extremamente chuvosos, e a variação de armazenamento de água no solo $(\triangle \mathrm{ARM})$, podem ser determinadas utilizando-se técnicas de estimativas, descritas por Reichardt (1996). Assim, resta como resíduo a ET. Essa metodologia de determinação da ET, é limitada em razão da elevada variabilidade espacial das características físicas do solo, como por exemplo a condutividade hidráulica, que é transferida para os resultados de ET. Exemplo disso, é apresentado por Villagra et al. (1995), que observaram um coeficiente de variação da ordem de $42 \%$ na estimativa da ET em um transecto de $125 \mathrm{~m}$ com 25 pontos de amostragem, concluindo que outros métodos de medida e estimativa da ET são mais viáveis para tal determinação, em áreas onde ocorre expressiva variabilidade espacial das características hidráulicas do solo.

A medida direta da evapotranspiração pode ser obtida a partir de lisímetro, também conhecido como evapotranspirômetro, que é um equipamento constituído de uma caixa impermeável, contendo um volume de solo, permitindo conhecer detalhadamente alguns dos termos do balanço de água no volume amostrado (Pereira et al., 1997a).

Os lisímetros são classificados de acordo com seu princípio de funcionamento. $\mathrm{O}$ lisímetro de drenagem, utilizado nos anos 40 por Thornthwaite (Thornthwaite, 1948) 
para a determinação da ETP e, posteriormente, empregado por Camargo (1962) no Estado de São Paulo, é um equipamento que se baseia no princípio de conservação de massa para a água num volume de solo. De acordo com Camargo (1971), os lisímetros de drenagem são grandes vasos com paredes impermeáveis enterrados até o nível do solo e plantados com vegetação idêntica à do terreno circundante, constituindo amostra representativa da área vegetada. O autor ainda cita que nesse tipo de lisímetro, as regas devem ser diárias ou a cada dois dias de modo a provocar pequeno percolado. Esse tipo lisímetro apresenta limitação na obtenção de dados diários (Silva, 1996), sendo normalmente utilizado para a obtenção de dados decendiais (Camargo, 1962).

Um outro tipo de lisímetro, bastante utilizado, é o de lençol freático constante, que adota um sistema automático de alimentação e registro da água reposta de modo a manter o nível do lençol freático constante, sendo a evapotranspiração diretamente proporcional à água que sai do sistema de alimentação (Assis, 1978). Esse tipo de lisímetro vem sendo o mais utilizado, atualmente, na determinação da ETc e do Kc (Barbieri, 1981; Cruz, 1995; Pereira et al., 1995a,b).

Um terceiro tipo de lisímetro é o de pesagem, o mais utilizado no meio científico atual, que emprega a medida automatizada de células de carga instaladas sob uma caixa impermeável, medindo a variação de peso desta. Desse modo, havendo consumo de água pelas plantas do lisímetro ocorre uma diminuição do peso do volume de controle, a qual é proporcional à evapotranspiração. Esse equipamento, vem sendo utilizado com excelentes resultados, tanto em ambientes naturais (Silva, 1996; Bergamaschi et al., 1997), como em ambientes protegidos (Gomide et al., 1996; Fernandes, 1996; Folegatti et al., 1997).

Trabalho realizado por Silva (1996) comparando os três tipos de lisímetros, descritos acima, nas condições climáticas de Piracicaba, SP, mostra que o de pesagem apresentou boa concordância com dados de ETo estimados pelo método de PenmanMonteith, além de possuir capacidade de realizar mensurações em intervalos de tempo inferiores a uma hora. Já os lisímetros de drenagem e de lençol freático constante, apresentaram resultados inconsistentes, tanto na escala diária como na quinquidiária. 
Resultados semelhantes foram observados por Cruz (1995), que, ao estudar a ETc da ervilha, verificou discrepância entre as medidas efetuadas pelos lisímetros de drenagem e de lençol freático constante. $\mathrm{O}$ autor atribuiu essa discrepância ao fato de que a água reposta automáticamente no lisímetro de lençol freático constante não representou a ETc, e, para o de drenagem, ao fato de ter havido retenção de água nas camadas mais profundas do lisímetro, contribuindo para superestimativas da ETc.

\subsection{Estimativa da evapotranspiração de referência}

Vários são os métodos de estimativa da ETo e a literatura sobre o assunto é bastante vasta, entre elas Camargo (1962), Doorenbos \& Pruitt (1977), Berlato \& Molion (1981), Ometto (1981), Rosenberg et al. (1983), Villa Nova \& Reichardt (1989), e Pereira et al. (1997a).

Dentre os vários métodos de estimativa da ETo, muitos tem grande aceitação, enquanto outros são bastante criticados e até desprezados (Pereira et al., 1997a). Segundo o autor, os critérios de rejeição, muitas vezes, não são claros ou acham-se associados à má interpretação do conceito de ETo e ao uso de lisímetros mal expostos, sem a devida área tampão, usados para o teste dos métodos.

Muitos trabalhos como os de Stanhill (1961), Camargo (1962), Hashemi \& Habibian (1979); Samani \& Pessarakli (1986), e mais recentemente Soriano \& Pereira (1993), Santos et al. (1994), Camargo \& Sentelhas (1997), e Medeiros (1998), em diferentes regiões avaliam o desempenho de diferentes métodos de estimativa da ETo. As conclusões, no entanto, variam muito segundo a condição climática do local de obtenção dos dados, o que dificulta a decisão sobre a conveniência de utilizar determinado método (Camargo \& Sentelhas, 1997).

Os métodos de estimativa da ETo dividem-se em empíricos, de balanço de energia, aerodinâmicos e combinados (Pereira et al., 1997a). 
Vários autores vêm se preocupando em testar e avaliar métodos de estimativa da evapotranspiração potencial ou de referência, buscando identificar o que melhor se adapta às condições climáticas de sua região.

Para as condições de Israel, Stanhill (1961) comparou oito métodos de estimativa de ETo e verificou que na escala mensal os métodos de Penman e do tanque de evaporação (área 3,24m², 0,6m de profundidade e enterrado), foram os que apresentaram as melhores estimativas quando comparadas às medidas realizadas em lisímetro de drenagem. Os demais métodos analisados pelo autor: Thornthwaite; Blaney \& Criddle; Makkink; tanque Classe A; evaporímetro de Piche; e Radiação Solar, apresentaram alta dispersão em alguns casos, e baixa exatidão em outros, levando a erros elevados. Essa constatação, se justifica em razão das condições climáticas de Israel, em que os métodos que levam em consideração o poder evaporante do ar se ajustam melhor.

No Brasil, na mesma década, Camargo (1962) realizou medidas em lisímetros de drenagem em três locais do Estado de São Paulo, utilizando-as para avaliar os métodos de Thorthwaite, Penman - van Bavel, e Blaney \& Criddle, na escala mensal. O autor verificou, para as três localidades do Planalto Paulista, que os métodos que mostraram os melhores ajustes foram o de Thornthwaite e o de Blaney \& Criddle modificado. O método de Blaney \& Criddle original, por ser desenvolvido para regiões áridas apresentou acentuada superestimativa da ETo, enquanto que o método de Penman com modificações propostas por van Bavel apresentou elevada dispersão, mostrando uma tendência de subestimativa nos meses de maior demanda evaporativa. Esses resultados mostram que mesmo sendo empírico, o método de Thorthwaite pode ser empregado de forma satisfatória para estimar a ETo em regiões de clima sub-úmido e úmido, semelhantes àquele no qual ele foi desenvolvido.

Nos anos 80, Samani \& Pessarakli (1986) avaliaram sete métodos de estimativa da ETo, para alfafa, para as condições de clima árido do Arizona, EUA. Os autores verificaram ao comparar as estimativas com dados de ETo obtidas pelo método do balanço de água do solo, que as melhores foram as obtidas pelos métodos Hargreaves, Hargreaves \& Samani e tanque Classe A, com a relação entre a ETo estimada e medida 
igual a $1,00(\mathrm{CV}=7,87 \%), 1,07(\mathrm{CV}=6,72 \%)$ e $1,06(\mathrm{CV}=7,09 \%)$, respectivamente. Os métodos de Jensen \& Haise original e Jensen \& Haise modificado apresentaram superestimativas, da ordem de 13 e $22 \%$, respectivamente, enquanto que os de Penman e Blaney \& Criddle deram subestimativas da ordem de 20\%. Sentelhas \& Camargo (1996), avaliando várias versões do método de Hargreaves, verificaram que esse método superestima acentuadamente a ETo para as condições do Estado de São Paulo. Isso evidencia que os métodos empíricos, apesar de muitas vezes precisos, somente são aplicáveis para as condições nas quais eles foram desenvolvidos.

Trabalho realizado por Soriano \& Pereira (1993) comparou as estimativas da ETo por diversos métodos e concluiu que para a sub-região de Nhecolândia, MS, não houve supremacia dos métodos baseados no balanço de energia sobre aqueles que utilizam apenas a temperatura do ar ou a radiação solar como variável independente. Já Santos et al. (1994), ao analisarem a estimativa da ETo, para alfafa, por diferentes métodos, verificaram que o melhor método foi o de Penman original, porém com a radiação líquida medida sobre a cultura.

Camargo \& Sentelhas (1997), aproveitando os dados obtidos por Camargo (1962), avaliaram 21 diferentes métodos de estimativa da ETo, desenvolvidos nas mais diferentes regiões do mundo. Os resultados obtidos pelos autores, para as condições do Planalto Paulista, permitiram observar, mais uma vez, que os métodos empíricos ajustados para a condição climática em questão mostraram bons resultados na escala, seguidos dos métodos de aplicação universal, como os de Priestley \& Taylor e PenmanMonteith. Na escala diária, Eltink et al. (1997) verificaram que a ETo estimada pelos métodos de Penman-Monteith e Priestley-Taylor foram os que apresentaram a melhor correlação com dados de lisímetro de pesagem, em comparação aos métodos de Camargo e tanque Classe A. Resultados apresentados por Medeiros (1998), na escala quinquidial, mostra que para as condições mesoclimáticas de Santa Maria, RS, os melhores métodos de estimativa daETo foram Penman, Camargo e Tamer \& Pelton.

Os resultados aqui relatados confirmam a observação de Pereira et al. (1997a), sobre o fato de que muitos métodos empíricos, pela sua simplicidade e facilidade de 
aplicação, não devem ser descartados, sendo muitas vezes os únicos com potencial de utilização. Entretanto, suas estimativas são confiáveis somente para períodos decendiais e mensais e sua aplicação fica limitada às condições climáticas nas quais eles foram desenvolvidos (Sediyama, 1996).

As contribuições de Penman (Penman 1948, 1956, 1963), sem dúvida nenhuma, foram as de maior relevância no estudo da estimativa da evapotranspiração de referência, especialmente na escala diária, sendo o método de Penman-Monteith (Monteith, 1965) recomendado pela FAO como padrão de estimativa de ETo (Smith, 1991), e fazendo parte obrigatória de currículos que abordam estudos de manejo de água e projetos de irrigação.

No caso do método de Penman, apresentado pela FAO, resultados obtidos em várias partes do mundo tem apresentado, com muita frequência, superestimativa da ETo, tendo a grama como referência (Smith, 1991; Sediyama, 1996; Alves et al., 1998). Essa tendência também foi constatada nas condições paulistas, onde se observou superestimativa da ordem de 20\%, na escala mensal (Camargo \& Sentelhas, 1997), o que também foi verificado por Allen (1986) e Allen at al. (1989) em várias condições climáticas, tanto na escala diária como na mensal, com superestimativas variando de 15 a $25 \%$. Dentre os motivos responsáveis por essa tendência, a literatura cita a função de velocidade do vento, o modo de cálculo do déficit de saturação (Pereira et al., 1996), e a ausência da resistência exercida pela cobertura vegetal à transferência de vapor para a atmosfera (Sediyama, 1996).

Como solução a esta última questão, Monteith (1965) desenvolveu, com base no método de Penman, uma equação que introduz a relação entre a resistência ao fluxo de vapor pela folha $\left(r_{c}\right)$ e a resistência aerodinâmica $\left(r_{a}\right)$, na tentativa de descrever o papel da turbulência atmosférica no processo de transporte do vapor d'água e as características fisiológicas da planta. A teoria da grande folha ("big leaf") adotada por Monteith (1965) assume que todas as folhas estão expostas às mesmas condições ambientais, embora essa não seja a condição real (Pereira et al, 1997a). Essa nova equação, de formulação teórica rigorosamente física que possibilita o entendimento dos processos físicos e biológicos 
envolvidos na evaporação da água de superfícies vegetadas, passou a ser denominada de Penman-Monteith, sendo adotada como padrão pela FAO a partir de 1991 (Smith, 1991). Assim, a FAO, baseada nos resultados de Allen et al. (1989), padronizou os procedimentos de cálculos da ETo, adotando $r_{c}=69 \mathrm{~s} \cdot \mathrm{m}^{-1}$ como padrão, porém, recomendando que as pesquisas fossem direcionadas no sentido de validar a equação em diferentes condições climáticas, e para avaliar mais rigorosamente as resistências, buscando compreender melhor os mecanismos físicos e biológicos envolvidos no processo (Sediyama, 1996).

Nessa linha, trabalhos realizados por Allen (1986) e Allen et al. (1989), em várias regiões, e por Maggiotto (1996), Peres et al. (1996), Campeche (1997), e Pereira (1998), no Estado de São Paulo, buscaram avaliar a resistência da cobertura padrão à transferência de vapor. De acordo com os trabalhos de Allen (1986) e Allen et al. (1989), o método de Penman-Monteith utilizando o modelo de resistência de Monteith (1965), foi o que proporcionou as melhores estimativas diárias de ETo, tanto para a grama como para a alfafa. Os resultados obtidos por Maggiotto (1996) mostram que os valores de $r_{c}$ adotados pela $\mathrm{FAO}$ proporcionaram boas estimativas de ETo, no período úmido. Peres et al. (1996) observaram que para a grama batatais (Paspalum notatum flügge), na escala mensal, a resistência da cobertura situou-se na faixa entre 60 e $80 \mathrm{s.m}^{-1}$, com indicações de que $80 \mathrm{~s}^{-\mathrm{m}^{-1}}$ seria o mais adequado para a estimativa de ETo. Campeche (1997), verificou que os valores de $r_{c}$ estimados a partir da termometria ao infra-vermelho foram bastante próximos do valor parametrizado pela FAO. Utilizando um período maior de dados, durante a estação seca, Pereira (1998) observou que o método de PenmanMonteith tendeu a subestimar a ETo, em $12 \%$, verificando ainda, que nesse periodo um valor de $r_{c}=40 \mathrm{~s} . \mathrm{m}^{-1}$ seria mais adequado, quando o erro médio caiu para $4 \%$. Resultados semelhantes já haviam sido observados por Allen (1986) que verificaram subestimativas da ETo em regiões de clima árido, quando da utilização desse método. Nesse caso, uma das hipóteses para tal subestimativa é o tamanho insuficiente da bordadura, proporcionando um adicional de energia por advecção para a evapotranspiração do lisímetro, condição que normalmente ocorre nas áreas irrigadas. 
Mesmo com a introdução de $r_{c}$ no método de Penman-Monteith, superestimativas de ETo foram observadas por Camargo \& Sentelhas (1997), na escala mensal, o que de acordo com Pereira et al. (1995) está relacionado à razão entre as resistências da cobertura e aerodinâmica à transferência de vapor $\left(r_{c} / r_{a}\right)$, que para valores de velocidade do vento a $2 \mathrm{~m}\left(\mathrm{U}_{2 \mathrm{~m}}\right)$ acima de $1,1 \mathrm{~m} \cdot \mathrm{s}^{-1}$ é subestimada grosseiramente. Esses autores propuseram uma nova equação de estimativa da relação $r_{c} / r_{a}$ em função da $U_{2 m}$, que assume valor constante e igual a 1 até $1,1 \mathrm{~m} \cdot \mathrm{s}^{-1}$, a partir de quando aumenta rapidamente de forma linear $\left(\mathrm{r}_{\mathrm{c}} / \mathrm{r}_{\mathrm{a}}=-1,67+1,67 \mathrm{U}_{2 \mathrm{~m}}\right)$.

De acordo com Alves et al. (1998), a determinação tanto de $r_{c}$ como de $r_{a}$ é o principal problema relacionado à aplicação do método de Penman-Monteith. De acordo com os autores, isso se torna ainda mais crítico quando se deseja determinar a ETc por um só passo, ou seja, conhecer a $r_{c}$ e a $r_{a}$ de culturas específicas. Os resultados obtidos pelos autores, utilizando alface, no verão, e trigo, no inverno, mostraram que a $r_{c}$ de culturas densas não pode ser obtida pela simples média da resistência estomática, porque o déficit de saturação de vapor do ar não é mantido constante sobre a cobertura. Além disso, os autores verificaram que $r_{c}$ não é unicamente um componente fisiológico mas também um termo aerodinâmico, correspondendo à transferência de vapor de dentro da cobertura para a superfície.

Outro método adaptado a partir do combinado de Penman e que tem apresentado resultados satisfatórios na estimativa da ETo é o de Priestley-Taylor (Priestley \& Taylor, 1972), que é uma simplificação do método de Penman, em que permanece apenas o termo radiativo corrigido por um coeficiente de ajuste $(\alpha)$, conhecido como parâmetro de Priestley-Taylor (Pereira \& Villa Nova, 1992). Determinações realizadas por Priestley \& Taylor (1972), sob condições de ausência de advecção e com superficie úmida, mostraram que $\alpha$ variou de 1,08 a 1,34, com média de 1,26 .

De acordo com as análises de Camargo \& Sentelhas (1997), o método de Priestley-Taylor foi o que apresentou o melhor desempenho, em escala mensal, entre os métodos que envolvem balanço energético, quando compararam a ETo estimada aos dados de lisímetro de drenagem. Resultados apresentados por Eltink et al. (1997), 
mostram que o método de Priestley-Taylor teve boa correlação com a ETo medida em lisímetro de pesagem, ficando atrás somente do método de Penman-Monteith. Apesar disso, Cunha \& Bergamaschi (1994) salientam que pelas características empíricas inerentes ao seu processo de estimação, o parâmetro de Priestley-Taylor não pode ser considerado de aplicação universal para diferentes climas e culturas. Isso é ilustrado pelos dados relatados por Doorenbos \& Pruitt (1977), em que $\alpha$ varia de 1,21 a 2,0.

Cunha \& Bergamaschi (1994) obtiveram para a cultura da alfafa valor de $\alpha$ igual a 1,35 e 1,40, respectivamente para as escalas diária e mensal. Utilizando os dados obtidos por Camargo (1962), Pereira et al. (1997b) verificaram que os valores de $\alpha$, para a grama, foram inferiores a 1,26, sendo igual a 1,00 para Campinas, 1,07 em Ribeirão Preto, e 1,17 em Pindamonhangaba. Peres et al. (1997) encontraram para a cana-deaçúcar valores iguais a 1,30 para a escala decendial e 1,34 para a escala mensal. No trabalho de Allen (1986), o autor verificou que em regiões de clima úmido e com baixa advecção, o método de Priestley-Taylor proporcionou bons resultados. No entanto, em climas áridos onde a advecção é substancial, tal método porporcionou subestimativas da ETo, o que segundo o autor sugere a utilização de $\alpha=1,34$, como encontrado por Priestley \& Taylor para a região árida da Austrália. Em seu livro, Pereira et al. (1997a) traz uma relação de valores de $\alpha$ para várias condições climáticas e de cobertura do terreno.

\subsection{Utilização de estações meteorológicas na estimativa da evapotranspiração de referência}

As informações climáticas e de previsão do tempo para planejamento e tomada de decisões na agricultura é extremamente importante, especialmente no tocante à otimização da prática da irrigação (Hashemi \& Decker, 1969), quer seja em áreas de clima árido ou semi-árido, onde a água é escassa, ou em áreas de clima sub-úmido, onde a seca é sazonal. 
A evolução tecnológica das estações meteorológicas automáticas a partir dos anos 60 (WMO, 1967), e a sua popularização atual, têm facilitado a aquisição e a organização dos dados, e o seu uso nos diversos métodos de estimativa da ETo, especialmente o de Penman-Monteith, em razão do grande número de variáveis exigidas (Bausch, 1990; Tanner, 1990).

Exemplos de utilização de redes de estações meteorológicas automáticas são apresentados por Hubbard et al. (1983), Meyer \& Hubbard (1992), e Woods (1998) para os Estados Unidos e Canadá. O objetivo é coletar dados necessários ao monitoramento da irrigação, de modo a tomá-la mais eficiente, racionalizando-se o uso da água e da energia (Hubbard \& Klocke, 1986), além de auxiliar na tomada de decisão de outras atividades agrícolas, como no manejo de pragas e no prognóstico de geadas (Curry et al., 1981; Cockerham \& Ortega, 1989).

Genere (1990) relata a instalação de uma pequena rede de estações automáticas na Ilha de Reunião, com o objetivo de monitorar a irrigação da cana-de-açúcar utilizando o método de Penman. Nesse caso, além do manejo da irrigação, os dados coletados possibilitaram melhor entendimento das relações produção-condições meteorológicas.

$\mathrm{Na}$ Itália, Testolin (1988) desenvolveu um sistema meteorológico automatizado para o manejo da irrigação, sendo a manutenção dos sensores um dos problemas encontrados, em dois anos de operação. Outro aspecto importante, é a altura de instalação dos sensores e Bausch (1990) testou seu efeito na estimativa da ETo, pelo método de Penman, verificando que as diferenças não ultrapassaram 3\%, quando a altura dos sensores de temperatura e umidade variaram de $1,5 \mathrm{~m}$ para $2 \mathrm{~m}$, e o de velocidade do vento de $2 \mathrm{~m}$ para $3 \mathrm{~m}$. Isso evidencia que, nesses intervalos, altura do sensor não foi uma importante fonte de erro na estimativa da ETo, quando mantidas as recomendações da WMO (1983). Apesar disso, Meyer \& Hubbard (1992) apresentam uma padronização com relação a altura e exposição dos sensores, manutenção dos equipamentos e coleta das informações meteorológicas quando o objetivo é a obtenção de dados para o manejo da irrigação. 
Segundo Campbell \& Tanner (1981), a escolha do sensor é de grande importância, devendo-se seguir a seguinte ordem de prioridade: precisão; custo; manutenção; e consumo de energia. A precisão dos sensores é o que preocupa mais quando o objetivo da coleta de dados é o manejo da irrigação, haja visto que a baixa precisão pode levar a erros grosseiros na determinação da ETo, como foi observado por Serrarens et al. (1997) ao comparar dados meteorológicos provenientes de diferentes estações automáticas de baixo custo.

Ao avaliarem sensores de radiação líquida, elemento fundamental na estimativa de ETo, Kustas et al. (1998) observaram que as diferenças entre os vários sensores testados foi desprezíveis, recomendando, no entanto, uma recalibração deles no caso de estudos de variabilidade espacial desse elemento.

Fernandes (1996) e Folegatti et al. (1997), utilizaram a coleta automatizada de dados meteorológicos para a determinação da evapotranspiração da cultura de crisântemo cultivado sob cobertura plástica. Os autores verificaram que, apesar das alterações físicas do ambiente provocadas pela cobertura plástica, os elementos meteorológicos foram os que apresentaram melhor correlação com a demanda hídrica da cultura, especialmente a radiação solar global.

Apesar das estações automáticas fornecerem dados com melhor caracterização das condições meteorológicas, em razão da aquisição contínua dos dados, elas nem sempre são disponíveis, havendo necessidade de utilização de dados meteorológicos provenientes de estações convencionais com menor representatividade, especialmente das condições médias (Sentelhas et al., 1997).

Comparando dados diários de radiação solar global, temperaturas máxima, mínima e média, umidade relativa, e chuva, obtidos concomitantemente por uma estação convencional e uma automática, Sentelhas et al. (1997) verificaram boa concordância entre as médias desses elementos apesar de algumas discrepâncias devidas às diferenças na precisão dos sensores e na frequência de amostragem. Na escala diária, os maiores erros médios absolutos foram: $1,2^{\circ} \mathrm{C}$ para a temperatura média; $3 \%$ para umidade relativa; e, 2,2 MJ.m.-2. $\mathrm{d}^{-1}$ para radiação solar global, o que pode ocasionar erros na 
estimativa da ETo. Análise semelhante foi realizada por Fisch \& Santos (1997), para os elementos temperatura média e umidade relativa média do ar. Os autores observaram tendência de valores maiores de temperatura na estação convencional, em média $1,2^{\circ} \mathrm{C}$. Com relação à umidade relativa, os autores detectaram uma constância negativa nas diferenças entre as estações convencional e automática, da ordem de 3,6\% na média.

Apesar de pequenas, as discrepâncias observadas devem ser levadas em consideração na determinação da ETo, em razão desses elementos serem fundamentais na sua estimativa, caso da radiação solar, da temperatura, e da umidade relativa do ar.

\subsection{Estimativa da radiação líquida a partir de dados meteorológicos}

Dentre os elementos climáticos, o mais importante nos estudos de evapotranspiração é a radiação líquida (Villanueva, 1987), ou saldo de radiação, a qual, muitas vezes não é medida diretamente, tanto em estações meteorológicas convencionais como automáticas, em razão do custo do sensor.

Usando dados de radiação medida com piranômetro de Eppley, Ometto (1968) determinou para Piracicaba, SP, as relações entre radiação solar global, radiação líquida, e insolação para duas épocas. O mesmo autor (Ometto, 1991) correlacionou valores medidos de radiação líquida com radiação solar extraterrestre e a razão de insolação, utilizando para tal dois períodos distintos caracterizados por declinações solares positivas e negativas, uma vez que a cobertura de nuvens local foi altamente diferenciada nos períodos, fato que fez com que fosse encontrada uma expressão específica para representar cada um dos períodos estudados.

Segundo Azevedo et al. (1991), o termo de maior dificuldade de determinação na equação do balanço de energia radiante é o referente ao balanço de ondas longas na superficie do solo, dependente sobretudo do vapor d'água na atmosfera e da cobertura de nuvens, sendo frequentemente estimada por fórmulas empíricas em função da temperatura do ar e da pressão parcial de vapor. Os referidos autores citam várias equações propostas para determinação do balanço de ondas longas na superficie, sendo 
todas obtidas em condição de céu claro e em função da temperatura absoluta. Funari et al. (1985) apresenta um estudo comparativo entre a equação de Brunt e a formulação proposta por Linacre (1967), ambas para determinação da radiação efetiva terrestre ou balanço de ondas longas. Neste sentido, Ometto (1995) propõe uma alternativa à equação de Brunt-Geiger, baseada na proposição de que características locais influenciam o balanço de ondas longas. 


\section{MATERIAL E MÉTODOS}

\subsection{Caracterização do local do experimento}

O trabalho teve sua parte experimental realizada nas dependências da Escola Superior de Agricultura "Luiz de Queiroz", Universidade de São Paulo (ESALQ/USP), situada no município de Piracicaba, SP, nas seguintes coordenadas geográficas: $22^{\circ} 42^{\prime} 30^{\prime \prime}$ de latitude Sul; 47 $30^{\prime} 00^{\prime \prime}$ de longitude Oeste; e a 546 m de altitude.

A região é classificada como de clima sub-tropical úmido, com verão chuvoso e seca de inverno (Figura 3), com as temperaturas médias mensais variando de $24,8^{\circ} \mathrm{C}$ no verão a $17,1^{\circ} \mathrm{C}$ no inverno, sendo a média anual igual a $21,4^{\circ} \mathrm{C}$. As chuvas são da ordem de $1278 \mathrm{~mm}$ anuais, sendo cerca de $1.000 \mathrm{~mm}$ de outubro a março, e $278 \mathrm{~mm}$ de abril a setembro, considerando-se o período de 1917 a 1997 (Sentelhas et al., 1998).

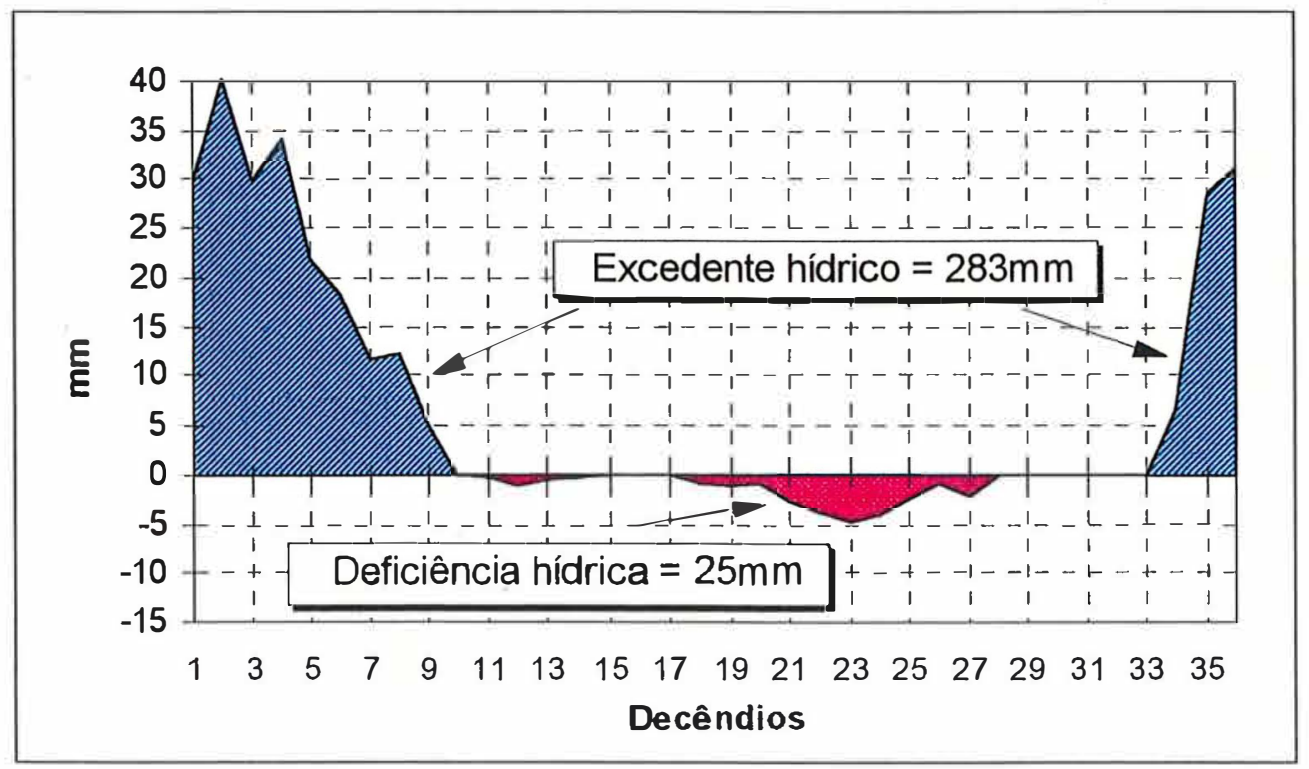

Figura 3. Extrato do balanço hídrico climatológico normal decendial, Thornthwaite \& Mather (1955), CAD = 100mm, de Piracicaba, SP, no período de 1917 a 1997. 


\section{2 Área experimental e equipamentos}

Foram utilizados dados provenientes de dois tipos de estação meteorológica: uma convencional (EMC), instalada no Posto Agrometeorológico do Departamento de Física e Meteorologia; e outra automática (EMA), instalada na área experimental de irrigação do Departamento de Engenharia Rural (ESALQ/USP), na Fazenda Areão, com aproximadamente $2 \mathrm{~km}$ entre elas, ocupando a mesma cota de altitude.

$\mathrm{Na}$ área da EMA ( $35 \times 90 \mathrm{~m}$ ) também havia um lisímetro de pesagem, com célula de carga (modelo LCCA-2K da Omega Engineering), constituído de um tanque de cimento-amianto $(0,65 \mathrm{~m}$ de profundidade; $1,20 \mathrm{~m}$ de comprimento, e $0,85 \mathrm{~m}$ de largura), cultivado com grama em crescimento ativo (Folegatti et al., 1997). As medidas de ETo no lisímetro e os dados da EMA foram coletadas por um sistema de aquisição de dados (Campbell Scientific, modelo CR10), com leitura a cada segundo e médias a cada 30 min. No caso da EMC, os valores foram observados (temperaturas extremas) e cotados manualmente de diagramas do higrógrafo, anemógrafo e heliógrafo.

Os elementos observados na EMC e na EMA, assim como cada sensor, fabricante, e resolução do equipamento, são apresentados na Tabela 1.

Tabela 1. Especificação dos equipamentos das estações meteorológicas convencional (EMC) e automática (EMA).

\begin{tabular}{|c|c|c|c|c|}
\hline $\begin{array}{c}\text { Estação } \\
\text { Meteorológica }\end{array}$ & $\begin{array}{c}\text { Elemento } \\
\text { Meteorológico }\end{array}$ & $\begin{array}{l}\text { Elemento } \\
\text { Sensor }\end{array}$ & $\begin{array}{l}\text { Resolução do } \\
\text { Equipamento }\end{array}$ & Fabricante \\
\hline \multirow[t]{4}{*}{$\begin{array}{l}\text { Convencional } \\
\text { (EMC) }\end{array}$} & $\begin{array}{l}\text { Temperatura } \\
\text { (T) }\end{array}$ & $\begin{array}{c}\text { Mercúrio } \\
\text { Álcool }\end{array}$ & $0,2^{\circ} \mathrm{C}$ & R Fuess \\
\hline & Umidade Relativa (UR) & $\begin{array}{c}\text { Cabelo } \\
\text { Humano }\end{array}$ & $5 \%$ & R Fuess \\
\hline & Velocidade do vento $(U)$ & $\begin{array}{c}\text { Conjunto de } 3 \\
\text { canecas }\end{array}$ & - & R Fuess \\
\hline & $\begin{array}{l}\text { Insolação } \\
\text { (n) }\end{array}$ & $\begin{array}{c}\text { Esfera de } \\
\text { Cristal }\end{array}$ & $0,1 \mathrm{~h}$ & R Fuess \\
\hline \multirow{4}{*}{$\begin{array}{l}\text { Automática } \\
\text { (EMA) }\end{array}$} & Temperatura $(\mathrm{T})$ & Termistor & $0,1^{\circ} \mathrm{C}$ & Vaisala \\
\hline & Umidade Relativa (UR) & Capacitor & $3 \%$ & Vaisala \\
\hline & Velocidade do vento (U) & $\begin{array}{c}\text { Conjunto de } 3 \\
\text { canecas }\end{array}$ & $0,11 \mathrm{~m} \cdot \mathrm{s}^{-1}$ & Met-One \\
\hline & Radiação líquida (Rn) & $\begin{array}{c}\text { Junções de } \\
\text { termopar }\end{array}$ & $0,01 \mathrm{MJ} \cdot \mathrm{m}^{-2}$ & REBS \\
\hline
\end{tabular}




\subsection{Período analisado}

Os dados analisados foram obtidos entre dezembro de 1995 e maio de 1996, período úmido, em que selecionou-se 41 eventos, e de agosto a dezembro de 1996, período seco, em que selecionou-se outros 86 eventos, correspondentes às medidas de ETo obtidas no lisímetro. A Figura 4 indica os períodos analisados, assim como o balanço hídrico dos anos de 1995 e 1996, utilizado para a caracterização do período seco e úmido

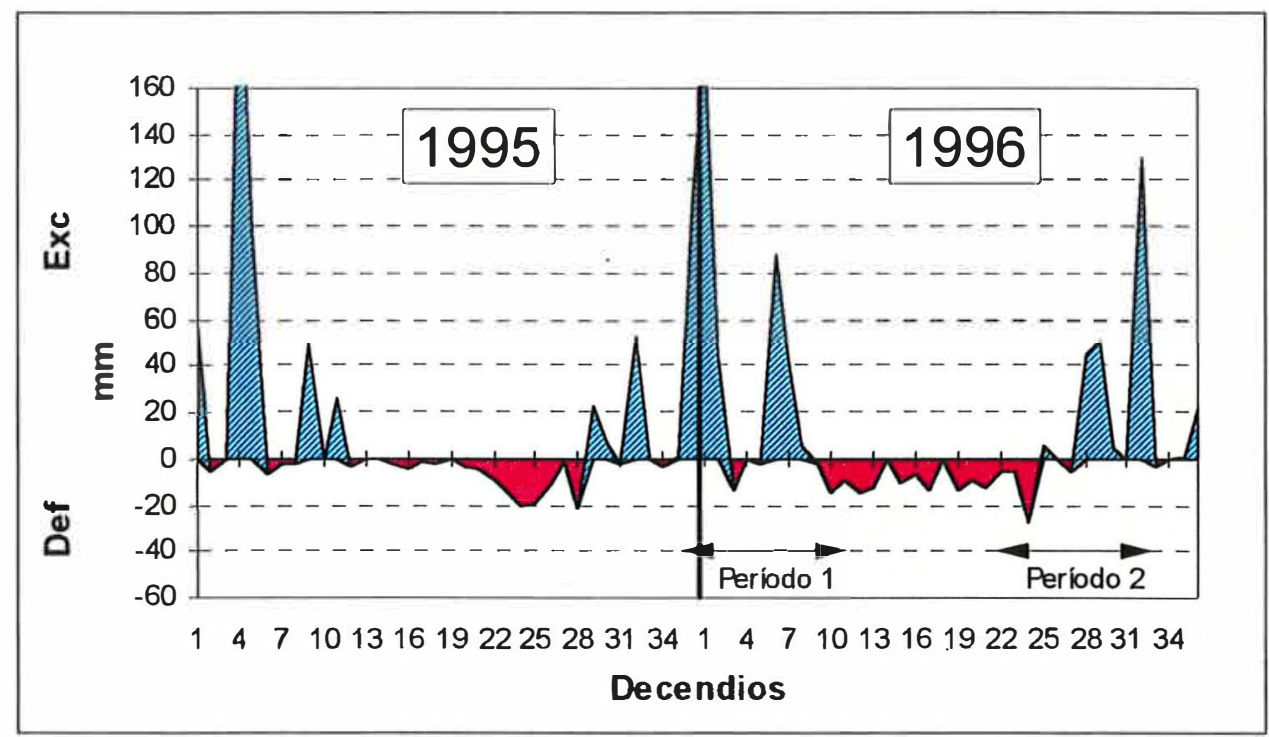

Figura 4. Extrato do balanço hídrico climatológico decendial (Thornthwaite \& Mather, 1955), em Piracicaba, SP, em 1995 e 1996.

\subsection{Estimativa da radiação líquida $(\mathbf{R n})$}

Para a estimativa da radiação líquida $(\mathrm{Rn})$ foram utilizados dados obtidos no Posto Agrometeorológico do Departamento de Física e Meteorologia da ESALQ/USP, durante o período de junho de 1996 a julho de 1997, tendo sido utilizadas 259 observações para definição dos modelos de estimativa propostos e 87 para validação. Os elementos meteorológicos obtidos na estação convencional (EMC) foram: temperatura 
máxima do ar (Tmax), em ${ }^{\circ} \mathrm{C}$; temperatura mínima do ar $(\mathrm{Tmin})$, em ${ }^{\circ} \mathrm{C}$; umidade relativa média do ar (UR), em \%; e insolação (n), em horas. A radiação solar global extraterrestre (Qo), em MJ.m $\mathrm{m}^{-2} \cdot \mathrm{d}^{-1}$, e o fotoperíodo $(\mathrm{N})$, em horas, foram calculados pelas equações utilizadas por Pereira (1997). A radiação solar global (Qg), em MJ.m.2. $\mathrm{d}^{-1}$, foi definida pela expressão (Ometto, 1981):

$$
Q g=(0,25+0,50 n / N) Q o
$$

No cálculo da $\mathrm{Rn}\left(\mathrm{MJ} \cdot \mathrm{m}^{-2} \cdot \mathrm{d}^{-1}\right)$, utilizando-se a equação de Brunt, atribuiu-se o valor de albedo da superfície gramada da ordem de 0,23 , a temperatura média diária do ar $\left(T_{K}\right)$ foi dada pela média aritmética entre Tmax e Tmin, e a pressão parcial de vapor ea, expressa em $\mathrm{kPa}$, foi definida por:

$$
e a=U R \cdot e s / 100
$$

sendo es a pressão de saturação de vapor, em kPa, calculada pela equação de Tétens:

$$
e s=0,6108 * 10^{\left(\frac{7,5 . T}{237,3+T}\right)}
$$

Assim, a equação de Rn utilizando-se a equação de Brunt é dada por:

$$
R n=0,77 Q g-\sigma T_{K}^{4}(0,56-0.24 \sqrt{e a}) \cdot(0,1+0,9 n / N)
$$

em que: $\sigma=4,8989 \cdot 10^{-9} \mathrm{MJ} \cdot \mathrm{m}^{-2} \cdot \mathrm{d}^{-1} \cdot \mathrm{K}^{-4}$, é a constante de Stefan-Boltzmann; $\mathrm{T}_{\mathrm{K}}$ é a temperatura absoluta do ar, em ${ }^{\circ} \mathrm{K}$.

Os elementos meteorológicos observados na estação automática foram: radiação solar global (Qg), em MJ.m ${ }^{-2} \cdot \mathrm{d}^{-1}$; temperatura média do ar $(\mathrm{T})$, em ${ }^{\circ} \mathrm{C}$; e umidade relativa 
média do ar (UR), em \%, cujos valores médios diários foram obtidos pela média aritmética de leituras realizadas a cada segundo.

A radiação líquida estimada foi comparada à medida através de um saldo radiômetro (Q-7 net radiometer - REBS) e utilizada para propor equações de regressão linear simples e múltipla, em função de temperatura do ar, pressão parcial de vapor d'água na atmosfera, e razão de insolação, considerando tais elementos climáticos obtidos a partir da EMC. Estudo semelhante foi desenvolvido em função de radiação solar global, temperatura do ar e tensão atual de vapor medidos em uma EMA.

\subsection{Estimativa da evapotranspiração de referência (ETo)}

Dados das duas estações meteorológicas, EMC e EMA, foram utilizados na estimativa da evapotranspiração de referência $\left(E T o, m m \cdot d^{-1}\right.$ ), pelos métodos de Penman (Penman, 1948), Penman-Monteith (Monteith, 1965), e Priestley-Taylor (Priestley \& Taylor, 1972).

\subsubsection{Método de Penman}

Para a estimativa da ETo pelo método de Penman, utilizou-se a parametrização apresentada por Pereira et al. (1997a), como segue:

$$
E T o=W \frac{(R n-G)}{\lambda}+(1-1) 86400 \rho C_{\gamma} \frac{\Delta e}{\gamma r a}
$$

em que: ETo é a evapotranspiração de referência, em mm.d $d^{-1}$; e $W=s /(s+\gamma)$ é um fator de ponderação dependente da temperatura do ar e do coeficiente psicrométrico (Wilson \& Rouse, 1972; Viswanadham et al., 1991):

$$
W=0,407+0,0145 \mathrm{~T} \quad \text { para } \quad 0,0<\mathrm{T}<16^{\circ} \mathrm{C} \text {. }
$$




$$
W=0,483+0,01 T \quad \text { para } 16,1<\mathrm{T}<32^{\circ} \mathrm{C}
$$

Rn é a radiação líquida em $M J \cdot m^{-2} \cdot d^{-1}$; G é o fluxo de calor no solo, em $M J \cdot m^{-2} \cdot d^{-1}$, sendo considerado igual a zero tanto na EMC como na EMA; $\lambda=2,45 \mathrm{MJ} \cdot \mathrm{kg}^{-1}$ é o calor latente de evaporação; $\rho=1,26 \mathrm{~kg} \cdot \mathrm{m}^{-3}$ é a massa específica do ar; $\mathrm{Cp}=0,001013 \mathrm{MJ} \cdot \mathrm{kg}$ ${ }^{10} \mathrm{C}^{-1}$ é o calor específico do ar; $\gamma=0,0622 \mathrm{kPa} .{ }^{\circ} \mathrm{C}^{-1}$ é o coeficiente psicrométrico; $\Delta \mathrm{e}$ é o déficit de pressão de vapor (es - ea), em kPa; e ra é resistência aerodinâmica, em s.m dada por:

$$
r a=\frac{250}{\left(1+0,526 U_{2 m}\right)}
$$

sendo $U_{2 m}$ a velocidade do vento a $2 \mathrm{~m}$ de altura (Thom \& Oliver, 1977).

\subsubsection{Método de Penman-Monteith}

Para a estimativa da ETo pelo método de Penman-Monteith, utilizou-se a parametrização apresentada por Smith (1991), baseada nos resultados de Allen et al. (1989), como segue:

$$
E T o=\frac{s \quad(R n-G)}{\left(s+\gamma^{*}\right)} \lambda+\frac{\gamma}{\left(s+\gamma^{*}\right)(T+275)}
$$

em que: s é a declividade da curva de pressão de vapor na temperatura média do ar, em $\mathrm{kPa} .{ }^{\circ} \mathrm{C}^{-1}$, dado por:

$$
s=\frac{4098 e s}{(T+237,3)^{2}}
$$


sendo $\mathrm{T}$ a temperatura média diária, em ${ }^{\circ} \mathrm{C}$; e $\gamma^{*}$ o coeficiente psicrométrico modificado, em $\mathrm{kPa} .{ }^{\circ} \mathrm{C}^{-1}$, dado por:

$$
\gamma^{*}=\gamma\left(1+\frac{r_{c}}{r_{a}}\right)
$$

sendo $r_{c}=69 \mathrm{~s} . \mathrm{m}^{-1}$ a resistência da cobertura vegetal à transferência de vapor, e ra a resistência aerodinâmica à transferência de vapor, dada por:

$$
r_{a}=\frac{\ln \left(\frac{z_{m}-d}{z_{o m}}\right) \cdot \ln \left(\frac{z_{h}-d}{z_{o h}}\right)}{k^{2} U z}
$$

em que: $\mathrm{z}_{\mathrm{m}}$ é a altura de medida da velocidade do vento, em $\mathrm{m}$; $\mathrm{d}$ é o deslocamento do plano zero do perfil de vento, em $\mathrm{m} ; \mathrm{z}_{\mathrm{om}}$ é o comprimento de rugosidade equivalente para a transferência de momentum, em $\mathrm{m} ; \mathrm{z}_{\mathrm{h}}$ é a altura em que é feita a medida de temperatura e umidade relativa do ar, em $\mathrm{m} ; \mathrm{z}_{\mathrm{oh}}$ é o comprimento de rugosidade equivalente para a transferência de calor sensível e calor latente, em $\mathrm{m} ; \mathrm{k}=0,41$ é a constante de von Karman; e Uz é a velocidade do vento medida na altura z, em m. $\mathrm{s}^{-1}$. Sendo d, $\mathrm{z}_{\mathrm{om}}$, e $\mathrm{z}_{\mathrm{oh}}$ obtidos pelas seguintes relações (Monteith, 1981; Brutsaert, 1982):

$$
\begin{aligned}
d & =\frac{2}{3} h c \ldots \\
z_{\text {om }} & =0,123 h c \\
z_{\text {oh }} & =0,1 z_{\text {om }}
\end{aligned}
$$

sendo $\mathrm{hc}=0,12 \mathrm{~m}$ a altura da cultura, o que resulta em:

$$
\gamma^{*}=\gamma\left(1+0,33 U_{2 m}\right)
$$


Rn é a radiação líquida em MJ.m. ${ }^{-2} \cdot \mathrm{d}^{-1} ; \mathrm{G}$ é o fluxo de calor no solo, em MJ.m. $\mathrm{m}^{-2} \cdot \mathrm{d}^{-1}$, sendo considerado igual a zero tanto na EMC como na EMA; $\lambda=2,45 \mathrm{MJ} \cdot \mathrm{kg}^{-1}$ é o calor latente de evaporação; $\gamma=0,0622 \mathrm{kPa}^{\circ} \mathrm{C}^{-1}$ é o coeficiente psicrométrico; $\mathrm{T}$ é a temperatura média do ar, em ${ }^{\circ} \mathrm{C} ; \mathrm{U}_{2 \mathrm{~m}}$ é a velocidade do vento a $2 \mathrm{~m}$, em m.s ${ }^{-1} ; \Delta$ e é o déficit de pressão de vapor, em $\mathrm{kPa}$.

No caso da EMC, os valores de Rn foram estimados pelo balanço global de radiação, utilizando a associação das equações de Angström e de Brunt (Equação 5), adotando-se o albedo da superfície gramada $(\mathrm{r}=0,23)$ sugerido por Smith (1991) e pelas equações de regressão linear aqui obtidas a partir de elementos meteorológicos observados na EMC e EMA.

A velocidade do vento, que na EMC é obtida a $10 \mathrm{~m}$ e no método de PenmanMonteith é requerida a $2 \mathrm{~m}$, foi estimada utilizando-se a conversão proposta por Smith (1991) para a cobertura padrão, como segue:

$$
\mathrm{U}_{2 \mathrm{~m}}=\left\{4,868[\operatorname{Ln}(67,75 \mathrm{Z}-5,42)]^{-1}\right\} \mathrm{U}_{\mathrm{Z}}=0,748 \mathrm{U}_{10 \mathrm{~m}}
$$

em que: $U_{10 m}$ é a velocidade média diária do vento $\left(\mathrm{m} \cdot \mathrm{s}^{-1}\right)$ na altura $\mathrm{Z}=10 \mathrm{~m}$.

Como os resultados de Pereira et al. (1995) indicam que a equação 17 subestima os valores de rc/ra, optou-se também por testar a relação por eles proposta e modificada por Pereira et al. (1998), de modo a verificar sua influência na estiamativa da ETo em período seco e úmido. A equação proposta pelos autores acima é:

$$
r_{c} / r_{a}=3,414 \sqrt{U_{2 m}}-3,205
$$

\subsubsection{Método de Priestley-Taylor}

Para a estimativa da ETo pelo método de Priestley-Taylor, utilizou-se a formulação apresentada por Pereira et al. (1997a), como segue: 


$$
E T o=\alpha W\left(\frac{R n-G}{\lambda}\right)
$$

em que $\alpha=1,26$ é um fator de ajuste, denominado de parâmetro de Priestley-Taylor.

Neste caso, além da utilização do parâmetro $\alpha=1,26$ determinou-se seus valores mais adequados para as condições experimentais, através da relação:

$$
\alpha=\frac{E T o}{W(R n-G)} .
$$

em que ETo é a evapotranspiração de referência medida no lisímetro de célula de carga.

\subsection{Análise dos resultados}

Os resultados obtidos no presente trabalho foram avaliados, basicamente, através da análise de regressão, por meio dos coeficientes linear (a), angular (b) e de determinação $\left(r^{2}\right)$, os quais traduzem tanto a exatidão, máxima quando $a=0$ e $b=1$, e a precisão, máxima quando $\mathrm{r}^{2}$ tende a 1 . Além disso, utilizou-se para quantificação do erro proporcionado pelas estimativas, o erro médio absoluto, expresso pela média dos valores absolutos do erro de cada estimativa. 


\section{RESULTADOS E DISCUSSÃO}

\subsection{Comparação de dados meteorológicos obtidos por estação meteorológica convencional (EMC) e automática (EMA)}

Analisando-se os dados meteorológicos diários obtidos no período do trabalho, pela EMC e pela EMA, com a finalidade de estimar a ETo, observa-se na Figura 5 que existiu boa concordância entre os dados medidos nas duas estações, especialmente com relação à temperatura média do ar (Figura 5a) e à umidade relativa média do ar (Figura $5 b)$.

No caso da temperatura, houve menor dispersão dos dados, sendo o $\mathrm{r}^{2}=0,9668$, indicando boa precisão, o que também foi observado com relação à exatidão ( $b=$ 0,9756). $\mathrm{O}$ erro médio absoluto foi de $0,63^{\circ} \mathrm{C}$ (Figura $5 \mathrm{c}$ ), valor inferior aos encontrados por Fisch \& Santos (1997) e Sentelhas et al. (1997), que observaram diferenças médias de $1,2^{\circ} \mathrm{C}$, para esse elemento. Essa diferença, com tendência de valores mais elevados na EMC, pode ser considerada pequena haja visto que as médias foram determinadas com amostras bastante distintas, duas na EMC e 86400 na EMA, e que a precisão dos sensores de temperatura utilizados variam de 0,1 a $0,2^{\circ} \mathrm{C}$.

Para a umidade relativa do ar, apesar da boa exatidão entre os dados das duas estações $(b=0,9939)$, a dispersão foi maior, sendo o $r^{2}=0,8145$ (Figura $5 b$ ). $O$ erro médio absoluto observado foi da ordem de 2,82\% (Figura 5d), bastante próximo dos $3 \%$ obtidos por Fisch \& Santos (1997) e dos 3,6\% relatados por Sentelhas et al. (1997), porém, sem tendência de valores maiores em qualquer das estações. Nesse caso, as diferenças constatadas se devem, basicamente, ao tipo de sensor empregado, pois na EMC o sensor do higrógrafo é constituído de mechas de cabelo humano, exigindo calibrações periódicas. 

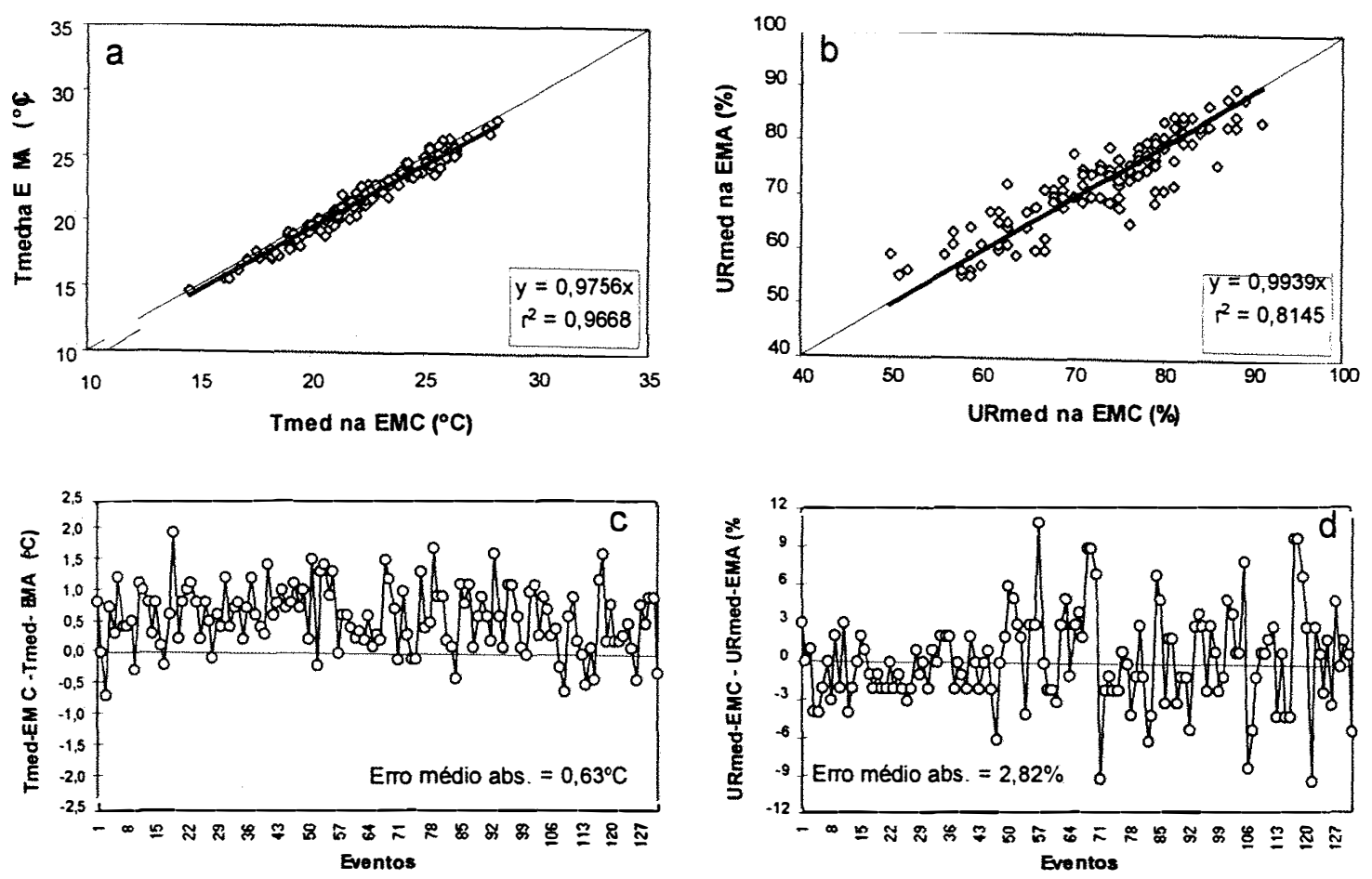

Figura 5. Relação entre dados meteorológicos diários: a) temperatura média do ar; b) umidade relativa média do ar; e desvio: c) temperatura média do ar; e d) umidade relativa média do ar, observados na EMC e na EMA, em Piracicaba, SP.

Com relação à velocidade média do vento (Figura 6a), a análise de regressão mostra, durante o período analisado, que não houve boa concordância entre as observações das duas estações meteorológicas. Apesar da boa exatidão, com erros da ordem de $4,4 \%(b=1,0439)$, a precisão foi baixa $\left(r^{2}=0,5691\right)$, sendo a pior entre os elementos meteorológicos analisados, com o erro médio absoluto sendo igual a $0,71 \mathrm{~m} \cdot \mathrm{s}^{-1}$ (Figura 6c). Essa grande dispersão dos dados em relação à reta da equação é devido ao fato de que a velocidade do vento a $2 \mathrm{~m}$ na EMC foi estimada em função da velocidade observada a 10m, segundo o método recomendado por Allen et al. (1989) e apresentado por Smith (1991), sendo, portanto, uma das fontes dos erros observados. 
Para a radiação líquida (Figura 6b), os resultados mostram que tanto a exatidão $(b=1,2301)$ como a precisão $\left(r^{2}=0,6653\right)$ foram baixas, com tendências de valores maiores na EMA em relação à EMC. O erro médio absoluto foi da ordem de 2,67 $M J \cdot m^{-2} \cdot d^{-1}$ (Figura 6d), o que mostra que a associação das equações de Angström, para determinação do balanço de ondas curtas, e de Brunt, para determinação do balanço de ondas longas, utilizando dados provenientes da EMC, não foi uma boa alternativa para a estimativa de Rn, ao contrário do que sugere Smith (1991), o que deve resultar em erros significativos na estimativa da ETo, pois Rn é o principal elemento meteorológico envolvido no processo de evapotranspiração de um gramado.
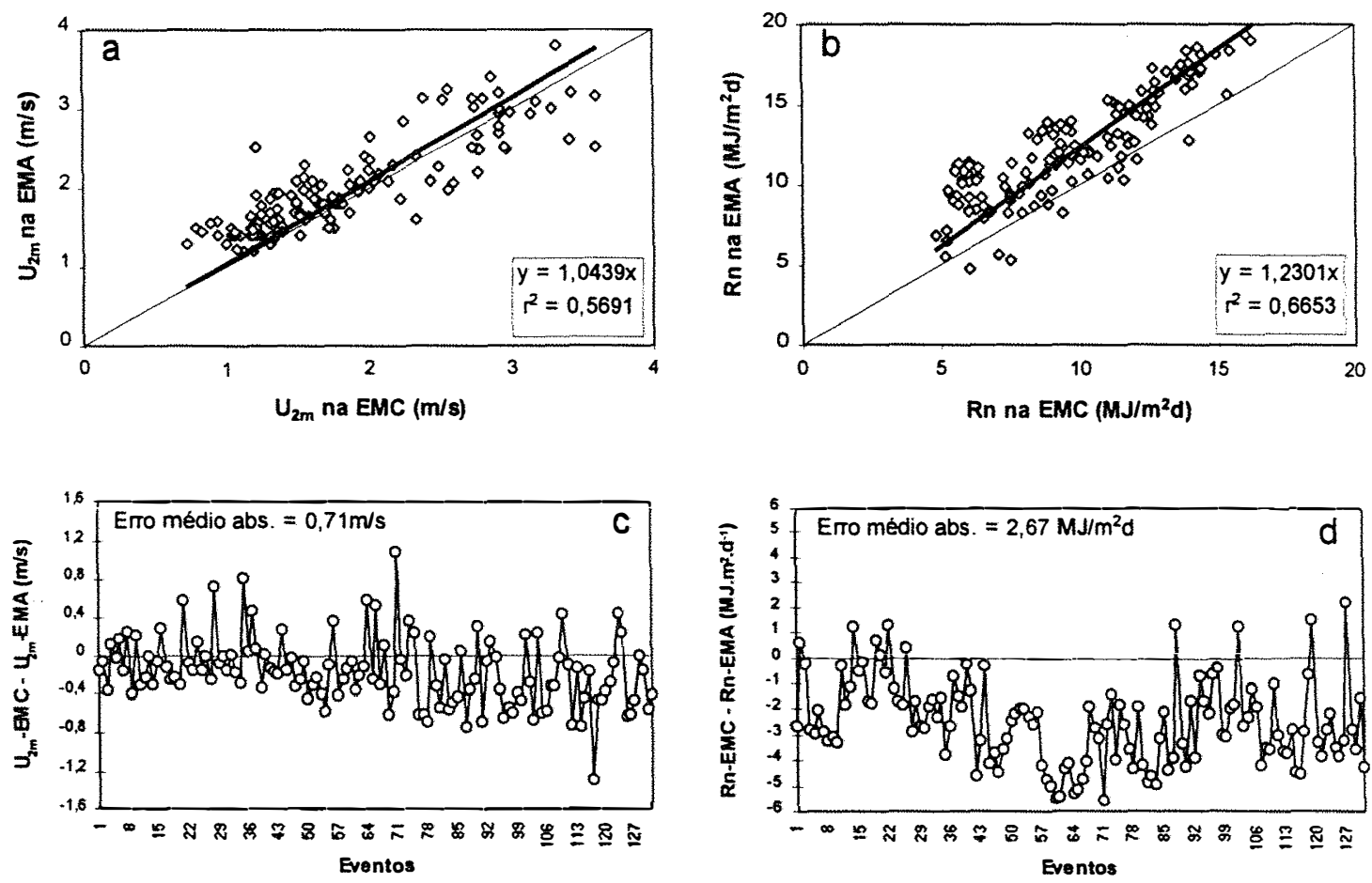

Figura 6. Relação entre dados meteorológicos diários: a) velocidade média do vento a $2 \mathrm{~m}$; e b) radiação líquida; e desvio: c) velocidade média do vento a $2 \mathrm{~m}$; e d) radiação líquida, observados na EMC e na EMA, em Piracicaba, SP. 


\subsection{Estimativa da radiação líquida a partir de elementos meteorológicos observados na EMC e na EMA}

Em razão da menor concordância entre $\mathrm{Rn}$ medida e estimada pela associação das equações de Angström e Brunt, como sugerido por Smith (1991), com dados da EMC (Figura 6b e 6d), foram elaboradas equações estatísticas de estimativa da Rn, tanto para dados provenientes da EMC como da EMA, visto que sensores para tais medidas são inexistentes na maioria das estações meteorológicas que operam no Brasil.

Na Tabela 2 são apresentadas as equações de regressão linear para a estimativa da $\mathrm{Rn}$ em função da radiação solar global extraterrestre (Qo), fotoperíodo $(N)$, temperatura média diária do ar $(\mathrm{T})$, pressão parcial do vapor d'água na atmosfera (ea), e insolação (n) observados em uma estação meteorológica convencional (EMC).

Tabela 2. Equações de regressão linear de estimativa da radiação líquida $(\mathrm{Rn})$, expressa em $M J \cdot m^{-2} \cdot d^{-1}$, em função dos elementos meteorológicos obtidos na estação meteorológica convencional (EMC).

\begin{tabular}{ccc}
\hline Variáveis & Equação de Regressão & $\mathrm{r}^{2}$ \\
\hline Qo, T, ea, $n / N$ & $\mathrm{Rn}=$ Qo $(-0,1049+0,0082 \cdot \mathrm{T}+0,0492 \cdot \sqrt{e a}+0,2634 \cdot n / N)$ & 0,8031 \\
Qo, T, $n / N$ & $\mathrm{Rn}=\mathrm{Qo}(-0,0734+0,0101 \cdot \mathrm{T}+0,2513 \cdot n / N)$ & 0,8014 \\
Qo, $n / N$ & $\mathrm{Rn}=\mathrm{Qo}(0,1578+0,2317 \cdot n / N)$ & 0,6353
\end{tabular}

$\mathrm{T}=$ temperatura média diária do ar $\left({ }^{\circ} \mathrm{C}\right)$; ea = pressão parcial do vapor d'água na atmosfera $(\mathrm{kPa}) ; n / N=$ razão de insolação; e Qo = radiação solar global extraterrestre $\left(M J \cdot \mathrm{m}^{-2} \cdot \mathrm{d}^{-1}\right)$.

Pela análise das equações apresentadas bem como pela análise de variância a que foram submetidos os dados de radiação líquida estimados pelos diferentes critérios aqui propostos, observa-se que as mesmas não diferem estatisticamente entre si, ao nível de $1 \%$ de probabilidade; no entanto, vale ressaltar que as equações que consideram as 
variáveis independentes $\mathrm{T}$, ea, e $n / N$ e, ainda, $\mathrm{T}$ e $\mathrm{n} / \mathrm{N}$ foram as que apresentaram os mais elevados valores de $\mathrm{r}^{2}$. Tal constatação, para a equação que considera a raiz quadrada da tensão atual de vapor ea, vai ao encontro do significado físico da equação de Brunt, a qual evidencia que o balanço de radiação de ondas longas é afetado pela temperatura, pelo vapor d'água presente na atmosfera e pela nebulosidade ou cobertura de nuvens, expressa pela razão de insolação. Para a equação que despreza a contribuição de ea na estimativa de $\mathrm{Rn}$, pode-se dizer que sua confiabilidade está fundamentada nos princípios envolvidos na emissão efetiva terrestre, que pode ser obtida em função da temperatura do ar e da razão de insolação, como relata Linacre (1967).

$\mathrm{Na}$ Tabela 3 são apresentadas as equações de regressão linear de estimativa da $\mathrm{Rn}$ em função da radiação solar global $(\mathrm{Qg})$, pressão parcial do vapor d'água na atmosfera (ea), e temperatura média do ar (T), observados na estação meteorológica automática (EMA).

Tabela 3. Equações de regressão linear de estimativa da radiação líquida $(R n)$, expressa em MJ.m.-2 $\cdot \mathrm{d}^{-1}$, em função dos elementos meteorológicos obtidos na estação meteorológica automática (EMA).

\begin{tabular}{ccc}
\hline Variáveis & Equação de Regressão & $\mathrm{r}^{2}$ \\
\hline Qg, ea, T & $\mathrm{Rn}=-7,1739+0,6432 \mathrm{Qg}+4,2579 \sqrt{e a}+0,0047 \mathrm{~T}$ & 0,9688 \\
$\mathrm{Qg}, \mathrm{T}$, & $\mathrm{Rn}=-5,1814+0,5861 \mathrm{Qg}+0,2346 \mathrm{~T}$ & 0,9578 \\
$\mathrm{Qg}$ & $\mathrm{Rn}=-1,74+0,6649 \mathrm{Qg}$ & 0,9288 \\
$\mathrm{Qg}$ & $\mathrm{Rn}=0,57378 \mathrm{Qg}$ & 0,9099
\end{tabular}

$\mathrm{T}=$ temperatura média diária do ar $\left({ }^{\circ} \mathrm{C}\right)$; ea = pressão parcial do vapor d'água na atmosfera $(\mathrm{kPa}) ; n / N=$ razão de insolação; e $Q g$ = radiação solar global $\left(M J \cdot m^{-2} \cdot d^{-1}\right)$.

Observa-se, pela análise das equações apresentadas na Tabela 3, bem como pela análise de variância com aplicação do teste $\mathrm{F}$ aos dados de $\mathrm{R} n$ estimados, que as mesmas não diferem estatisticamente entre si, ao nível de $1 \%$ de probabilidade, devendo-se 
destacar que as equações que levam em consideração as variáveis independentes Qg, ea, e T, bem como Qg e T foram aquelas que apresentaram os mais elevados valores de $\mathrm{r}^{2}$. Assim, para a obtenção de dados mais precisos sugere-se a utilização de uma das duas primeiras equações apresentadas, podendo, ainda, ser recomendada a adoção das demais, a nível de projeto e utilização prática, em muitos trabalhos nas áreas de micrometeorologia e irrigação, particularmente na estimativa da evapotranspiração de referência (ETo), pelos métodos combinados, como os de Penman, Penman-Monteith, e Priestley-Taylor

Para a validação das referidas equações, uma série independente de 87 dias foi tomada. Na Figura 7 são apresentadas as validações para as equações de estimativa da $\mathrm{Rn}$ em função dos dados meteorológicos observados na EMC. Observa-se que tanto a equação mais complexa, envolvendo dados de $\mathrm{T}$, ea e $n / N$, como as mais simples, envolvendo somente $\mathrm{T}$ e/ou $\mathrm{n} / \mathrm{N}$, apresentaram ajustes bem superiores, b variando de 1,0031 a 1,0332 e $\mathrm{r}^{2}$ de 0,8183 a 0,8818, ao método de estimativa que envolve as equações de Angström e Brunt, tanto para o período de validação (Figura 8), quando $b=$ 1,0785 e $\mathrm{r}^{2}=0,7077$, como para o período em que se comparou os dados da EMC aos da EMA (Figuras 6b e 6d) quando $b=1,2301$ e $\mathrm{r}^{2}=0,6653$.

$\mathrm{Na}$ Figura 9 são apresentadas as validações para as equações de estimativa de $\mathrm{Rn}$ em função de dados da EMA. Apesar de a princípio não parecer justificável esse tipo de estimativa para a EMA, esse recurso é extremamente útil em razão do número elevado de EMA's em operação para fins de manejo da irrigação que não possuem tal sensor, em função de seu custo e da necessidade de troca frequente de sua cúpula de polietileno, o que restringe a utilização deste sensor quase que exclusivamente para trabalhos científicos.

Os resultados obtidos pela validação são promissores, com os valores de b variando de 0,9981 a 1,0035 e de $\mathrm{r}^{2}$ de 0,9073 a 0,969, indicando excelente precisão e exatidão das estimativas. Para fins operacionais de manejo da irrigação, a relação $\mathrm{Rn}=$ 0,57379Qg é a recomendada por ser mais simples. 

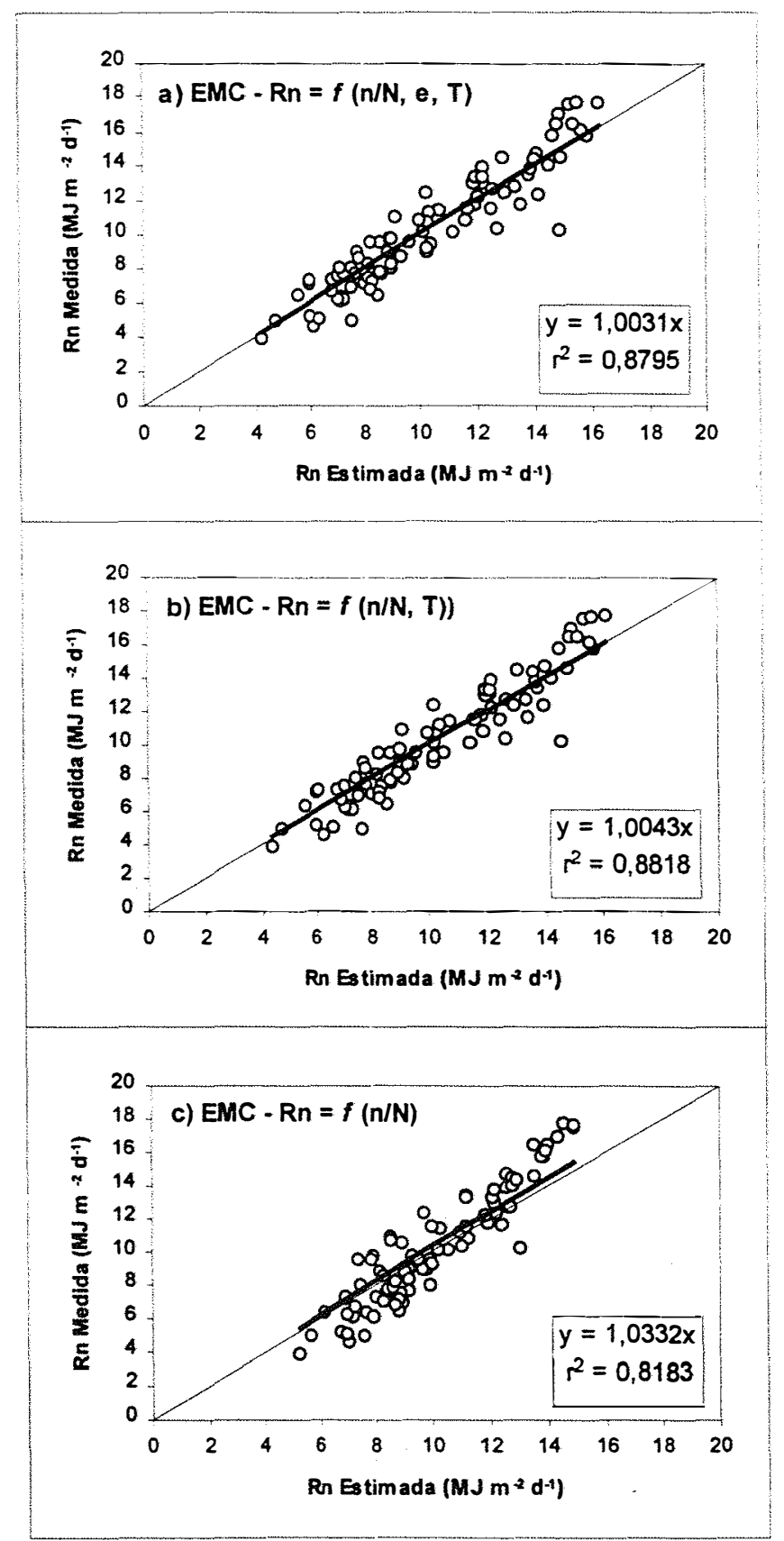

Figura 7. Relação entre a radiação líquida $(R n)$ medida e estimada a partir de dados da EMC: a) temperatura, pressão parcial de vapor e razão de insolação; b) temperatura e razão de insolação; c) razão de insolação, em Piracicaba, SP. 


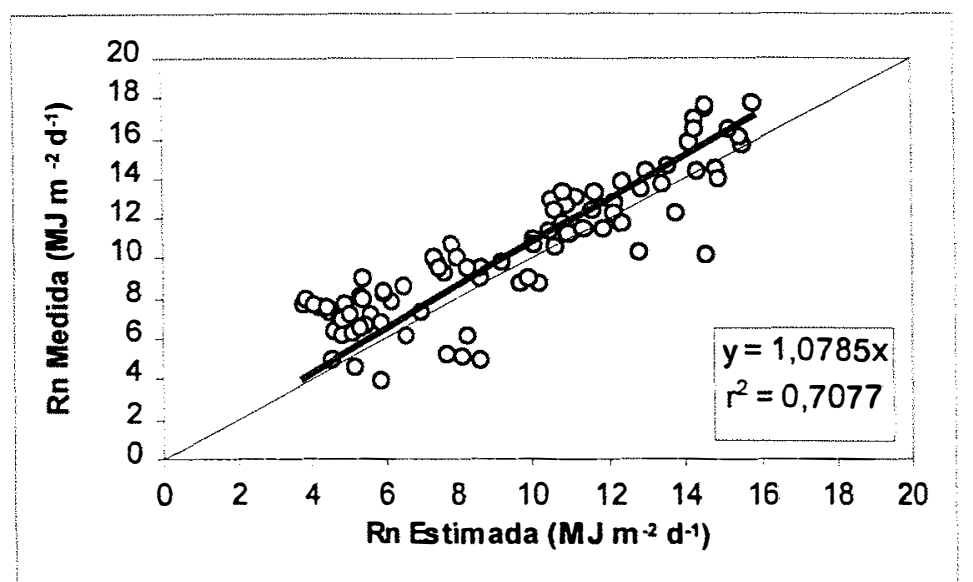

Figura 8. Relação entre a radiação líquida $(\mathrm{R} n)$ medida e estimada pelas equações de Angström e Brunt, utilizando-se dados da EMC, em Piracicaba, SP.

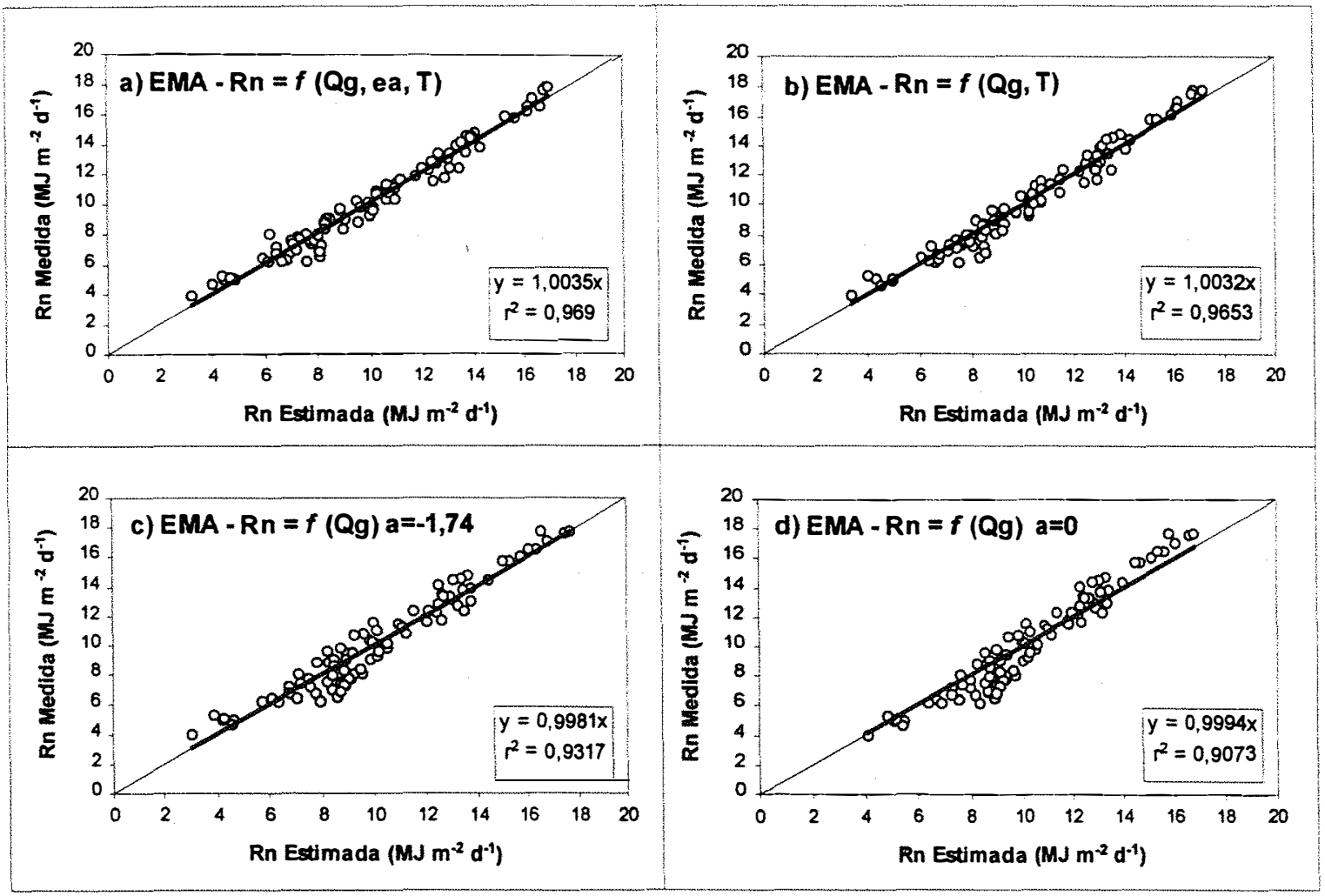

Figura 9. Relação entre a radiação líquida $(R n)$ medida e estimada a partir de dados da EMA: a) temperatura, pressão parcial de vapor e radiação solar global; b) temperatura e radiação solar global; c) radiação solar global, com a $=-1,74$; d) radiação solar global, com $a=0$, em Piracicaba, $S P$. 
Para fins operacionais neste trabalho adotou-se as seguintes equações de estimativa: $\mathrm{Rn}=\mathrm{Qo}(-0,0734+0,0101 \cdot \mathrm{T}+0,2513 . \mathrm{n} / \mathrm{N})$, para dados da $\mathrm{EMC} ; \mathrm{e} \mathrm{Rn}=$ 0,57378 Qg, para dados da EMA. O emprego dessas equações, no período das observações lisimétricas de ETo, são apresentados na Figura 10, onde observa-se a manutenção dos níveis de exatidão, b igual a 1,0972 e 1,0562, e de precisão, $\mathrm{r}^{2}$ de 0,8856 e 0,9361, respectivamente, para a EMC e a EMA (Figuras 10a e b), com os erros médios absolutos de 1,28 e 0,79 MJ.m. ${ }^{-2}$ d $^{-1}$ (Figuras 10c e d), no caso da EMC, 52\% inferior ao observado para as estimativas pelo procedimento recomendado pela FAO (Smith, 1991), que foi da ordem de 2,67 MJ.m.'. $\mathrm{d}^{-1}$ (Figura 6d).
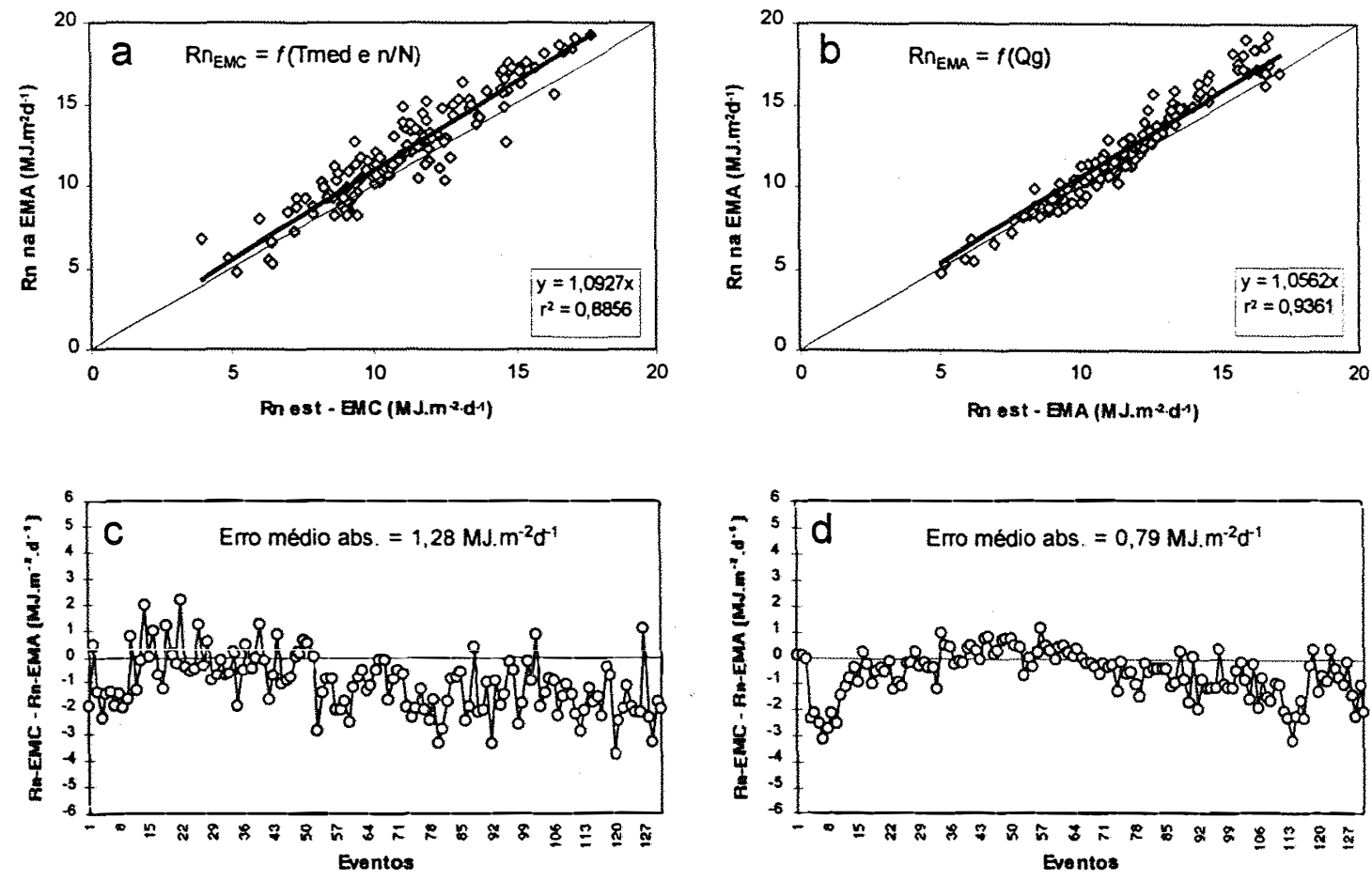

Figura 10. Relação e desvio entre a radiação líquida $(R n)$ medida na EMA e estimada a partir de dados da EMC (a e c) e da EMA (b e d), utilizando-se equações de regressão em função da temperatura e razão de insolação, na EMC, e da radiação solar global, na EMA, no período de observações lisimétricas de ETo, em Piracicaba, SP. 


\subsection{Estimativa da evapotranspiração de referência a partir de elementos meteorológicos observados na EMC e na EMA}

\subsubsection{Método de Penman}

\subsubsection{Com Rn estimada pelas equações de Angström e Brunt}

As estimativas da ETo por Penman utilizando-se dados da EMC e da EMA são apresentadas nas Figuras 11 e 12, em que se utilizou para a estimativa da Rn a associação das equações de Angström e Brunt. Observa-se que nos dois casos houve boa exatidão das estimativas, porém, com tendência de subestimativa da ordem de $7 \%$ quando utilizou-se dados da EMC (Figura 11a) e de superestimativa de $11 \%$ quando da utilização de dados da EMA (Figura 12a), sendo que em ambos os casos a precisão foi mediana, respectivamente, 0,56 e 0,77 , com tendência de menores dispersões nas estimativas com os dados da EMA, apesar do erro médio absoluto ser praticamente igual, respectivamente, 0,68 e $0,62 \mathrm{~mm} \cdot \mathrm{d}^{-1}$. Essa diferença entre as estimativas de ETo com dados das duas estações, observada na Figura 13, se deve principalmente às discrepâncias entre a Rn medida na EMA e estimada na EMC, como visto nas Figuras $6 \mathrm{~b}$ e $6 \mathrm{~d}$.
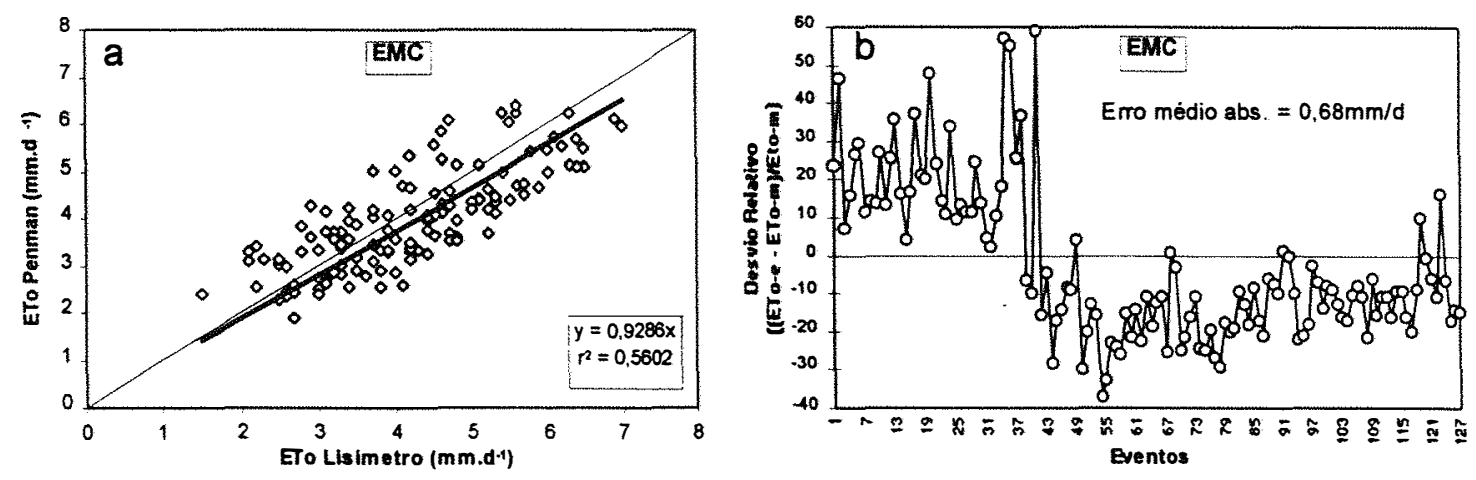

Figura 11. Relação entre a ETo estimada pelo método de Penman com dados da EMC e medida em lisímetro (a) e desvio relativo da ETo (b), com Rn estimada por Angström-Brunt, em Piracicaba, SP. 

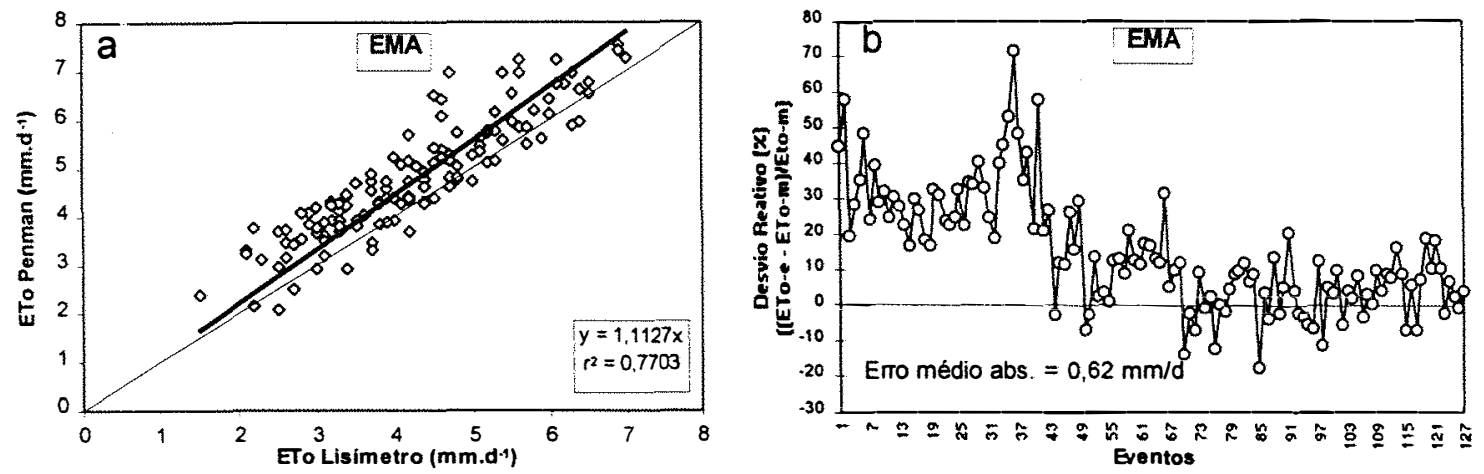

Figura 12. Relação entre a ETo estimada pelo método de Penman com dados da EMA e medida em lisímetro (a) e desvio relativo da ETo (b), em Piracicaba, SP.
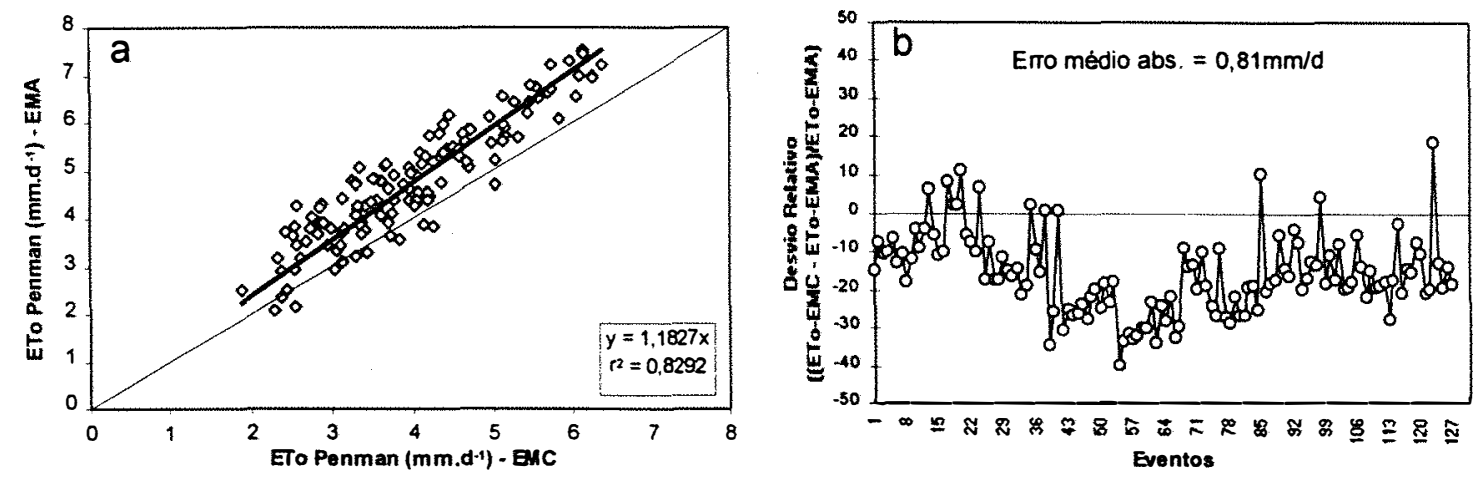

Figura 13. Relação entre a ETo estimada pelo método de Penman, com dados da EMC e da EMA (a) e desvio relativo da ETo (b), com Rn na EMC estimada por Angström-Brunt, em Piracicaba, SP.

Nas Figuras $11 \mathrm{~b}$ e $12 \mathrm{~b}$, observa-se dicotomia na série de estimativas, sendo um período de superestimativa e outro de subestimativa, coincidindo, respectivamente, com os períodos úmido e seco. No caso da utilização de dados da EMA, o período seco teve as melhores estimativas com os desvios oscilando em torno de zero. Resultados semelhantes foram encontrados por Allen (1986) e Allen et al. (1989) ao avaliarem a estimativa de ETo por diferentes versões do método de Penman. Os autores verificaram 
que sob condições de aridez, a ETo foi subestimada em cerca de $10 \%$, em razão da advecção, enquanto que sob condições de clima úmido a superestimativa foi de $15 \%$. Isso pode ser melhor visualizado na Figura 14, onde é apresentada a relação entre ETo medida em lisímetro e a Rn medida na EMA, para o período analisado. Verifica-se que no período úmido $69,9 \%$ da $\mathrm{Rn}$ foi empregada no processo de evapotranspiração, ao passo que no período seco esse valor chegou a 90,8\%, indicando que houve adicional de energia por adveção neste último caso, haja visto que sob condições adequadas de área tampão o valor máximo da relação ETo/Rn dificilmente passa de 0,80 (Rosenberg et al., 1983).

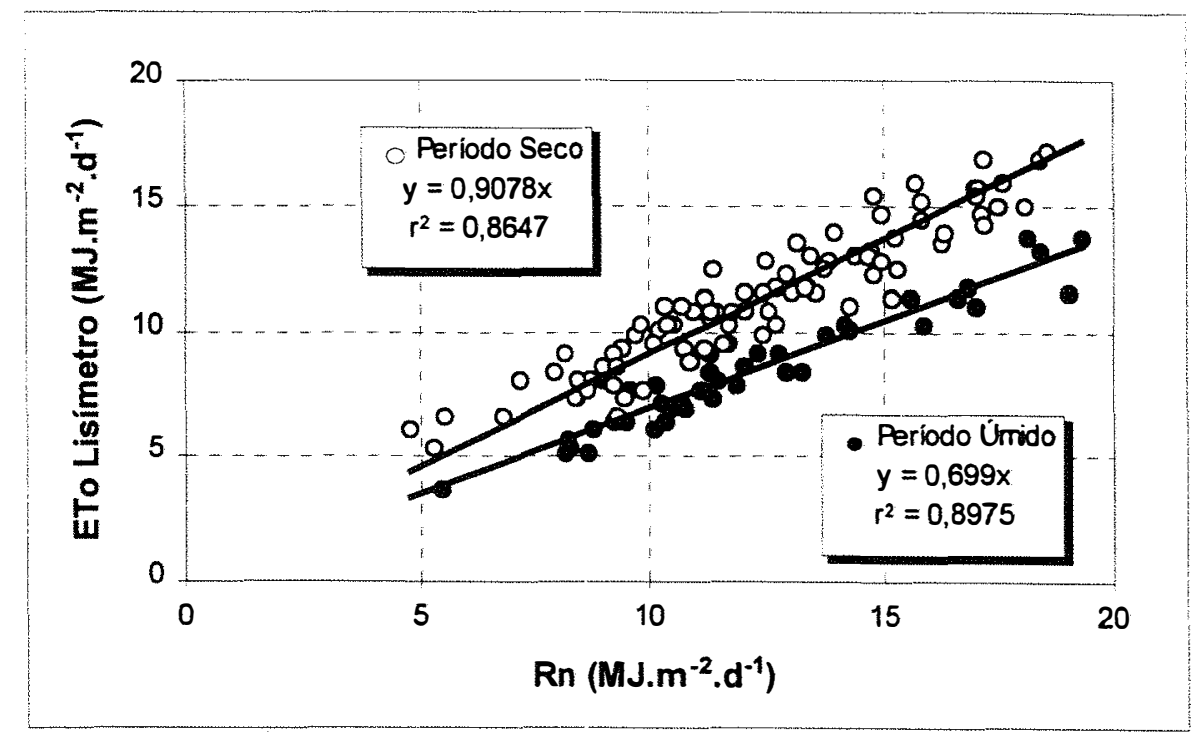

Figura 14. Relação entre a ETo medida em lisímetro e a Rn medida na EMA, para os períodos úmido e seco, em Piracicaba, SP.

Analisando-se separadamente os períodos úmido e seco, tanto para as estimativas a partir da EMC como da EMA, observou-se tendência de superestimativa da ETo no período úmido utilizando-se dados de qualquer estação. $\mathrm{Na}$ estimativa com dados da EMC a superestimativa é da ordem de $18 \%$, ao passo que com dados da EMA essa 
superestimativa passa a ser de $31 \%$ (Figura 15), em razão da subestimativa da $R n$ na EMC.
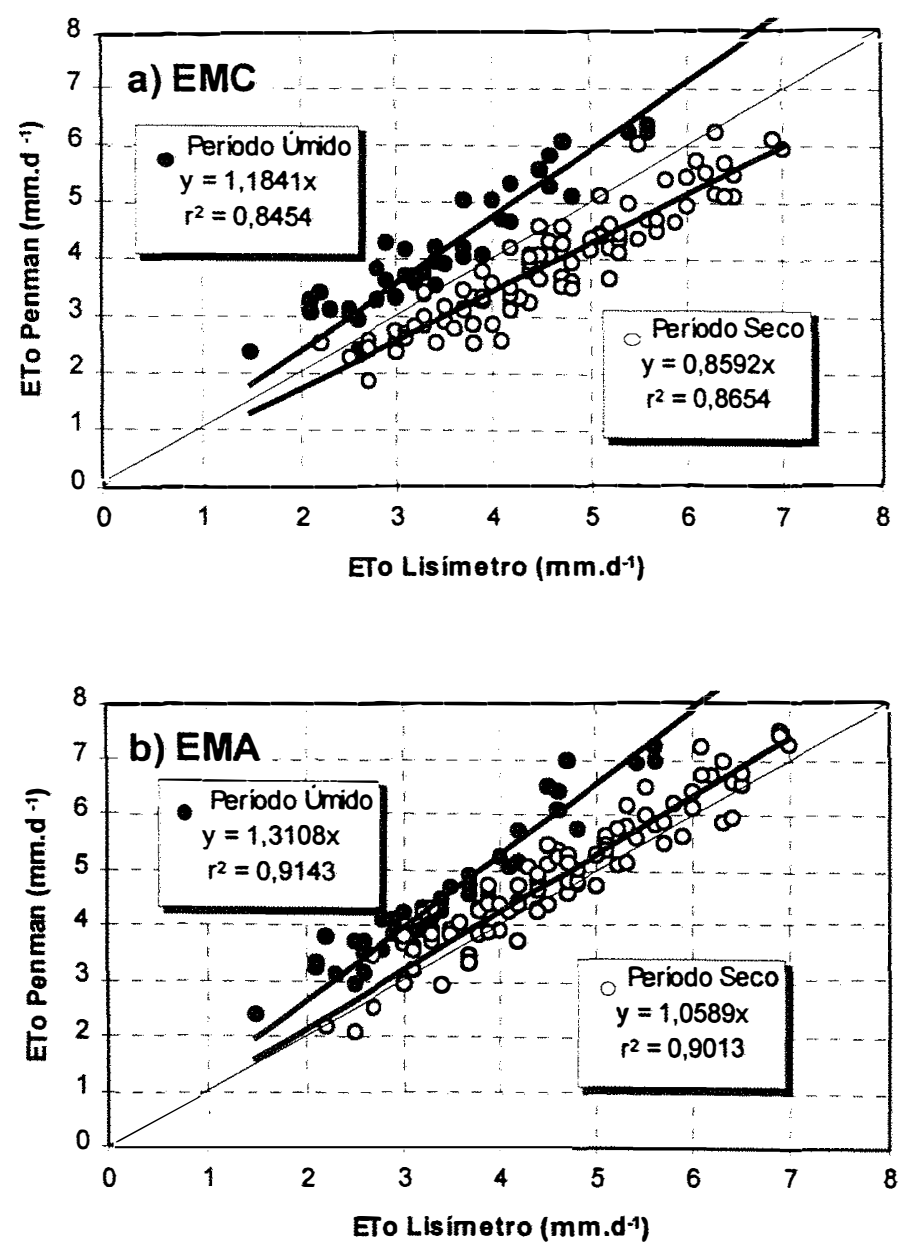

Figura 15. Relação entre a ETo estimada pelo método de Penman, com dados da EMC (a) e da EMA (b), e medida em lisímetro, para o período úmido e seco, com dados de Rn na EMC estimados pela equação de Angström-Brunt, em Piracicaba, SP.

No período seco, observa-se variação nas estimativas. Naquelas efetuadas com dados da EMC houve tendência de subestimativa da ETo em cerca de $14 \%$, ao passo que nas estimativas com dados da EMA a tendência foi de superestimativa de apenas $6 \%$, 0 
que indica ser o método de Penman uma boa alternativa para a estimativa da ETo em áreas irrigadas sob condição de clima seco.

\subsubsection{Com Rn estimada pelos métodos de regressão linear}

Análise semelhante foi feita para valores de Rn estimados tanto na EMC como na EMA, a partir das seguintes equações:

$$
\begin{array}{r}
\mathrm{Rn}_{\mathrm{EMC}}=\mathrm{Qo}(-0,0734+0,0101 \cdot \mathrm{T}+0,2513 . n / N) \\
\mathrm{Rn}_{\mathrm{EMA}}=0,57378 \mathrm{Qg} \ldots \ldots \ldots \ldots \ldots \ldots \ldots \ldots \ldots \ldots
\end{array}
$$

Os resultados mostraram uma melhora na exatidão das estimativas de ETo, que apresentaram leve tendência de superestimativa da ordem de $2,6 \%$ e de $6,4 \%$, respectivamente para a EMC e a EMA (Figuras 16a e 17a), porém, sem alterar a precisão nas estimativas realizadas com dados da EMC, $\mathrm{r}^{2}=0,56$, e piorando-as naquelas realizadas com dados da EMA, $\mathrm{r}^{2}=0,67$. Com relação ao erro médio absoluto, observouse manutenção com a utilização dos da EMC, e decréscimo com os da EMA (Figuras $16 \mathrm{~b}$ e $17 \mathrm{~b})$.
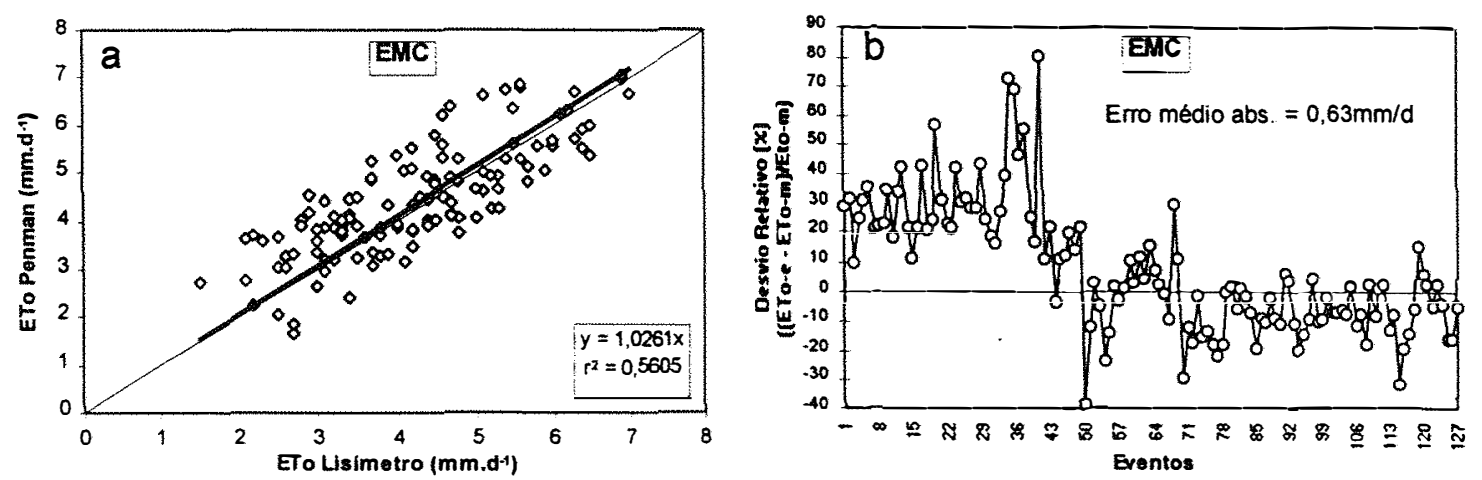

Figura 16. Relação entre a ETo estimada pelo método de Penman com dados da EMC e medida em lisímetro (a) e desvio relativo da ETo (b), com $\mathrm{Rn}$ estimada pela equação 22, em Piracicaba, SP. 

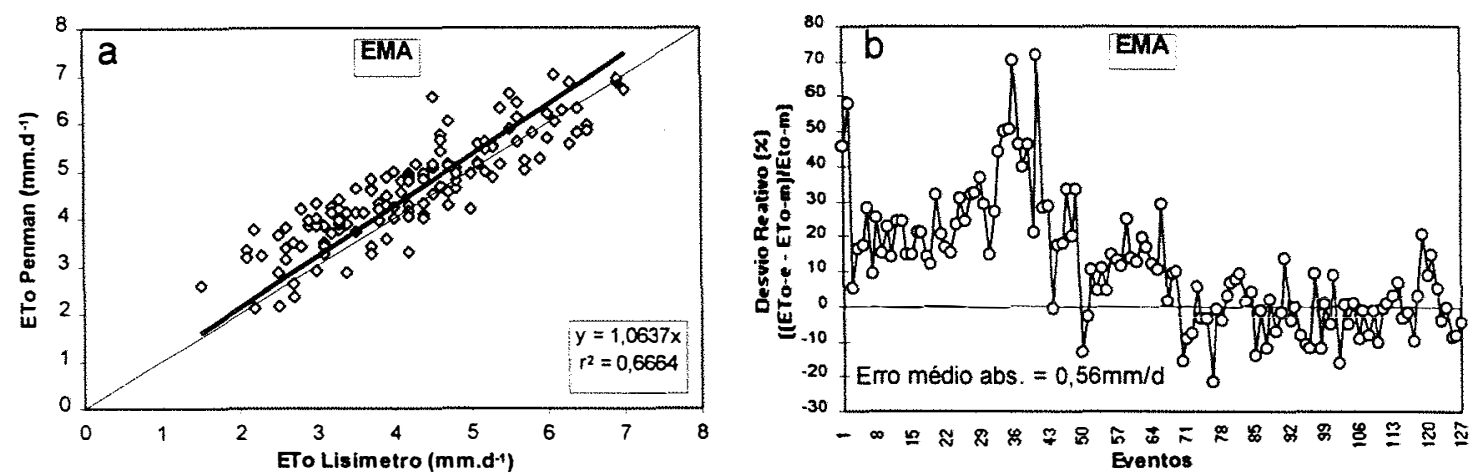

Figura 17. Relação entre a ETo estimada pelo método de Penman com dados da EMA e medida em lisímetro (a) e desvio relativo da ETo (b), com Rn estimada pela equação 23, em Piracicaba, SP.

Analisando-se a relação entre a ETo estimada pelo método de Penman com os valores de $\mathrm{Rn}$ obtidos pelas equações 22, na EMC, e 23, na EMA, observa-se que a concordância é elevada, com $b=1,0272, r^{2}=0,8457$ e erro médio absoluto de apenas $0,36 \mathrm{~mm}^{\mathrm{d}} \mathrm{d}^{-1}$ (Figura 18), mostrando, desse modo, a substancial melhoria nas estimativas de ETo a partir de dados obtidos na EMC.
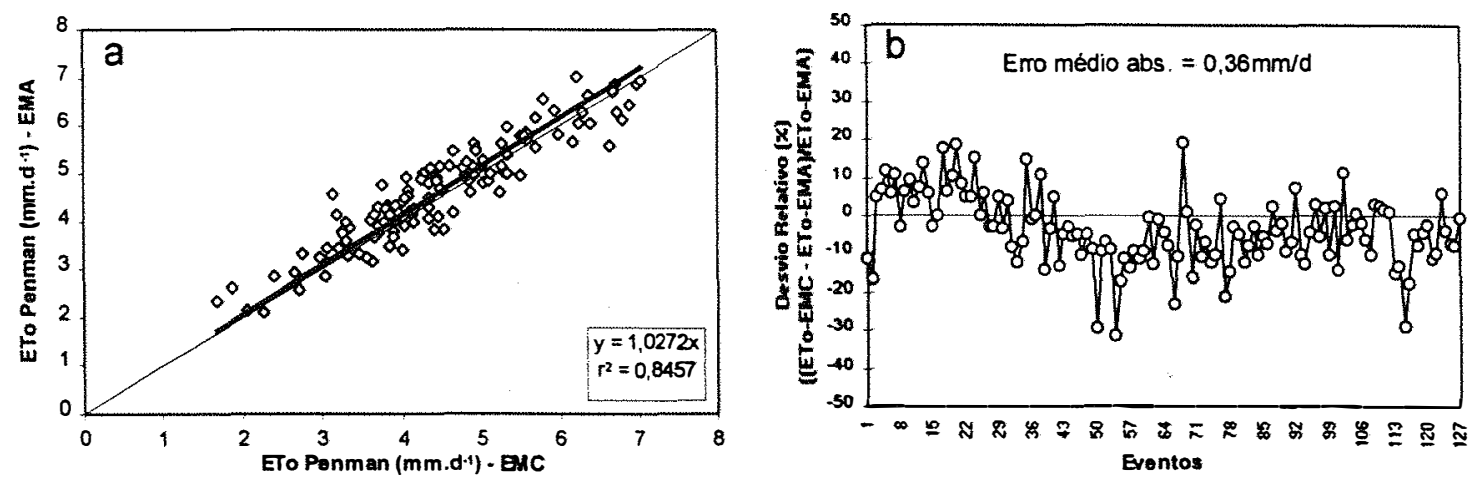

Figura 18. Relação entre a ETo estimada pelo método de Penman, com dados da EMC e da EMA (a) e desvio relativo da ETo (b), com Rn estimada pelas equações 22 e 23, respectivamente, em Piracicaba, SP. 
Apesar disso, a dicotomia na série de estimativas volta a ser observada, porém, com tendência semelhante para as duas estimativa, ou seja, com dados da EMC e da EMA (Figura 16b e 17b).

Assim, analisando-se separadamente os períodos úmido e seco (Figura 19), observa-se, praticamente, a mesma tendência para as estimativas de ETo, tanto com dados da EMC como da EMA, ou seja, superestimativa no período úmido, respectivamente, de $28 \%$ e $24 \%$, e elevada exatidão no período seco, com b $=0,9564$ nas estimativas com dados da EMC e $b=1,0159$ nas estimativas com dados da EMA.
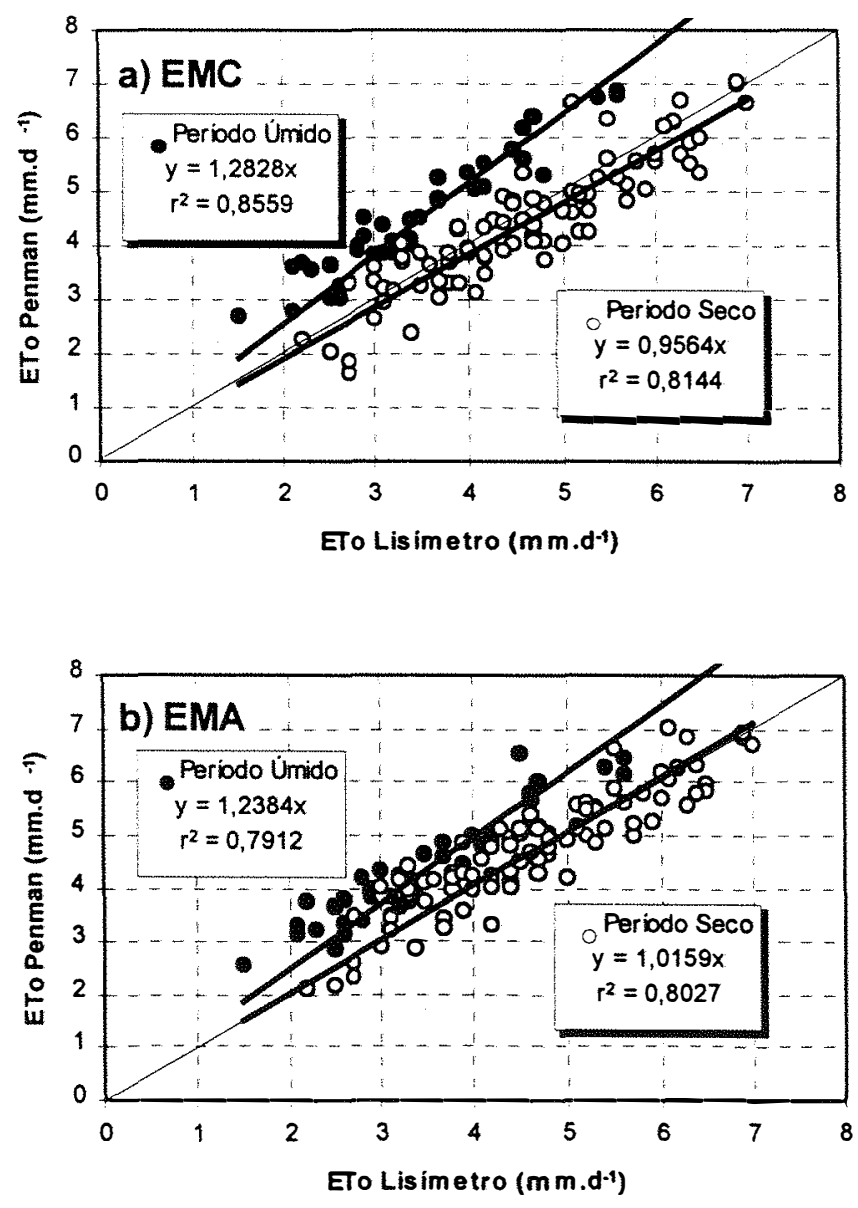

Figura 19. Relação entre a ETo estimada pelo método de Penman, com dados da EMC (a) e da EMA (b), e medida em lisímetro, para o período úmido e seco, com dados de Rn estimados pelas equações 22 e 23, em Piracicaba, SP. 
Apesar disso, a precisão sofreu redução, especialmente, no caso das estimativas com dados da EMA, que passaram da faixa de $\mathrm{r}^{2}=0,90$, com a Rn medida, para a de $\mathrm{r}^{2}=$ 0,80, com dados estimados de $\mathrm{Rn}$. Esses resultados voltam a indicar que o método de Penman para a estimativa da ETo durante o período seco ou em condições de aridez proporcionou bons resultados, quer seja com dados de Rn medidos ou estimados, especialmente a partir da EMA.

\subsubsection{Método de Priestley-Taylor}

\subsubsection{Com Rn estimada pelas equações de Angström e Brunt}

O método de Priestley \& Taylor (1972), por ser uma simplificação do método de Penman, vem sendo bastante empregado (Pereira \& Villa Nova, 1992; Cunha \& Bergamaschi, 1994; Pereira et al., 1997b). No entanto, devido às características empíricas inerentes ao processo de estimação do parâmetro de Priestley-Taylor $(\alpha)$, ele não pode ser considerado de aplicação universal para diferentes climas e culturas (Cunha \& Bergamaschi, 1994). Isso é melhor visualizado na Figura 20, em que se tem a estimativa da ETo a partir do método de Priestley-Taylor utilizando-se $\alpha=1,26$, como sugerido pelos autores, empregando-se dados provenientes da EMC e da EMA.

Observa-se que para as estimativas a partir dos dados obtidos na EMC (Figura 20a) não houve boa concordância com os dados de ETo medidos em lisímetro tanto para o período úmido, com superestimativa de $14 \%$, como para o seco, com subestimativa de $26 \%$, o que se deve em parte a estimativa deficiente de $\mathrm{Rn}$ utilizando-se a associação das equações de Angström e Brunt para as condições de Piracicaba, mas também em razão do uso de $\alpha=1,26$ para os dois períodos. Utilizando-se dados da EMA, em que a Rn foi medida (Figura 20b), nota-se que houve no período úmido elevação da superestimativa de ETo, que passou para $31 \%$. No período seco, houve melhoria substancial na concordância entre as estimativas de ETo e os valores medidos, caindo a subestimativa para apenas 3\%. Essas constatações evidenciam a necessidade de adequação dos valores 
de $\alpha$ para diferentes condições climáticas e também para dados provenientes de diferentes tipos de estação meteorológica.
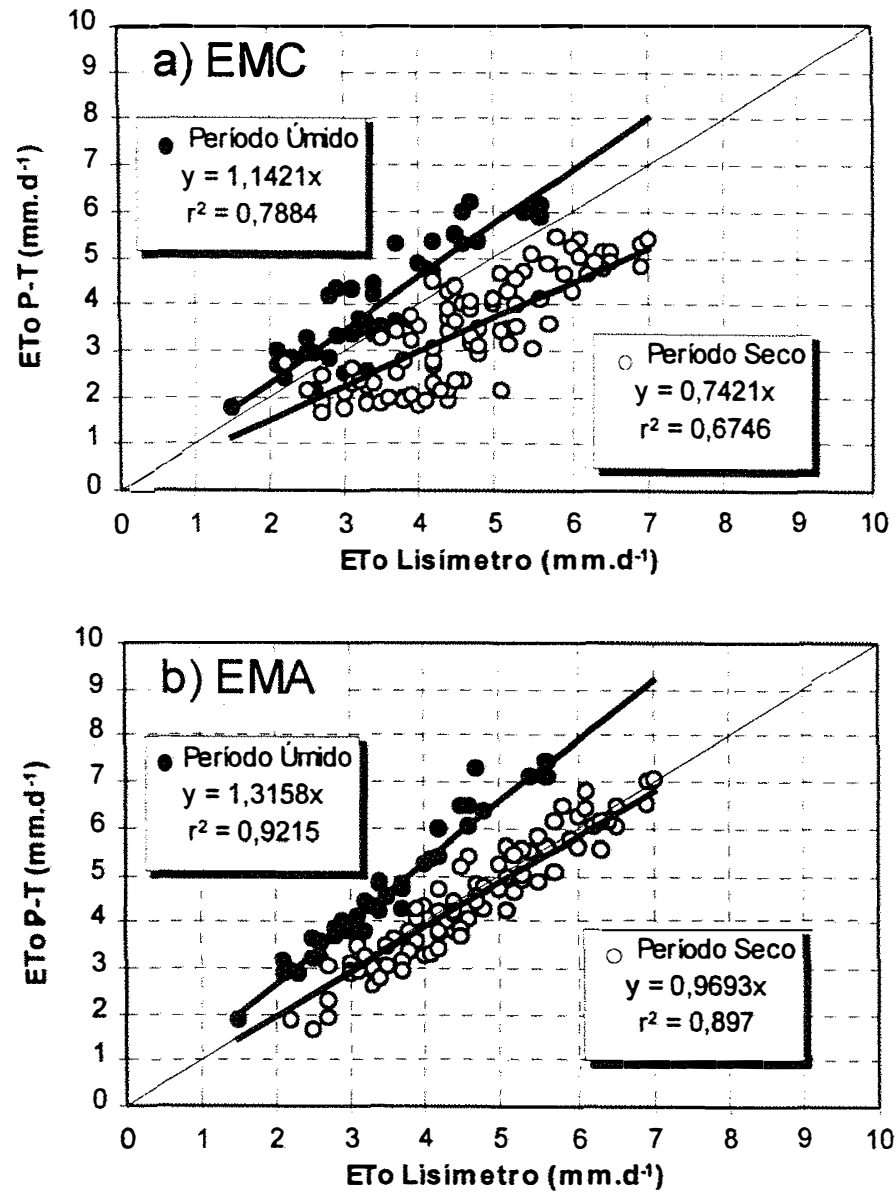

Figura 20. Relação entre a ETo estimada pelo método de Priestley-Taylor $(\alpha=1,26)$, com dados da EMC (a) e da EMA (b), e medida em lisímetro, para o período úmido e seco, com Rn na EMC estimada pela equação de Angström-Brunt.

Na Figura 21 são apresentados os valores de $\alpha$ para os períodos úmido e seco, utilizando-se dados provenientes da EMC e EMA. Os valores de $\alpha$ variaram significativamente, sendo na média, respectivamente para os dados obtidos na EMC e na EMA, iguais a 1,13 e 0,97 para o período úmido e iguais a 1,62 e 1,33 para o período seco, considerando-se neste caso os valores de $\mathrm{Rn}$ medidos na EMA e estimados por Angström-Brunt na EMC. Esses valores encontram-se dentro dos limites apresentados 
por Priestley \& Taylor (1972), Doorenbos \& Pruitt (1977), Allen (1986), Cunha \& Bergamaschi (1994), Pereira et al. (1997b) e Peres et al. (1997), que oscilam entre 1,0 e 2,0. Assim, para a correta estimativa da ETo por este método, os valores de $\alpha$ a serem empregados, devem estar de acordo com o tipo de estação meteorológica e das condições de umidade em questão, para se minimizar as diferenças em relação aos valores medidos.

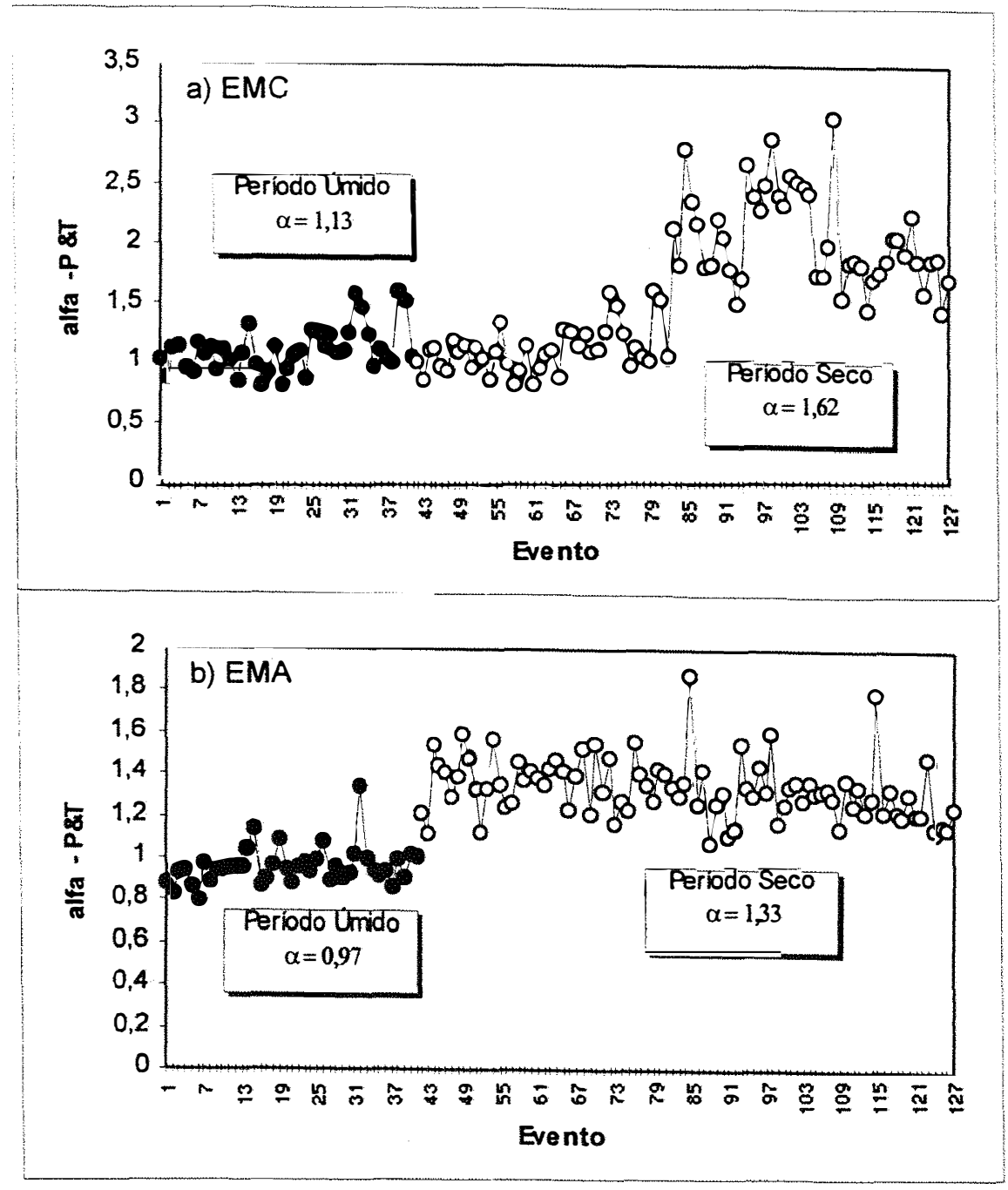

Figura 21. Valores diários e médios do parâmetro de Priestley-Taylor nos períodos úmido e seco, utilizando-se dados provenientes da EMC (a) e da EMA (b), com Rn por Angström-Brunt e medida, respectivamente, em Piracicaba, SP. 


\subsubsection{Com Rn estimada pelos métodos de regressão linear}

Análise semelhante foi realizada para os valores de $\mathrm{Rn}$ estimados a partir das equações 22 e 23 . Verificou-se uma melhora nas estimativas de ETo, a partir dos dados da EMC (Figura 22a), no período seco, caindo a subestimativa para 14\%, porém, uma piora nas estimativas de ETo no período úmido, com a superestimativa chegando a $27 \%$. Para as estimativas a partir dos dados da EMA (Figura 22b), ocorreu o inverso, piorando no período seco, com elevação da subestimativa para $9 \%$, e melhorando no período úmido, com diminuição da superestimativa para $22 \%$.
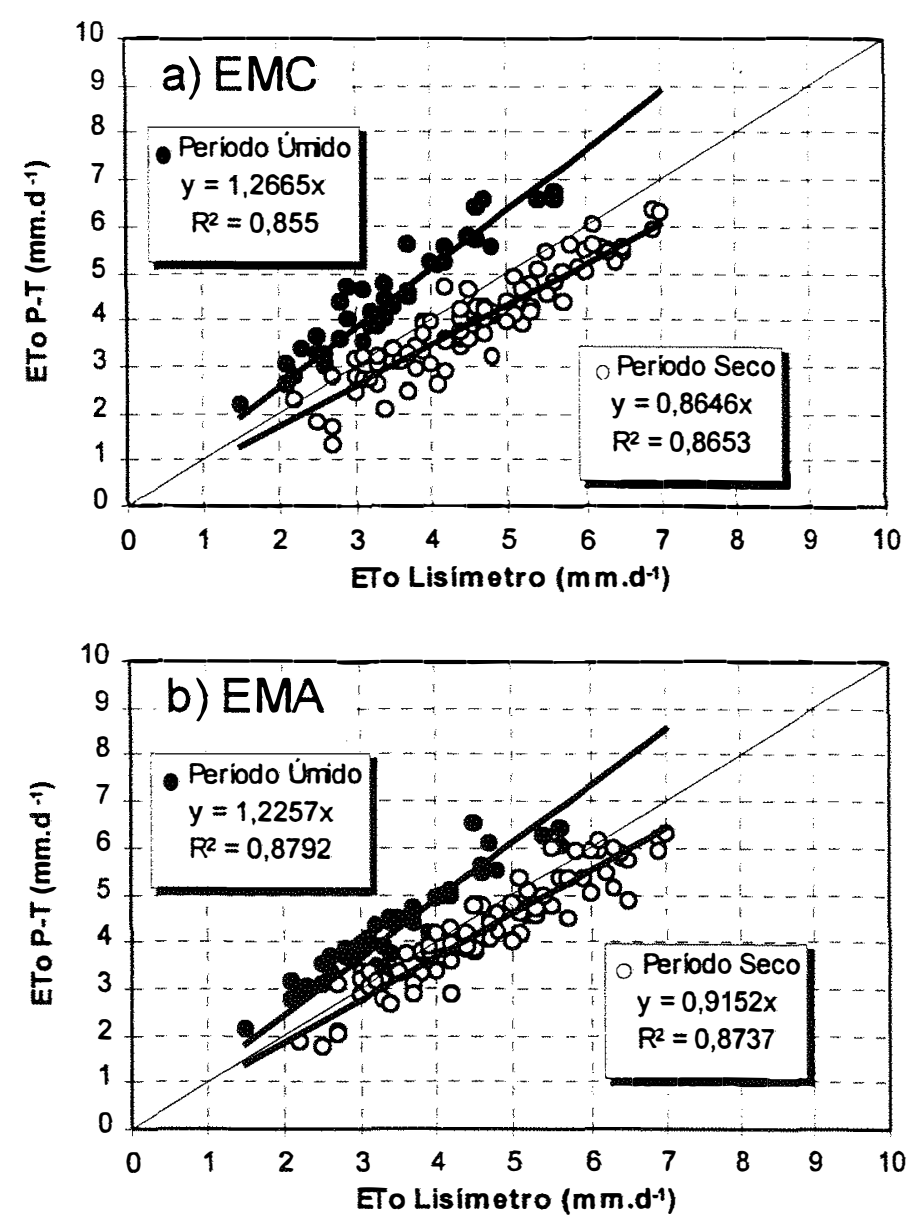

Figura 22. Relação entre a ETo estimada pelo método de Priestley-Taylor $(\alpha=1,26)$, com dados da EMC (a) e da EMA (b), e medida em lisímetro, no período úmido e seco, com Rn estimada pelas eq. 22 e 23 , respectivamente. 
Nesse caso, os valores de $\alpha$ determinados a partir da relação entre a ETo e o produto W.Rn, foram da ordem de 0,99 e 1,01, no período úmido, e da ordem de 1,28 e 1,38, no período seco, respectivamente, para a Rn estimada com dados da EMC e da EMA (Figura 23). Novamente, os valores de $\alpha$ se encontram dentro dos limites apresentados na literatura e continuam a indicar a necessidade de utilização de valores adequados nas diferentes condições de estimativa da ETo.

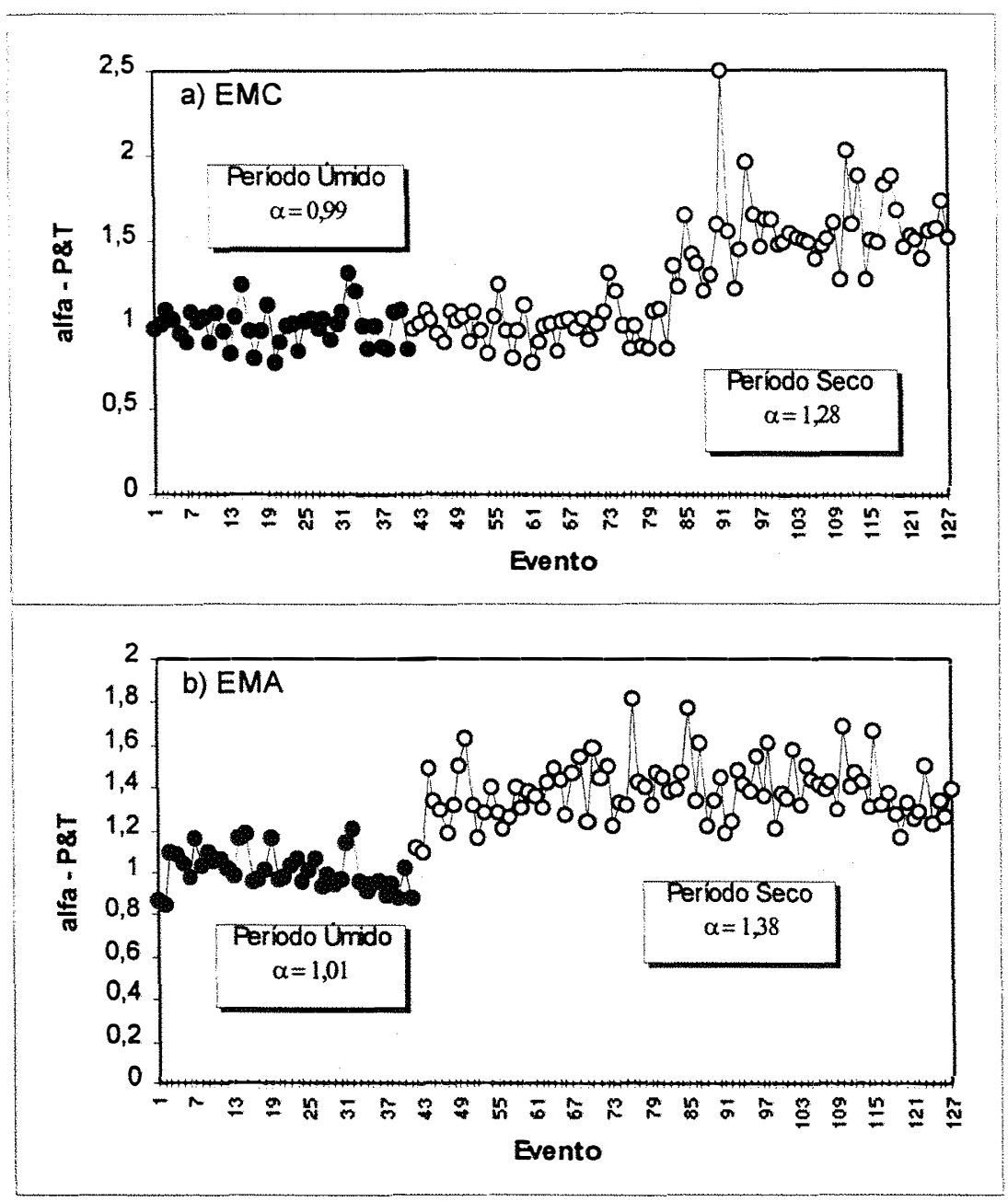

Figura 23. Valores diários e médios do parâmetro de Priestley-Taylor nos períodos úmido e seco, utilizando-se dados provenientes da EMC (a) e da EMA (b), sendo $R n$ estimada pelas equações 22 e 23 , respectivamente. 
Na Figura 24 são apresentadas as estimativas de ETo pelo método de PriestleyTaylor, a partir dos dados obtidos na EMA, com valores de $\alpha$ igual a 1,0 no período úmido, e igual a 1,33 para o período seco.

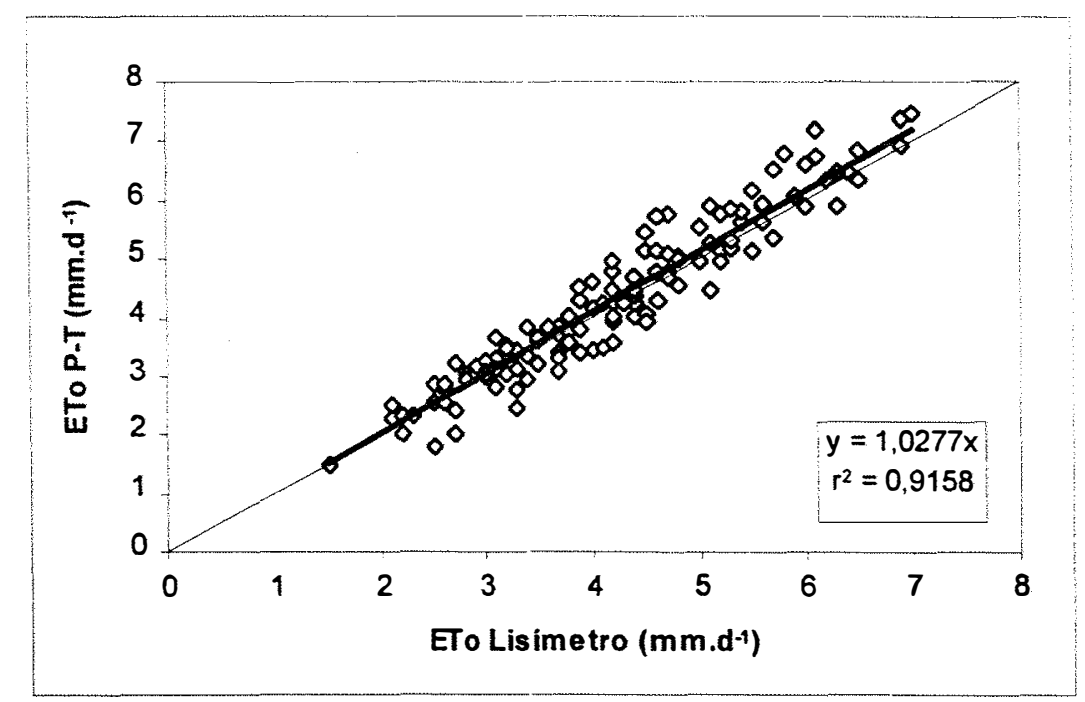

Figura 24. Relação entre a ETo estimada pelo método de Priestley-Taylor e medida em lisímero, utilizando-se $\alpha$ igual a 1,00 no período úmido e igual a 1,33 no período seco, a partir dos dados meteorológicos obtidos na EMA, em Piracicaba, SP.

Mediante a adoção dos valores médios de $\alpha$, observa-se boa concordância entre os valores estimados e medidos de ETo, com tendência de leve superestimativa, da ordem de $2,8 \%$, indicando alta exatidão, e com baixa dispersão, ou seja, alta precisão $\left(\mathrm{r}^{2}\right.$ $=0,9158)$ das estimativas, o que mostra que a utilização de valores diferenciados de $\alpha$ nos períodos úmido e seco deve ser levado em conta no emprego deste método quando se visa o manejo da irrigação. 


\subsubsection{Método de Penman-Monteith}

\subsubsection{Com Rn estimada pelas equações de Angström e Brunt}

Primeiramente, analisou-se as estimativas de ETo pelo método de PenmanMonteith, seguindo-se as recomendações da FAO (Smith, 1991), ou seja, com a utilização da Rn estimada pela equação Angström-Brunt e da relação entre a resistência da cobertura e a aerodinâmica $\left(\mathrm{r}_{\mathrm{c}} / \mathrm{r}_{\mathrm{a}}\right)$ igual a $0,33 \mathrm{U}_{2 \mathrm{~m}}$, com dados meteorológicos obtidos na EMC e na EMA.

Na Figura 25 são apresentadas as estimativas de ETo utilizando-se dados da EMC. Observa-se que não houve boa concordância entre as estimativas e as medidas, sendo clara a tendência de subestimativa de ETo pelo método de Penman-Monteith, da ordem de 21\%, além da baixa precisão, $r^{2}=0,53$ (Figura 25a). Verifica-se na Figura 25b, que novamente houve dicotomia na série de estimativas, sendo o desvio relativo em torno de zero no período úmido, passando a oscilar em torno de 30\% no período seco. De acordo com as análises apresentadas no item 4.1, é evidente que parte das discrepâncias observadas nas estimativas é decorrente da subestimativa da Rn a partir do método recomendado pela FAO para as condições de Piracicaba.
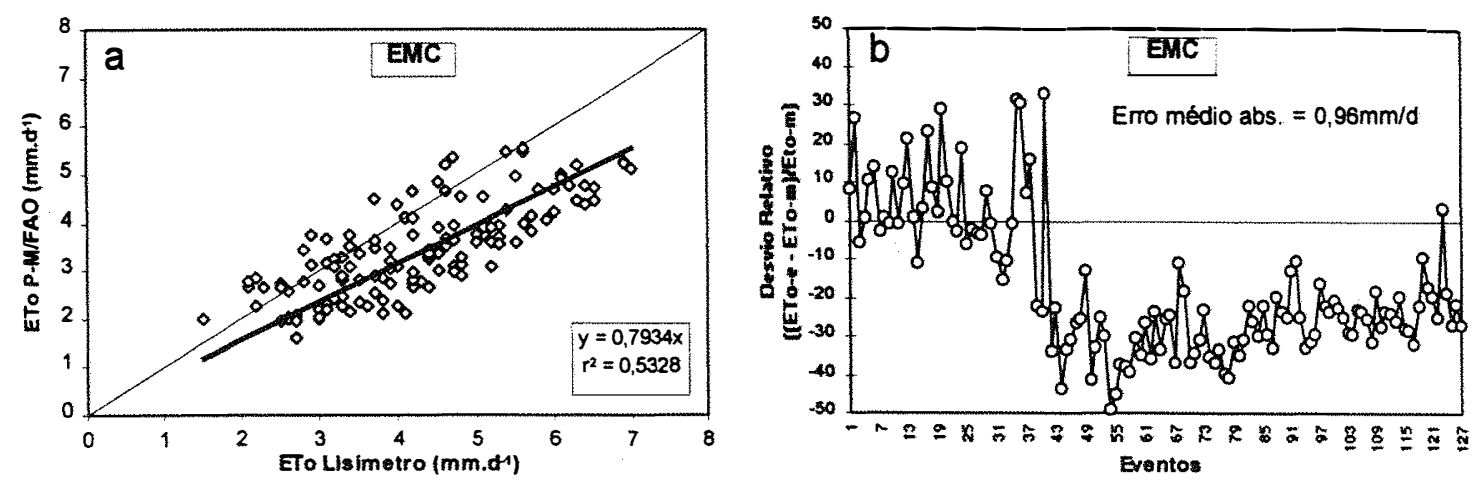

Figura 25. Relação entre a ETo estimada pelo método de Penman-Monteith com dados da EMC e medida em lisímetro (a) e desvio relativo da ETo (b), com Rn estimada por Angström-Brunt, em Piracicaba, SP. 
Utilizando-se dados observados na EMA para estimar a ETo pelo método de Penman-Monteith, observa-se melhoria significativa na concordância entre as estimativas e os dados medidos, com elevação da exatidão, $b=0,9521$, e da precisão, $\mathrm{r}^{2}=0,7522$ (Figura 26a). Apesar disso, a dicotomia da série de dados ainda é observada, porém com o erro médio absoluto passando de $0,96 \mathrm{~mm} \cdot \mathrm{d}^{-1}$ para $0,49 \mathrm{~mm} \cdot \mathrm{d}^{-1}$, não havendo tendência de melhor exatidão no período seco ou úmido (Figura 26b). Isso mostra a tendência clara de melhores estimativas da ETo a partir de dados da EMA e também que, muitas vezes, a falta de atenção para esses detalhes podem levar a interpretações erradas a respeito do método, com relação à sua confiabilidade.
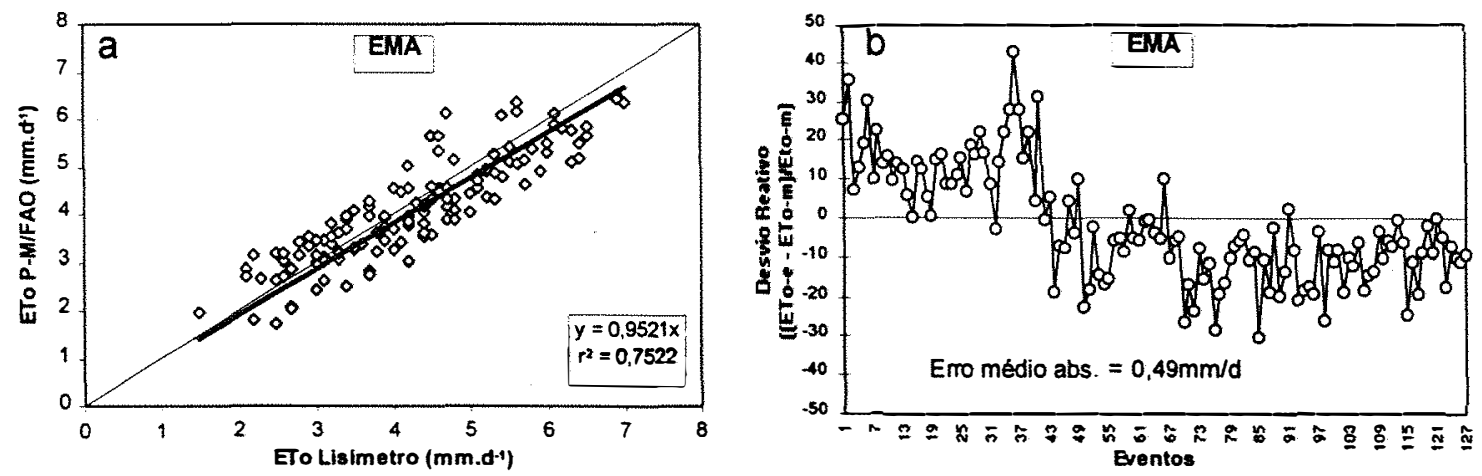

Figura 26. Relação entre a ETo estimada pelo método de Penman-Monteith com dados da EMA e medida em lisímetro (a) e desvio relativo da ETo (b), em Piracicaba, SP.

A Figura 27 mostra a diferença sistemática entre as estimativa de ETo por Penman-Monteith, utilizando-se dados da EMC e da EMA, em que observa-se discrepâncias da ordem de $18 \%$, sendo a ETo sempre maior nas estimativas a partir da EMA. Isso evidencia, principalmente, a necessidade de métodos de estimativa da Rn a partir de dados da EMC, para se minimizar os erros decorrentes da utilização de estações meteorológicas dessa natureza na estimativa da ETo e no manejo da irrigação. 

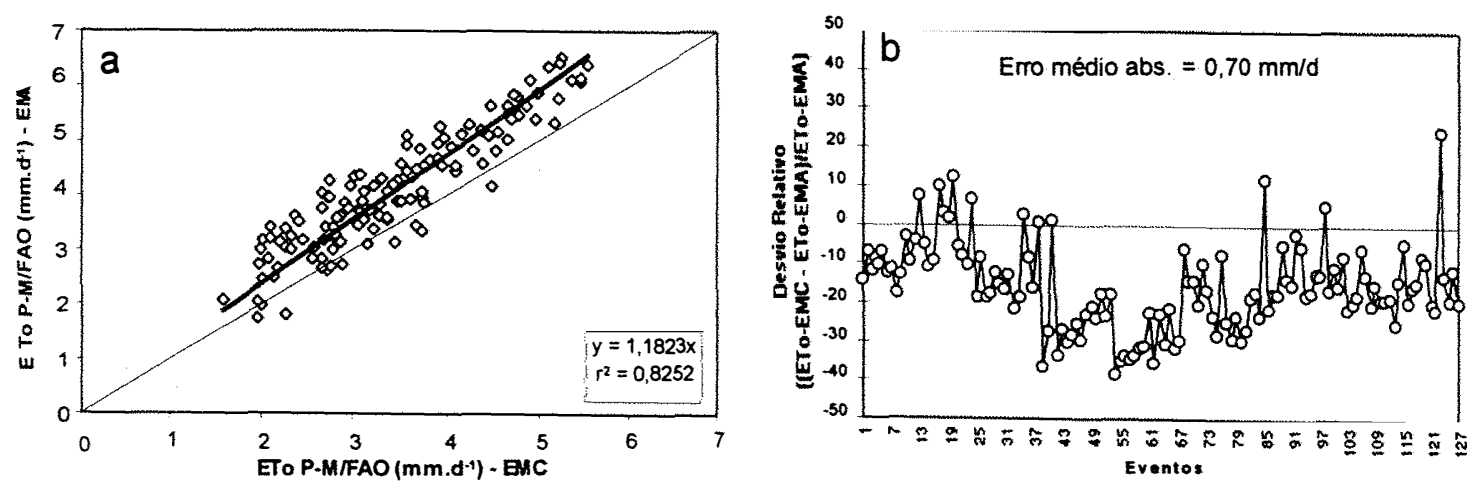

Figura 27. Relação entre a ETo estimada pelo método de Penmam-Monteith, com dados da EMC e da EMA (a) e desvio relativo da ETo (b), com Rn estimado na EMC por Angström-Brunt, em Piracicaba, SP.

Em razão da dicotomia da série de estimativas observada, foram analisados separadamente os períodos úmido e seco, tanto para as estimativas a partir da EMC como da EMA (Figura 28). As estimativas a partir da EMC mostraram tendência de melhores ajuste aos dados medidos em lisímetro, no período úmido, em que verificou-se leve superestimativa da ordem de $3 \%$. No período seco, no entanto, a tendência foi de subestimativa da ordem de $27 \%$. Utilizando-se os dados da EMA, as estimativas tiveram melhor precisão, com $r^{2}$ acima de 0,9 , havendo elevação na superestimativa no período úmido, que passou para $14 \%$, mas por outro lado, uma reducão na subestimativa no período seco, que caiu para 10\%. De acordo com Allen (1986) e Allen (1989) essa tendência de subestimativa, quer seja com dados da EMC ou da EMA, se deve à grande influencia da advecção, que em período seco se torna significativa. Já a superestimativa no período úmido, e que normalmente vem sendo observada com o emprego deste método (Sediyama, 1996; Camargo \& Sentelhas, 1997; Alves et al., 1998), está relacionada à razão entre as resistências da cobertura e aerodinâmica à transferência de vapor $\left(\mathrm{r}_{\mathrm{c}} / \mathrm{r}_{\mathrm{a}}\right)$, que para valores de velocidade do vento a $2 \mathrm{~m}$ acima de $1,1 \mathrm{~m} . \mathrm{s}^{-1}$ é subestimada grosseiramente, de acordo com observações feitas por Pereira et al. (1995), que propuseram uma nova função que descreve essa relação, sendo aprimorada por Pereira et al. (1998). 

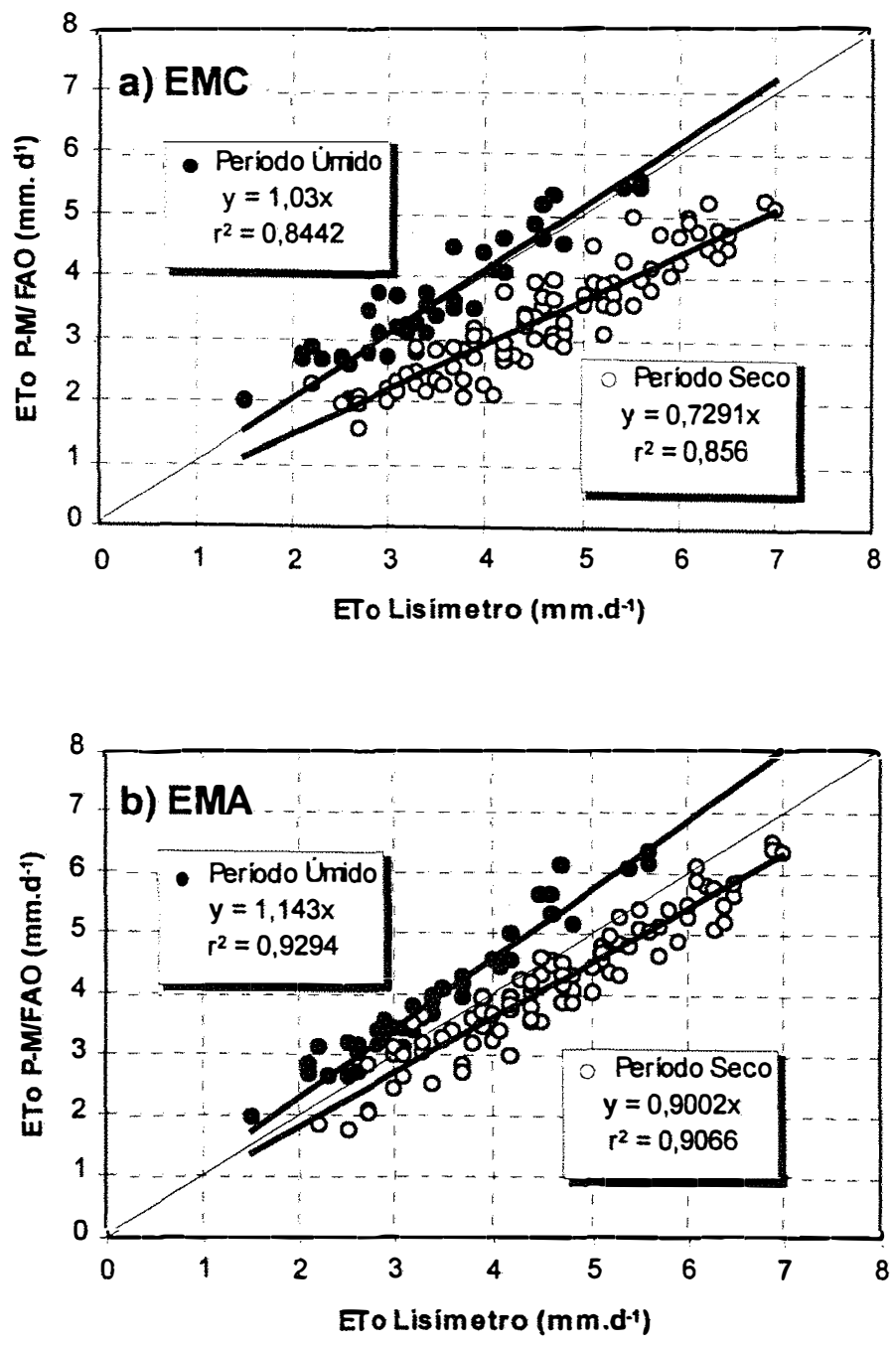

Figura 28. Relação entre a ETo estimada pelo método de Penman-Monteith, com dados da EMC (a) e da EMA (b), e medida em lisímetro, para o período úmido e seco, com dados de Rn estimados na EMC por Angström-Brunt, em Piracicaba, SP.

\subsubsection{Com Rn estimada pelos métodos de regressão linear}

Buscando-se melhorar as estimativas a partir dos dados da EMC e apresentar uma alternativa de estimativa da ETo a partir de EMA's que não possuem sensor para 
Rn, elaborou-se análise da estimativa da ETo por Penman-Monteith, utilizando-se dados de Rn estimados pelas equações 22 e 23 .

A Figura 29 mostra que houve uma leve melhora na exatidão das estimativas de ETo utilizando $\mathrm{Rn}$ estimado pela equação 22 a partir de dados da EMC, com a subestimativa caindo para $12 \%$ e o erro médio para a faixa de $0,74 \mathrm{~mm}^{-\mathrm{d}^{-1}}$, porém, sem haver melhora na precisão, com $\mathrm{r}^{2}=0,5481$.
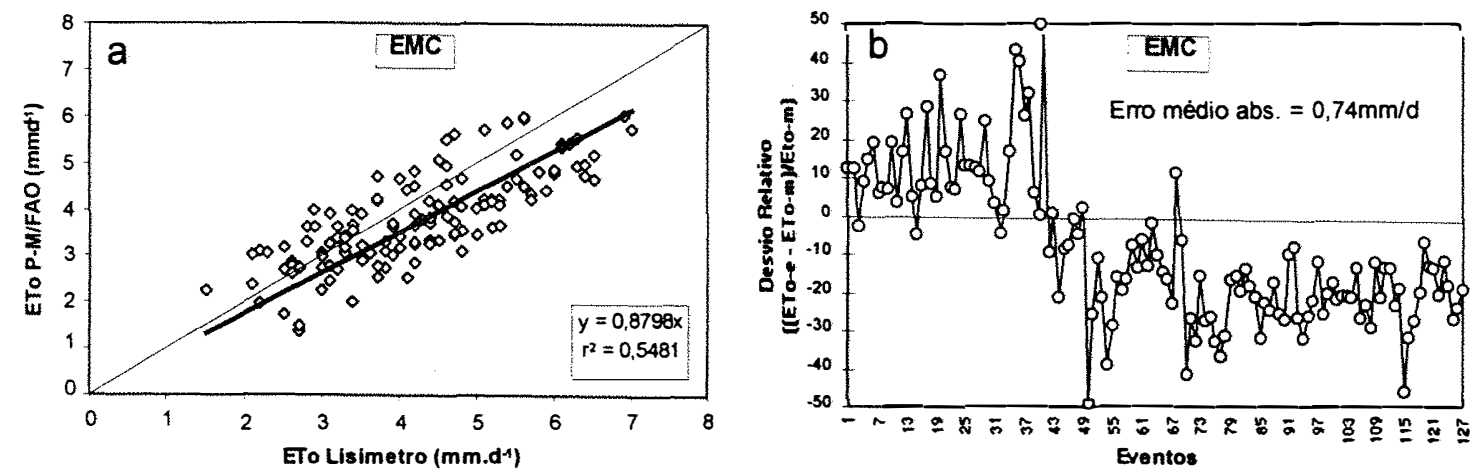

Figura 29. Relação entre a ETo estimada pelo método de Penman-Monteith com dados da EMC e medida em lisímetro (a) e desvio relativo da ETo (b), com $\mathrm{Rn}$ estimada pela equação 22, em Piracicaba, SP.
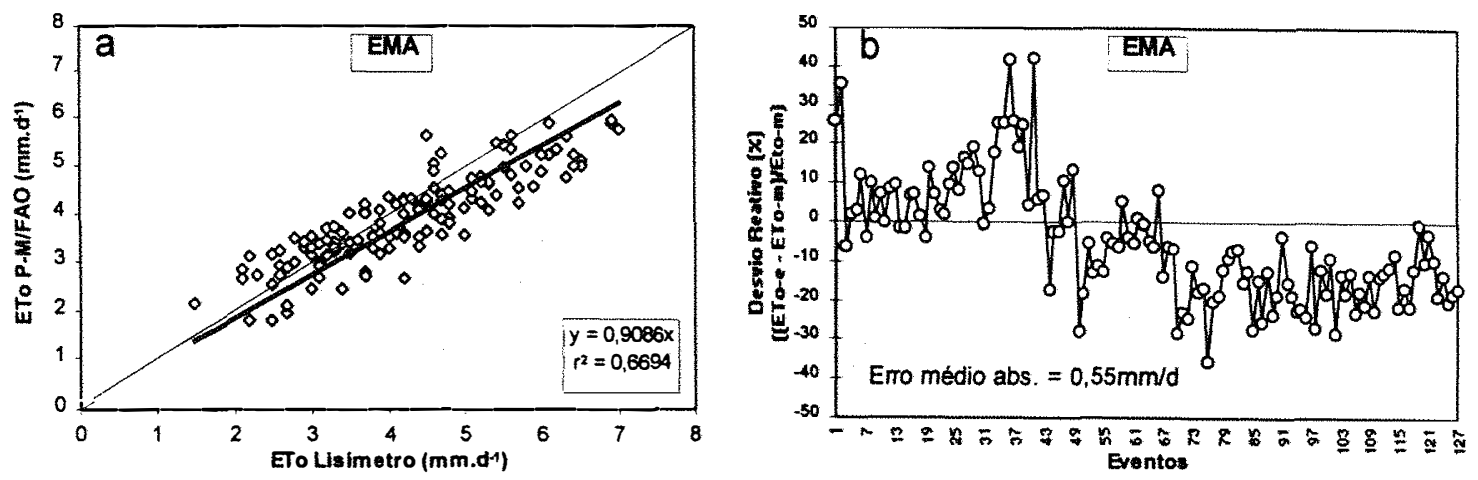

Figura 30. Relação entre a ETo estimada pelo método de Penman-Monteith com dados da EMA e medida em lisímetro (a) e desvio relativo da ETo (b), com Rn estimada pela equação 23, em Piracicaba, SP. 
Utilizando-se dados da EMA para a estimativa da ETo e estimando-se Rn pela equação 23 , observa-se um redução na exatidão, com a subestimativa aumentando para $10 \%$, e também na precisão, com $\mathrm{r}^{2}$ caindo para 0,67 (Figura 30).

Apesar da redução nos níveis de precisão e exatidão das estimativas, a utilização da estimativa de $R n$ pelas equações 22 e 23 , proporcionam uma opção bastante viável para a estimativa da ETo quando sensores de $R n$ não são disponíveis. A boa concordância entre as estimativas de ETo a partir dos dados meteorológicos das duas estações é apresentada na Figura 31. Observa-se que o ajuste é quase perfeito, com $b=$ 1,0225 e $\mathrm{r}^{2}=0,8561$, sendo a diferença média entre as duas estações da ordem de 0,3 $\mathrm{mm} \cdot \mathrm{d}^{-1}$.
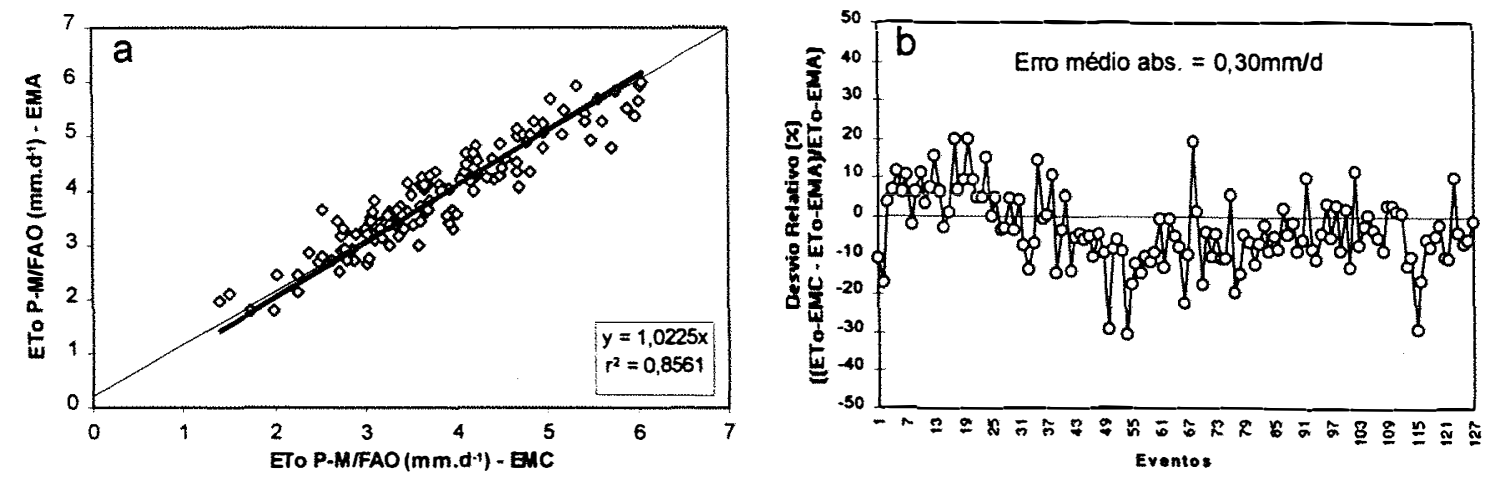

Figura 31. Relação entre a ETo estimada pelo método de Penmam-Monteith, com dados da EMC e da EMA (a) e desvio relativo da ETo (b), com Rn estimada, respectivamente, pelas equações 22 e 23, em Piracicaba, SP.

Essa boa concordância entre as estimativas de ETo por Penman-Monteith utilizando-se os dados de Rn estimados, tanto na EMC como na EMA, também pode ser visualizada pela análise dos períodos úmido e seco (Figura 32). No período úmido, manteve-se a tendência de superestimativa, observada na análise anterior, $11,8 \%$ e 7,7\%, respectivamente, para as estimativas com dados da EMC e da EMA. No período seco, manteve-se também a subestimativa, sendo maior a partir de dados da EMC, da ordem 
de $18,5 \%$, e menor naquelas que utilizaram dados da EMA, da ordem de $13,7 \%$. Os níveis de precisão foram semelhantes, na faixa de 82 a $87 \%$.
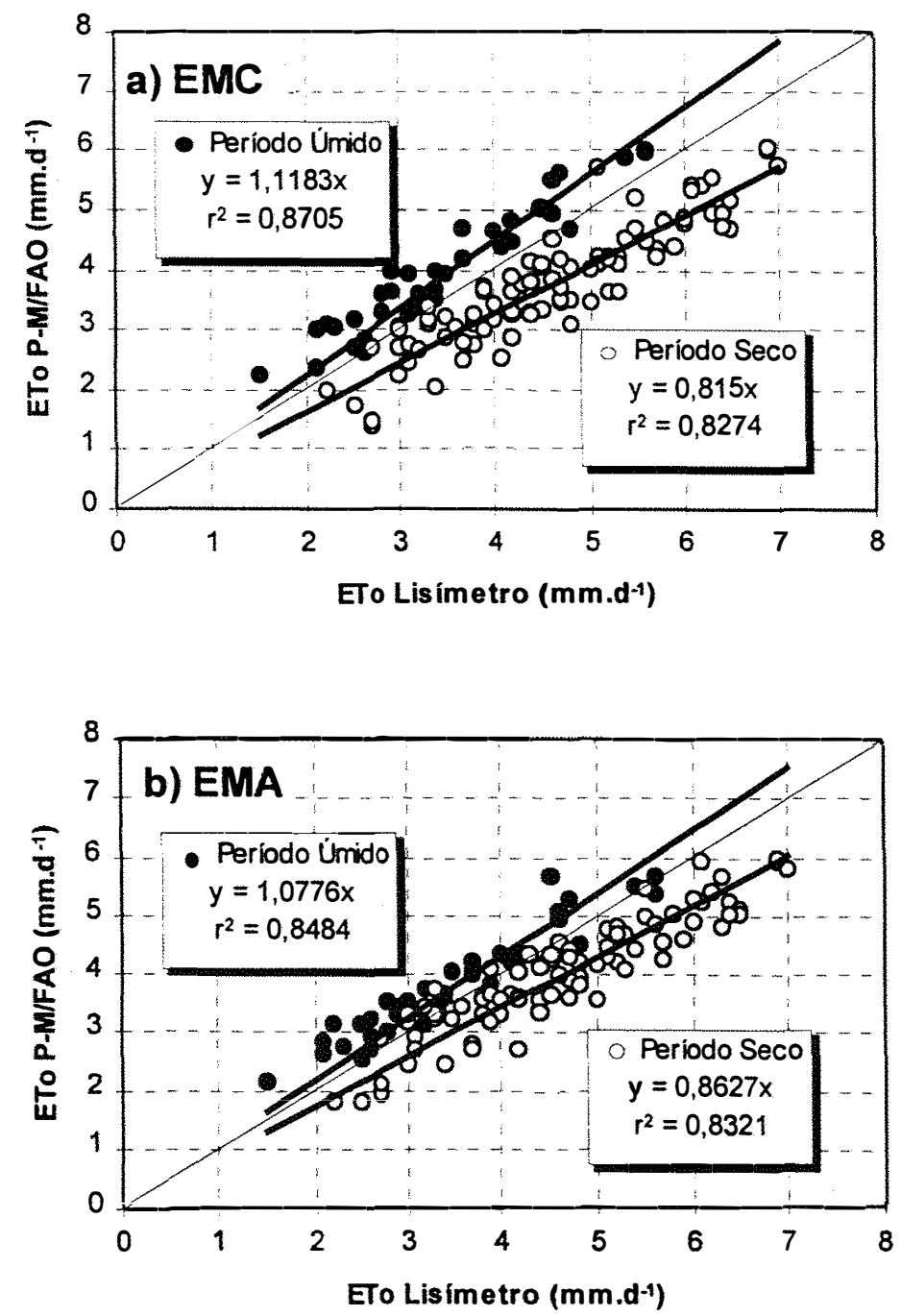

Figura 32. Relação entre a ETo estimada pelo método de Penman-Monteith, com dados da EMC (a) e da EMA (b), e medida em lisímetro, para o período úmido e seco, com dados de $\mathrm{Rn}$ estimados pelas equações 22 e 23 , respectivamente, na EMC e na EMA, em Piracicaba, SP. 


\subsubsection{Efeito da relação $r_{c} / r_{a}$}

Outro fator que vem mostrando ser uma importante fonte de erro na estimativa de ETo é a relação $r_{c} / r_{a}$, que segundo Alves et al. (1998) é o principal problema na aplicação prática do método de Penman-Monteith. Desse modo, testou-se a função que descreve a relação $r_{c} / r_{a}$ formulada por Pereira et al. (1995) e melhorada por Pereira et al. (1998), na estimativa da ETo. A Figura 33 apresenta, primeiramente, a estimativa da ETo a partir dos dados da EMC, sendo a Rn estimada por Angström-Brunt. Os resultados mostram, de um modo geral, que o emprego da nova relação $r_{c} / r_{a}$ não proporcionou melhoria significativa nas estimativas da ETo, que foi subestimada em cerca de 32\% (Figura 33a). A mesma tendência foi observada nas estimativas a partir dos dados da EMA, em que a subestimativa foi da ordem de $21 \%$ (Figura 34a).
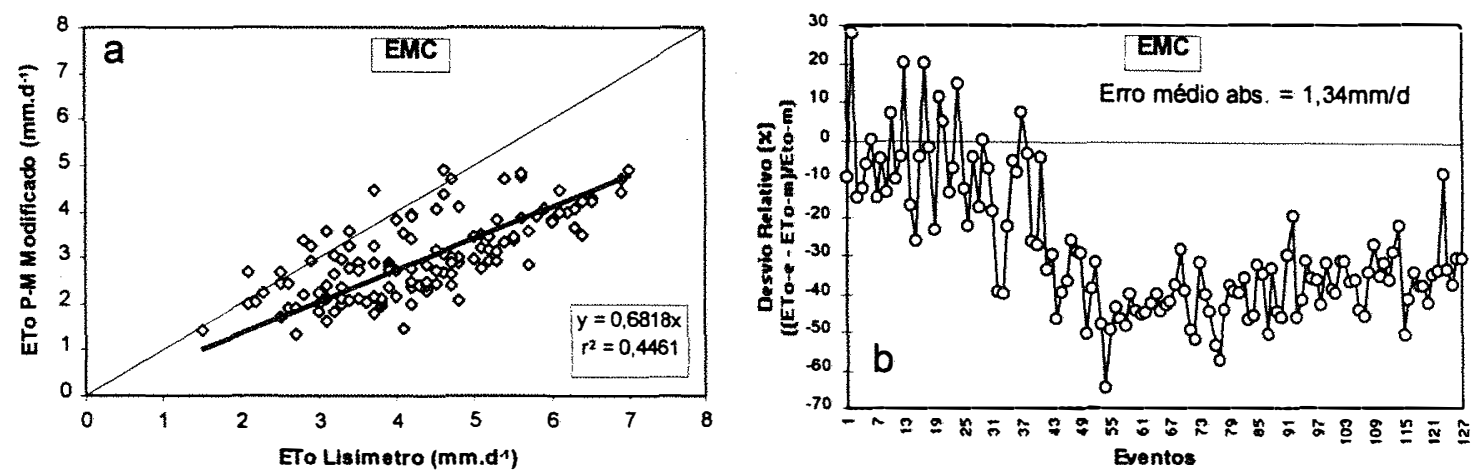

Figura 33. Relação entre a ETo estimada pelo método de Penman-Monteith com dados da EMC e medida em lisímetro (a) e desvio relativo da ETo (b), com Rn estimada por Angström-Brunt e $r_{c} / r_{a}$ por Pereira et al. (1998), em Piracicaba, SP. 

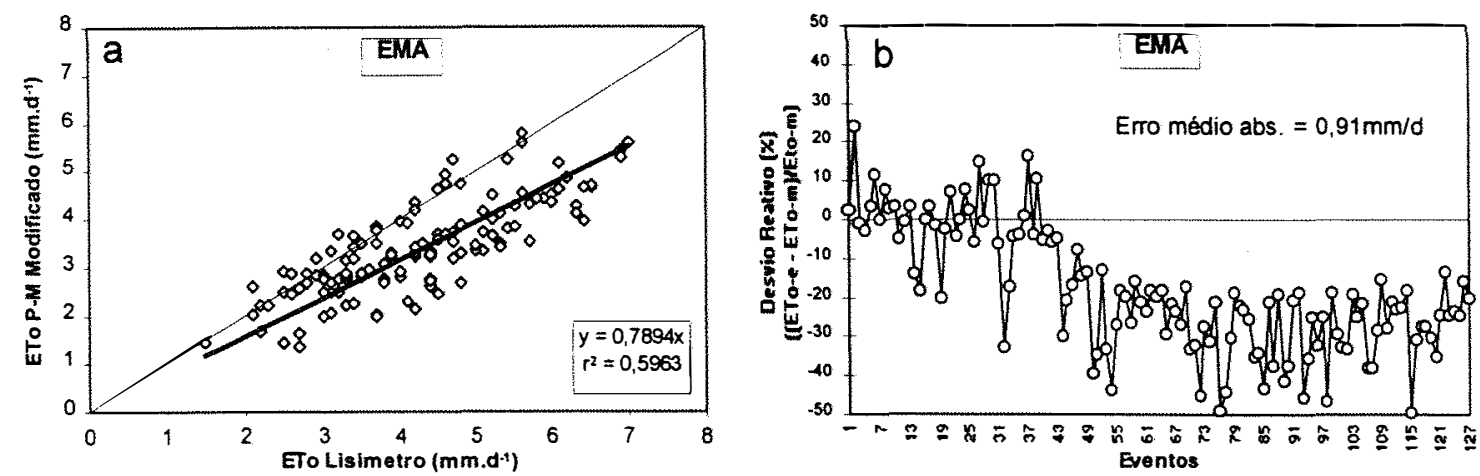

Figura 34. Relação entre a ETo estimada pelo método de Penman-Monteith com dados da EMA e medida em lisímetro (a) e desvio relativo da ETo (b), com Rn medida e $r_{c} / r_{a}$ por Pereira et al. (1998), em Piracicaba, SP.

No entanto, analisando-se as Figuras $33 \mathrm{~b}$ e $34 \mathrm{~b}$ observa-se que as estimativas no período úmido tiveram desvio em torno de zero, ou seja, com a eliminação da tendência de superestimativa. Ao contrário, no período seco, os desvios negativos ou subestimativas se intensificaram, passando a ser da ordem de 40 e $30 \%$, respectivamente para as estimativas a partir de dados da EMC e da EMA.

Apesar das discrepâncias ainda serem observadas entre as estimativas de ETo, observa-se pela Figura 35 que houve leve redução nas diferenças entre as estimativas efetuadas com dados das duas estações, que caiu cerca de $4 \%$.

$\mathrm{Na}$ Figura 36, em que analisa-se separadamente os períodos seco e úmido, podese visualizar melhor a influência da adoção da relação $r_{c} / r_{a}$ sugerida por Pereira et al. (1998). Nota-se que as estimativas de ETo no período úmido proporcionaram excelentes resultados, com $b=0,9112$ nas estimativas com dados da EMC, e b =0,9977 nas estimativas com dados da EMA. Em contrapartida, no período seco as subestimativas foram intensificadas, sendo da ordem de $39 \%$ e $27 \%$, respectivamente, para as estimativas com dados da EMC e da EMA, havendo também, em todos os casos, redução na precisão das estimativas. 

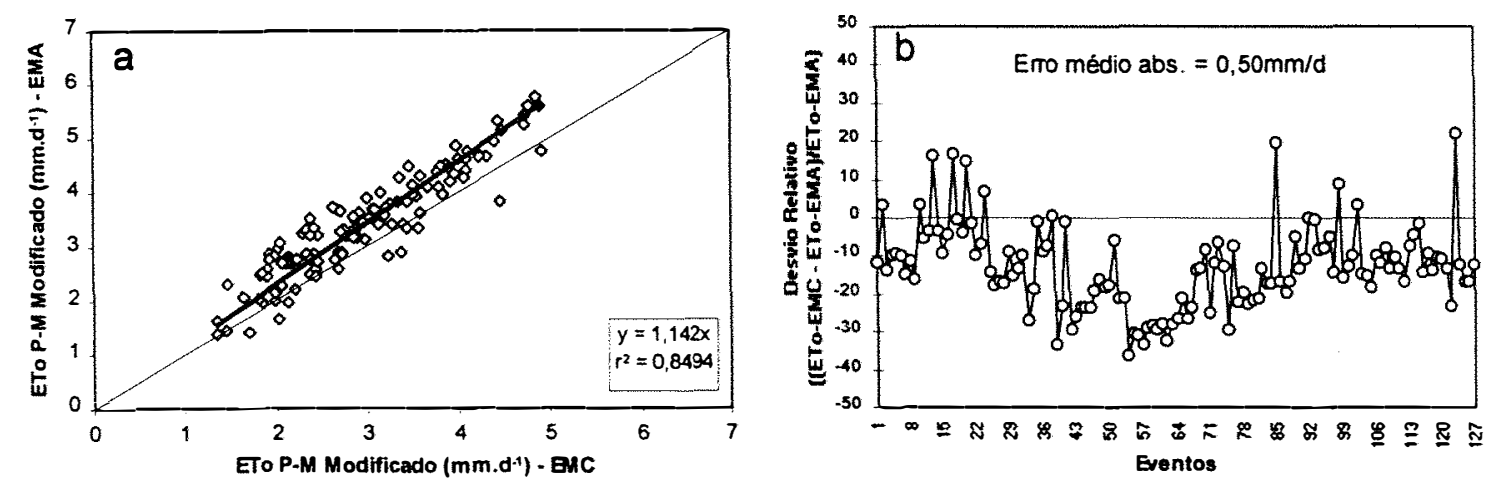

Figura 35. Relação entre a ETo estimada pelo método de Penmam-Monteith, com dados da EMC e da EMA (a) e desvio relativo da ETo (b), com Rn estimada por Angström-Brunt na EMC e $r_{c} / r_{a}$ por Pereira et al. (1998), em Piracicaba, SP.

Desse modo, conclui-se que o emprego dessa nova relação $r_{c} / r_{a}$ torna-se viável somente no período úmido, ao passo que no período seco as melhores estimativas são obtidas quando $r_{c}$ é considerado igual a zero, ou seja, com o método de Penman, como observa-se nas Figuras 15b e 19.

Analisando-se os dados sob o mesmo enfoque, porém, com a estimativa da $\mathrm{Rn}$ pelas equações 22 e 23, respectivamente, para a EMC e a EMA, observa-se que as estimativas com dados das duas estações proporcionaram tendência de subestimativas da ETo, da ordem de $25 \%$, mantendo-se os níveis de precisão e com leve aumento nos erros médios absolutos (Figuras 37 e 38). No entanto, a concordância entre as estimativas com dados das duas estações foi elevada, com $b=0,9838$ e $r^{2}=0,8776$, com diferença média absoluta de apenas 0,23 mm.d $\mathrm{d}^{-1}$ entre as estimativas (Figura 39).

A análise distinta dos períodos úmido e seco, com a $\mathrm{Rn}$ estimada pelas equações 22 e 23, respectivamente, na EMC e na EMA (Figura 40), mostra novamente que o método de Penman-Monteith, com o emprego da relação $r_{c} / r_{a}$ proposta por Pereira et al. (1998), possibilita melhores ajustes entre as estimativas e medidas de ETo em relação ao método proposto por Smith (1991), somente no período úmido, havendo, neste caso, melhoria nas estimativas a partir dos dados da EMC, sendo $b=0,9892$ e $\mathrm{r}^{2}=0,7847$ (Figura 40a), e piora nas estimativas a partir dos dados da EMA, sendo $b=0,9392$ e $\mathrm{r}^{2}=$ 
0,8624 (Figura 40b). No período seco, observou-se a mesma tendência de melhoria nas estimativas a partir dos dados da EMC e piora nas estimativas a partir de dados da EMA, sendo a subestimativa em ambas da ordem de $30 \%$ e a precisão de $74 \%$.
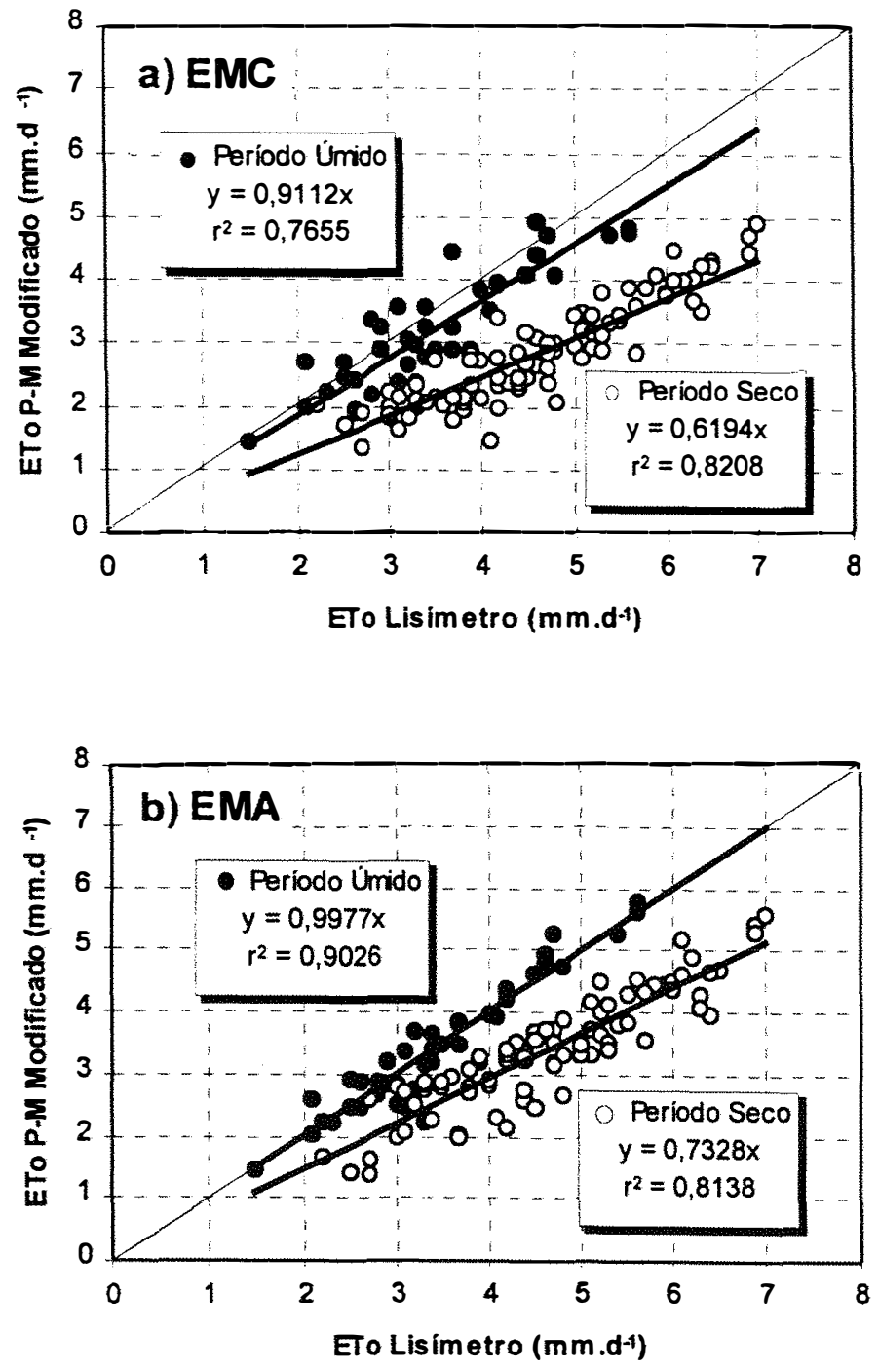

Figura 36. Relação entre a ETo estimada pelo método de Penman-Monteith, com dados da EMC (a) e da EMA (b), e medida em lisímetro, para o período úmido e seco, com dados de Rn estimado por Angström-Brunt na EMC e $r_{c} / r_{a}$ por Pereira et al. (1998), em Piracicaba, SP. 

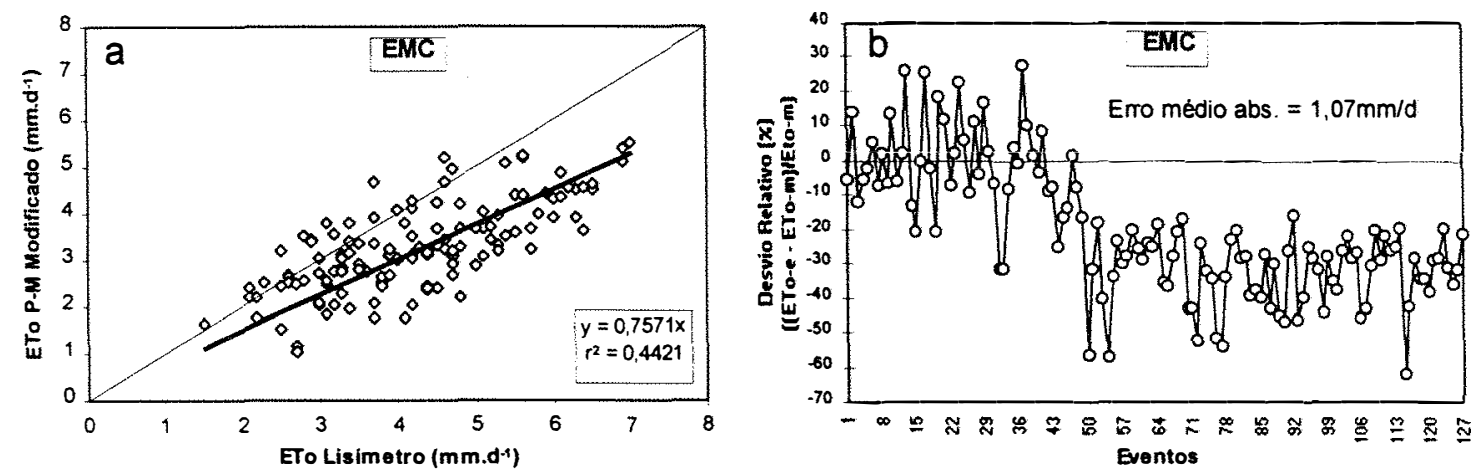

Figura 37. Relação entre a ETo estimada pelo método de Penman-Monteith com dados da EMC e medida em lisímetro (a) e desvio relativo da ETo (b), com Rn estimada pela equação 22 e $r_{c} / r_{a}$ por Pereira et al. (1998), em Piracicaba, SP.
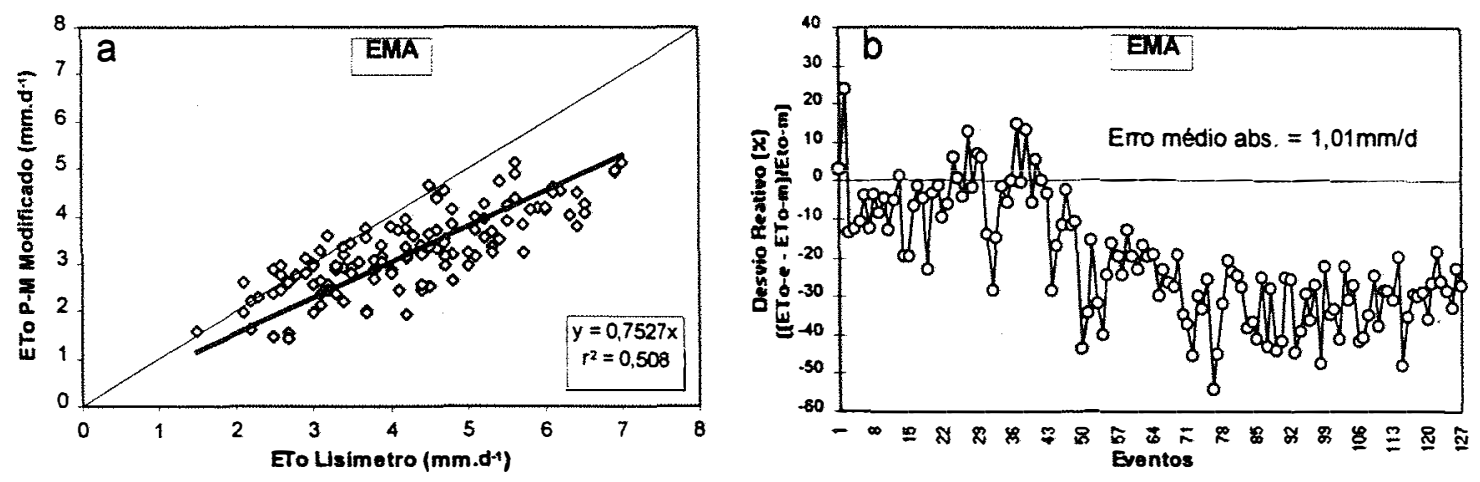

Figura 38. Relação entre a ETo estimada pelo método de Penman-Monteith com dados da EMA e medida em lisímetro (a) e desvio relativo da ETo (b), com Rn estimada pela equação 23 e $r_{c} / r_{a}$ por Pereira et al. (1998), em Piracicaba, SP. 

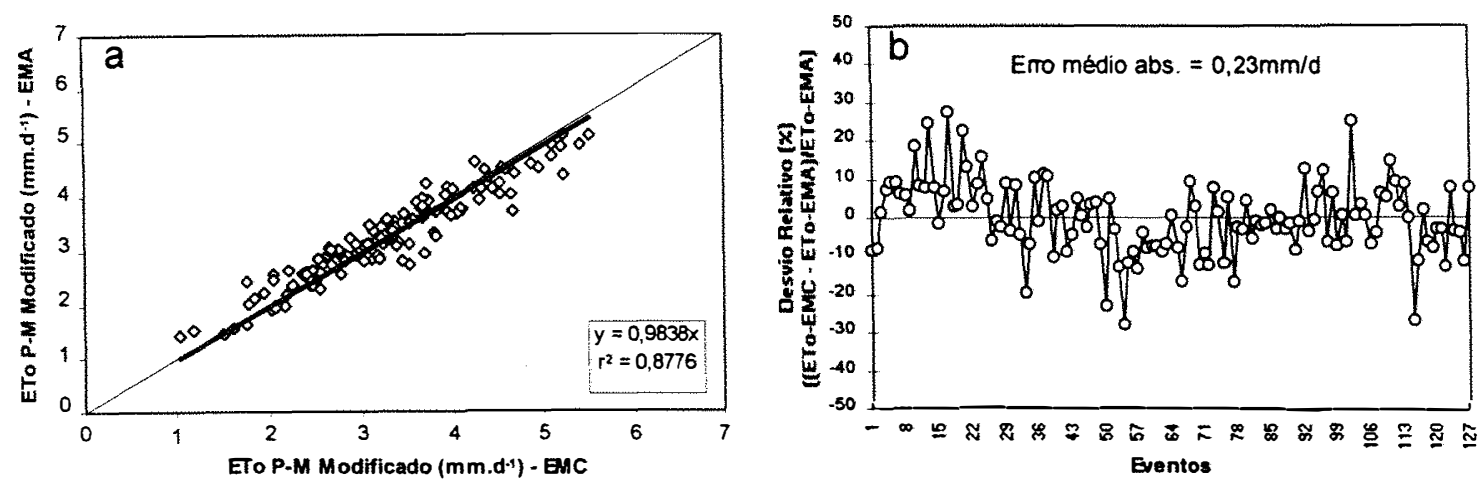

Figura 39. Relação entre a ETo estimada pelo método de Penmam-Monteith, com dados da EMC e da EMA (a) e desvio relativo da ETo (b), com Rn estimada, respectivamente, pelas equações 22 e 23 e $r_{c} / r_{a}$ por Pereira et al. (1998), em Piracicaba, SP.

\subsubsection{Análise global dos métodos de estimativa da ETo}

$\mathrm{Na}$ Tabela 4, 5 e 6 são apresentados os índices estatísticos obtidos pelos diferentes métodos de estimativa da ETo com as variações na estimativa de $R n$ e da relação $r_{c} / r_{a}$. Essa análise global possibilita uma visão generalizada do desempenho dos diferentes métodos tanto no período integral de observações como nos períodos úmido e seco.

Tabela 4. Coeficiente angular (b) e de determinação $\left(r^{2}\right)$ da relação entre a ETo estimada pelo método de Penman e medida em lisímetro, nos períodos integral, úmido e seco, utilizando-se dados da EMC e da EMA, em Piracicaba, SP.

\begin{tabular}{cccccccc}
\hline Estação & $\mathrm{Rn}$ & \multicolumn{2}{c}{ Período Integral } & \multicolumn{2}{c}{ Período Úmido } & \multicolumn{2}{c}{ Período Seco } \\
& & $\mathrm{b}$ & $\mathrm{r}^{2}$ & $\mathrm{~b}$ & $\mathrm{r}^{2}$ & $\mathrm{~b}$ & $\mathrm{r}^{2}$ \\
\hline EMC & $\mathrm{A}-\mathrm{B}^{1}$ & 0,93 & 0,56 & 1,18 & 0,84 & 0,86 & 0,86 \\
& Eq.22 & 1,03 & 0,56 & 1,28 & 0,85 & 0,96 & 0,81 \\
\hline EMA & Medida & 1,11 & 0,77 & 1,31 & 0,91 & 1,06 & 0,90 \\
& Eq.23 & 1,06 & 0,66 & 1,24 & 0,79 & 1,01 & 0,80 \\
\hline
\end{tabular}

A-B é o método de Angström-Brunt para estimativa da $\mathrm{Rn}$. 

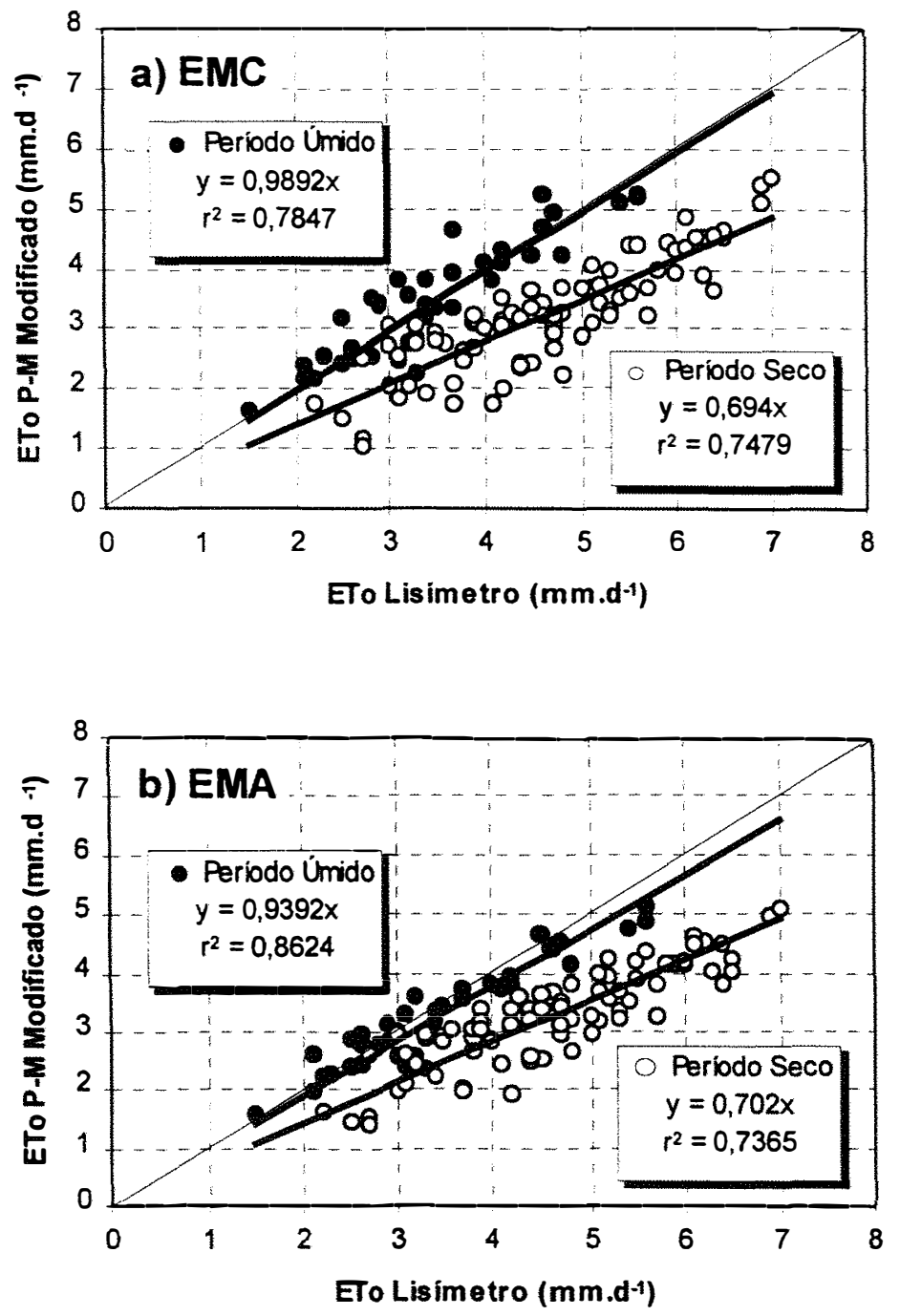

Figura 40. Relação entre a ETo estimada pelo método de Penman-Monteith, com dados da EMC (a) e da EMA (b), e medida em lisímetro, para o período úmido e seco, com dados de Rn estimado, respectivamente, pelas equações 22 e 23 e $r_{c} / r_{a}$ por Pereira et al. (1998), em Piracicaba, SP. 
Tabela 5. Coeficiente angular (b) e de determinação $\left(\mathrm{r}^{2}\right)$ da relação entre a ETo estimada pelo método de Priestley-Taylor e medida em lisímetro, nos períodos integral, úmido e seco, utilizando-se dados da EMC e da EMA, em Piracicaba, SP.

\begin{tabular}{ccccccccc}
\hline Estação & $\alpha$ & Rn & \multicolumn{2}{c}{ Período Integral } & \multicolumn{2}{c}{ Período Úmido } & \multicolumn{2}{c}{ Período Seco } \\
& & & $\mathrm{b}$ & $\mathrm{r}^{2}$ & $\mathrm{~b}$ & $\mathrm{r}^{2}$ & $\mathrm{~b}$ & $\mathrm{r}^{2}$ \\
\hline EMC & 1,26 & $\mathrm{~A}^{2} \mathrm{~B}^{1}$ & - & - & 1,14 & 0,79 & 0,74 & 0,67 \\
& 1,26 & Eq.22 & - & - & 1,27 & 0,85 & 0,86 & 0,86 \\
\hline EMA & 1,26 & Medida & - & - & 1,31 & 0,92 & 0,97 & 0,90 \\
& 1,26 & Eq.23 & - & - & 1,22 & 0,88 & 0,91 & 0,87 \\
& $1,00 / 1,33$ & Medida & 1,03 & 0,91 & - & - & - & - \\
\hline
\end{tabular}

TA-B é o método de Angström-Brunt para estimativa da $\mathrm{Rn}$.

Tabela 6. Coeficiente angular (b) e de determinação $\left(\mathrm{r}^{2}\right)$ da relação entre a ETo estimada pelo método de Penman-Monteith e medida em lisímetro, nos períodos integral, úmido e seco, utilizando-se dados da EMC e da EMA, em Piracicaba, SP.

\begin{tabular}{|c|c|c|c|c|c|c|c|c|}
\hline \multirow[t]{2}{*}{ Estação } & \multirow[t]{2}{*}{$\mathrm{Rn}$} & \multirow[t]{2}{*}{$r_{c} / r_{a}$} & \multicolumn{2}{|c|}{ Período Integral } & \multicolumn{2}{|c|}{ Período Úmido } & \multicolumn{2}{|c|}{ Período seco } \\
\hline & & & b & $r^{2}$ & b & $r^{2}$ & $\mathrm{~b}$ & $r^{2}$ \\
\hline \multirow[t]{4}{*}{ EMC } & $\mathrm{A}-\mathrm{B}^{-}$ & $\begin{array}{c}\text { FAO - Smith } \\
(1991)\end{array}$ & 0,79 & 0,53 & 1,03 & 0,84 & 0,73 & 0,86 \\
\hline & Eq. 22 & $\begin{array}{c}\text { FAO - Smith } \\
(1991)\end{array}$ & 0,88 & 0,55 & 1,11 & 0,87 & 0,81 & 0,83 \\
\hline & $A-B$ & $\begin{array}{l}\text { Pereira et al. } \\
\text { (1998) }\end{array}$ & 0,68 & 0,44 & 0,91 & 0,76 & 0,62 & 0,82 \\
\hline & Eq.22 & $\begin{array}{c}\text { Pereira et al. } \\
\quad(1998)\end{array}$ & 0,76 & 0,44 & 0,99 & 0,78 & 0,69 & 0,75 \\
\hline \multirow[t]{4}{*}{ EMA } & Medida & $\begin{array}{c}\text { FAO - Smith } \\
(1991)\end{array}$ & 0,95 & 0,75 & 1,14 & 0,93 & 0,90 & 0,91 \\
\hline & Eq.23 & $\begin{array}{c}\text { FAO - Smith } \\
(1991)\end{array}$ & 0,91 & 0,67 & 1,08 & 0,85 & 0,86 & 0,83 \\
\hline & Medida & $\begin{array}{c}\text { Pereira et al. } \\
\quad(1998)\end{array}$ & 0,79 & 0,60 & 0,99 & 0,90 & 0,73 & 0,81 \\
\hline & Eq.23 & $\begin{array}{l}\text { Pereira et al. } \\
\text { (1998) }\end{array}$ & 0,75 & 0,51 & 0,94 & 0,86 & 0,70 & 0,73 \\
\hline
\end{tabular}

TA-B é o método de Angström-Brunt para estimativa da Rn.

Observa-se que para a estimativa da ETo a partir de dados da EMC, para o período integral, o melhor método foi o de Penman, com $R n$ estimada pela equação 22, 
em que obteve-se $u m b=1,03$ e com $r^{2}=0,56$ (Tabela 4). Para o período úmido, a estimativa com dados da EMC que proporcionou melhor ajuste com os dados medidos foi aquela a partir do método de Penman-Monteith, utilizando-se Rn estimada pela equação 22 e $r_{c} / r_{a}$ por Pereira et al. (1998), em que obteve-se $b=0,99$ e $r^{2}=0,78$ (Tabela 6). No período seco, as melhores estimativas de ETo com dados da EMC foi com o método de Penman com $b=0,96$ e $\mathrm{r}^{2}=0,81$ (Tabela 4).

Para as estimativas a partir dos dados da EMA, as melhores estimativas de ETo no período integral foram a partir do método de Penman-Monteith, com Rn medida e $r_{c} / r_{a}$ calculado pelo método proposto pela FAO, em que $b=0,95$ e $r^{2}=0,75$ (Tabela 6), seguido do método de Priestley-Taylor, com Rn medida e $\alpha$ igual a 1 para o período úmido e igual a 1,33 para o período seco, em que obteve-se $\mathrm{b}=1,03$ e $\mathrm{r}^{2}=0,91$ (Tabela 5). Considerando-se o período úmido, as melhores estimativas foram obtidas a partir do método de Penman-Monteith, com Rn medida e $r_{c} / r_{a}$ calculada por Pereira et al. (1998), com $b=0,99$ e $r^{2}=0,90$ (Tabela 6). No período seco, no entanto, as melhores estimativas de ETo foram com o método de Priestley-Taylor, com Rn medida e $\alpha=1,26$ (Tabela 5), seguido do método de Penman, com Rn medida, em que $b=1,06$ e $\mathrm{r}^{2}=0,90$ (Tabela 4).

Esses resultados mostram, primeiramente, o quanto é importante determinar corretamente a $\mathrm{Rn}$, seja através de medidas ou de estimativas, para que se obtenha resultados confiáveis de ETo, haja visto que a Rn é a principal fonte de energia para o processo (Rosenberg et al., 1983). Além disso, mostram que apesar de sua formulação fisica, o método de Penman-Monteith ainda apresenta restrições na estimativa de ETo, especialmente, no que se refere a seus ajustes empíricos, como é o caso da relação $r_{c} / r_{a}$, que segundo Alves et al. (1998), é o principal fator limitante à aplicação prática desse método em diferentes condições, inclusive de cobertura do terreno. 


\section{CONCLUSÕES}

Os resultados do presente trabalho permitem concluir que:

a) na comparação entre dados meteorológicos obtidos na EMC e na EMA, houve boa concordância para a temperatura média do ar $(\mathrm{T})$ e para a umidade relativa média do ar (UR), com b igual a 0,97 e 0,99 e $\mathrm{r}^{2}$ igual a 0,97 e 0,81, respectivamente. Para a velocidade do vento a $2 \mathrm{~m}\left(\mathrm{U}_{2 \mathrm{~m}}\right)$ e radiação líquida $(\mathrm{Rn})$, não houve boa concordância entre os dados das duas estações, em razão da necessidade de estimar esses elementos na EMC, tendo a $U_{2 m}$ baixa precisão $\left(r^{2}=0,57\right)$ e a $R n$ baixa exatidão, com tendência de subestimativa na EMC da ordem de $23 \%$, configurando-se, assim, como a principal fonte de diferença entre a ETo estimada com dados das duas estações;

b) a estimativa da Rn na EMC mostrou-se mais precisa e exata quando se utilizou os métodos de estimativa de regressão linear, com a temperatura e a razão de insolação, ao invés da associação das equações de Angström-Brunt;

c) os métodos de regressão linear de estimativa da Rn a partir de dados da EMA também mostraram-se bastante promissores, sendo uma alternativa para as EMA's que não possuem o sensor para esse elemento;

d) houve tendência de melhores estimativas da ETo, por qualquer dos métodos empregados, a partir dos dados da EMA em relação à EMC. Isso se deve, basicamente, à subestimativa da Rn na EMC, o que pode ser minimizado quando da utilização dos métodos de regressão linear de estimativa desse elemento;

e) foi observado durante o período analisado dicotomia na série de estimativas, sendo a ETo por Penman bem estimada no período seco e superestimada no período úmido, em cerca de $31 \%$; 
f) utilizando-se o método de Priestley-Taylor observou-se, novamente, estimativas precisas no período seco e superestimativas no período úmido, da ordem de $31,6 \%$, quando adotou-se $\alpha$ igual a 1,26 ;

g) o cálculo de $\alpha$ utilizando ETo medida em lisímetro e Rn medida na EMA, mostrou que esse parâmetro foi próximo de 1,00 no período úmido, e de 1,33 no período seco, o que justifica a superestimativa que ocorreu na primeira situação. Quando empregouse esses valores de $\alpha$ distintamente nos dois períodos, o método de Priestley-Taylor proporcionou excelentes estimativas $\left(b=1,028\right.$ e $\left.\mathrm{r}^{2}=0,91\right)$;

h) o método de Penman-Monteith mostrou tendência de melhores estimativas da ETo, considerando-se o período integral das análises, porém, analisando-se distintamente os períodos seco e úmido foi observado resultados diferentes dos demais métodos, ou seja, superestimativa no período úmido e subestimativas no período seco, respectivamente, da ordem de 14 e $10 \%$;

i) quando empregou-se ao método de Penman-Monteith o cálculo da relação $r_{c} / r_{a}$ sugerida por Pereira et al. (1998), houve melhoria na estimativa de ETo no período úmido $\left(b=0,9977\right.$ e $\left.\mathrm{r}^{2}=0,90\right)$, porém, piora no período seco, que passou a subestimar mais a ETo, na ordem de $27 \%$;

j) para a estimativa da ETo no período integral a partir de dados da EMC, o método de Penman, com $\mathrm{Rn}$ estimada pela equação 22 , foi o que apresentou os melhores resultados. Para a estimativa no período úmido, o melhor método foi o de PenmanMonteith, com Rn estimada pela equação 22, e $r_{c} / r_{a}$ por Pereira et al. (1998). Para o período seco, a melhor estimativa foi pelo método de Penman com Rn estimada pelo método da regressão linear em função da temperatura e da razão de insolação; 
k) para a estimativa a partir dos dados da EMA, no período integral, os melhores resultados foram proporcionados pelo método de Penman-Monteith, com $r_{c} / r_{a}$ proposto pela FAO, seguido do método de Priestley-Taylor, utilizando $\alpha=1,00$ no período úmido e $\alpha=1,33$ no período seco. Considerando-se somente o período úmido, a melhor estimativa foi a partir do método de Penman-Monteith com $r_{c} / r_{a}$ proposto por Pereira et al. (1998). No periodo seco, no entanto, a melhor estimativa foi com o método de Priestley-Taylor $(\alpha=1,26)$, seguido do método de Penman, o que sugere a adoção, nesse período, de uma valor de $r_{c}$ igual a zero. 
ANEXOS 
Tabela 7. Média diária dos dados meteorológicos observados na Estação Meteorológica Convencional (EMC): temperatura do ar (T); umidade relativa do ar (UR); velocidade do vento a $2 \mathrm{~m}\left(\mathrm{U}_{2 \mathrm{~m}}\right)$; e número de horas de brilho solar $(\mathrm{n})$, em Piracicaba, SP.

\begin{tabular}{|c|c|c|c|c|}
\hline Data & $\mathrm{T}\left({ }^{\circ} \mathrm{C}\right)$ & UR (\%) & $\mathrm{U}_{2 \mathrm{~m}}(\mathrm{~m} / \mathrm{s})$ & n (horas) \\
\hline $23 / 12 / 95$ & 26,2 & 76 & 1,9 & 9,2 \\
\hline $01 / 01 / 96$ & 21,4 & 80 & 1,0 & 1,8 \\
\hline $13 / 01 / 96$ & 26,1 & 80 & 1,5 & 8,5 \\
\hline $14 / 01 / 96$ & 26,9 & 69 & 1,8 & 11,3 \\
\hline $18 / 01 / 96$ & 26,4 & 78 & 1,9 & 8,4 \\
\hline $22 / 01 / 96$ & 26,3 & 75 & 1,6 & 11,8 \\
\hline $25 / 01 / 96$ & 28,2 & 68 & 1,7 & 10,2 \\
\hline $26 / 01 / 96$ & 27,7 & 75 & 1,3 & 7,8 \\
\hline $28 / 01 / 96$ & 26,1 & 68 & 1,7 & 12,6 \\
\hline $31 / 01 / 96$ & 27,9 & 75 & 1,3 & 10,0 \\
\hline $05 / 02 / 96$ & 26,0 & 81 & 1,5 & 3,5 \\
\hline $22 / 02 / 96$ & 26,4 & 75 & 1,7 & 7,9 \\
\hline $23 / 02 / 96$ & 25,7 & 79 & 1,1 & 9,6 \\
\hline $02 / 03 / 96$ & 25,2 & 84 & 2,0 & 5,4 \\
\hline $11 / 03 / 96$ & 22,6 & 74 & 1,9 & 7,6 \\
\hline $13 / 03 / 96$ & 23,7 & 85 & 1,3 & 8,6 \\
\hline $14 / 03 / 96$ & 25,5 & 87 & 1,2 & 7,1 \\
\hline $17 / 03 / 96$ & 23,4 & 88 & 1,0 & 4,4 \\
\hline $21 / 03 / 96$ & 24,3 & 82 & 2,8 & 4,7 \\
\hline $22 / 03 / 96$ & 24,6 & 82 & 1,7 & 8,8 \\
\hline $24 / 03 / 96$ & 25,4 & 83 & 1,2 & 8,5 \\
\hline $25 / 03 / 96$ & 25,2 & 80 & 1,7 & 10,2 \\
\hline $26 / 03 / 96$ & 25,6 & 77 & 1,2 & 10,1 \\
\hline $28 / 03 / 96$ & 25,3 & 82 & 1,2 & 8,2 \\
\hline $03 / 04 / 96$ & 26,3 & 72 & 1,3 & 9,9 \\
\hline 04/04/96 & 25,6 & 76 & 2,3 & 10,0 \\
\hline $06 / 04 / 96$ & 25,3 & 79 & 1,1 & 8,8 \\
\hline 07/04/96 & 25,6 & 77 & 1,8 & 9,2 \\
\hline $10 / 04 / 96$ & 25,7 & 77 & 1,3 & 8,0 \\
\hline $13 / 04 / 96$ & 24,2 & 84 & 1,3 & 5,9 \\
\hline $15 / 04 / 96$ & 25,1 & 80 & 1,5 & 8,3 \\
\hline $18 / 04 / 96$ & 19,1 & 75 & 2,9 & 8,9 \\
\hline $19 / 04 / 96$ & 17,2 & 76 & 3,4 & 10,1 \\
\hline $20 / 04 / 96$ & 19,6 & 76 & 2,1 & 10,3 \\
\hline $26 / 04 / 96$ & 21,2 & 79 & 2,9 & 7,0 \\
\hline $27 / 04 / 96$ & 20,6 & 74 & 3,2 & 6,1 \\
\hline $29 / 04 / 96$ & 21,6 & 77 & 1,1 & 9,1 \\
\hline $30 / 04 / 96$ & 20,9 & 79 & 1,8 & 8,5 \\
\hline $04 / 05 / 96$ & 19,8 & 76 & 1,2 & 9,8 \\
\hline $17 / 05 / 96$ & 19,9 & 81 & 1,2 & 9,5 \\
\hline $24 / 05 / 96$ & 19,1 & 81 & 2,8 & 5,9 \\
\hline $02 / 08 / 96$ & 16,2 & 62 & 1,1 & 9,9 \\
\hline $03 / 08 / 96$ & 16,4 & 66 & 1,3 & 9,7 \\
\hline
\end{tabular}


Tabela 7. Continuação...

\begin{tabular}{|c|c|c|c|c|}
\hline $04 / 08 / 96$ & 18,3 & 57 & 1,2 & 9,8 \\
\hline $05 / 08 / 96$ & 18,3 & 59 & 1,4 & 10,0 \\
\hline $06 / 08 / 96$ & 18,3 & 62 & 1,3 & 9,7 \\
\hline $07 / 08 / 96$ & 19,0 & 66 & 1,0 & 9,8 \\
\hline $08 / 08 / 96$ & 21,7 & 67 & 1,2 & 8,3 \\
\hline $09 / 08 / 96$ & 22,0 & 58 & 2,0 & 5,3 \\
\hline $11 / 08 / 96$ & 18,6 & 85 & 1,7 & 1,4 \\
\hline $12 / 08 / 96$ & 19,5 & 80 & 1,3 & 6,0 \\
\hline $13 / 08 / 96$ & 20,9 & 83 & 1,8 & 8,8 \\
\hline $15 / 08 / 96$ & 19,1 & 83 & 2,4 & 7,6 \\
\hline $16 / 08 / 96$ & 14,6 & 76 & 2,7 & 10,2 \\
\hline $17 / 08 / 96$ & 16,8 & 70 & 1,3 & 10,1 \\
\hline $18 / 08 / 96$ & 17,7 & 65 & 1,4 & 10,4 \\
\hline $19 / 08 / 96$ & 18,2 & 63 & 1,6 & 9,3 \\
\hline $21 / 08 / 96$ & 19,8 & 56 & 1,6 & 10,4 \\
\hline $22 / 08 / 96$ & 20,9 & 59 & 1,6 & 9,3 \\
\hline $23 / 08 / 96$ & 21,1 & 64 & 1,7 & 10,3 \\
\hline $24 / 08 / 96$ & 21,1 & 60 & 2,6 & 10,4 \\
\hline $25 / 08 / 96$ & 21,0 & 60 & 1,6 & 10,5 \\
\hline $26 / 08 / 96$ & 23,0 & 59 & 2,6 & 10,4 \\
\hline $27 / 08 / 96$ & 24,3 & 58 & 1,5 & 9,2 \\
\hline $28 / 08 / 96$ & 23,4 & 80 & 2,8 & 8,1 \\
\hline $29 / 08 / 96$ & 22,0 & 81 & 2,5 & 5,9 \\
\hline $30 / 08 / 96$ & 23,5 & 75 & 1,3 & 8,4 \\
\hline $31 / 08 / 96$ & 24,2 & 50 & 3,6 & 10,1 \\
\hline $02 / 09 / 96$ & 21,2 & 69 & 1,6 & 9,5 \\
\hline $04 / 09 / 96$ & 20,0 & 79 & 1,2 & 2,8 \\
\hline 07/09/96 & 19,0 & 73 & 2,2 & 10,3 \\
\hline $12 / 09 / 96$ & 17,6 & 78 & 2,9 & 5,9 \\
\hline $13 / 09 / 96$ & 21,0 & 80 & 1,5 & 10,0 \\
\hline $14 / 09 / 96$ & 21,1 & 77 & 1,3 & 10,2 \\
\hline $15 / 09 / 96$ & 21,5 & 71 & 0,8 & 9,7 \\
\hline $17 / 09 / 96$ & 20,6 & 80 & 3,1 & 5,8 \\
\hline $18 / 09 / 96$ & 18,4 & 76 & 2,8 & 8,6 \\
\hline $19 / 09 / 96$ & 20,8 & 68 & 1,2 & 9,9 \\
\hline 20/09/96 & 21,3 & 61 & 1,4 & 10,5 \\
\hline $22 / 09 / 96$ & 24,0 & 51 & 1,3 & 10,2 \\
\hline $23 / 09 / 96$ & 24,2 & 67 & 1,6 & 9,3 \\
\hline $24 / 09 / 96$ & 24,5 & 74 & 2,0 & 7,6 \\
\hline $26 / 09 / 96$ & 23,0 & 71 & 3,0 & 9,2 \\
\hline $27 / 09 / 96$ & 23,9 & 71 & 2,4 & 9,1 \\
\hline $28 / 09 / 96$ & 20,3 & 85 & 1,6 & 1,4 \\
\hline $29 / 09 / 96$ & 22,9 & 73 & 1,3 & 6,7 \\
\hline $30 / 09 / 96$ & 23,2 & 71 & 2,8 & 10,0 \\
\hline $04 / 10 / 96$ & 21,3 & 74 & 1,8 & 8,9 \\
\hline $07 / 10 / 96$ & 22,0 & 88 & 2,9 & 8,2 \\
\hline $08 / 10 / 96$ & 21,0 & 81 & 2,9 & 6,7 \\
\hline $09 / 10 / 96$ & 22,4 & 77 & 2,0 & 9,6 \\
\hline $11 / 10 / 96$ & 24,9 & 83 & 0,9 & 7,9 \\
\hline
\end{tabular}


Tabela 7. Continuação...

\begin{tabular}{|c|c|c|c|c|}
\hline $15 / 10 / 96$ & 20,4 & 78 & 2,9 & 7,0 \\
\hline $16 / 10 / 96$ & 20,6 & 76 & 1,5 & 9,1 \\
\hline $17 / 10 / 96$ & 22,8 & 73 & 1,1 & 11,0 \\
\hline $18 / 10 / 96$ & 25,0 & 69 & 1,4 & 10,7 \\
\hline $19 / 10 / 96$ & 26,0 & 75 & 2,7 & 5,5 \\
\hline $21 / 10 / 96$ & 22,4 & 87 & 2,7 & 4,5 \\
\hline $22 / 10 / 96$ & 23,1 & 79 & 0,9 & 10,0 \\
\hline $23 / 10 / 96$ & 25,3 & 78 & 2,5 & 8,9 \\
\hline $24 / 10 / 96$ & 22,4 & 79 & 2,2 & 7,9 \\
\hline $28 / 10 / 96$ & 22,5 & 70 & 1,4 & 8,5 \\
\hline 29/10/96 & 23,7 & 62 & 1,2 & 9,2 \\
\hline $30 / 10 / 96$ & 24,3 & 63 & 1,5 & 9,5 \\
\hline $31 / 10 / 96$ & 25,2 & 62 & 1,9 & 10,8 \\
\hline $04 / 11 / 96$ & 22,8 & 84 & 2,9 & 5,1 \\
\hline $05 / 11 / 96$ & 22,7 & 72 & 2,9 & 11,1 \\
\hline $06 / 11 / 96$ & 23,4 & 73 & 1,2 & 10,6 \\
\hline $07 / 11 / 96$ & 25,0 & 67 & 1,5 & 11,4 \\
\hline $08 / 11 / 96$ & 25,8 & 65 & 1,6 & 9,1 \\
\hline $09 / 11 / 96$ & 25,8 & 57 & 1,5 & 11,9 \\
\hline $10 / 11 / 96$ & 25,2 & 52 & 1,9 & 10,9 \\
\hline $11 / 11 / 96$ & 26,3 & 79 & 1,2 & 6,1 \\
\hline $12 / 11 / 96$ & 25,7 & 86 & 1,2 & 1,8 \\
\hline $22 / 11 / 96$ & 19,2 & 91 & 3,3 & 0,0 \\
\hline $23 / 11 / 96$ & 21,2 & 79 & 1,8 & 7,0 \\
\hline $24 / 11 / 96$ & 21,7 & 63 & 1,2 & 11,3 \\
\hline $25 / 11 / 96$ & 22,7 & 73 & 2,1 & 11,5 \\
\hline $26 / 11 / 96$ & 21,8 & 69 & 3,6 & 12,0 \\
\hline $27 / 11 / 96$ & 22,2 & 63 & 3,4 & 11,7 \\
\hline $28 / 11 / 96$ & 22,9 & 63 & 2,0 & 11,7 \\
\hline $29 / 11 / 96$ & 22,3 & 62 & 0,8 & 8,7 \\
\hline $30 / 11 / 96$ & 21,9 & 88 & 0,9 & 0,6 \\
\hline $05 / 12 / 96$ & 25,1 & 78 & 2,0 & 9,5 \\
\hline $06 / 12 / 96$ & 25,9 & 82 & 1,7 & 6,8 \\
\hline $08 / 12 / 96$ & 24,7 & 89 & 0,7 & 3,2 \\
\hline 09/12/96 & 25,6 & 59 & 1,2 & 11,4 \\
\hline
\end{tabular}


Tabela 8. Média diária dos dados meteorológicos observados na Estação Meteorológica Automática (EMA): temperatura do ar (T); umidade relativa do ar (UR); velocidade do vento a $2 \mathrm{~m}\left(\mathrm{U}_{2 \mathrm{~m}}\right)$; e radiação líquida $\left(\mathrm{MJ} \cdot \mathrm{m}^{-2} \cdot \mathrm{d}^{-1}\right)$, em Piracicaba, SP.

\begin{tabular}{|c|c|c|c|c|}
\hline Data & $\mathrm{T}\left({ }^{\circ} \mathrm{C}\right)$ & UR (\%) & $U_{2 m}\left(m \cdot s^{-1}\right)$ & $\mathrm{Rn}\left(\mathrm{MJ} \cdot \mathrm{m}^{-2} \cdot \mathrm{d}^{-1}\right)$ \\
\hline $23 / 12 / 95$ & 25,4 & 73 & 2,1 & 17,03 \\
\hline $01 / 01 / 96$ & 22,1 & 79 & 1,4 & 8,67 \\
\hline $13 / 01 / 96$ & 25,4 & 84 & 1,4 & 16,83 \\
\hline $14 / 01 / 96$ & 26,6 & 73 & 1,8 & 18,40 \\
\hline $18 / 01 / 96$ & 25,2 & 80 & 1,7 & 15,89 \\
\hline $22 / 01 / 96$ & 25,9 & 75 & 1,8 & 19,05 \\
\hline $25 / 01 / 96$ & 27,8 & 71 & 1,5 & 18,13 \\
\hline $26 / 01 / 96$ & 27,2 & 73 & 1,7 & 16,61 \\
\hline $28 / 01 / 96$ & 26,4 & 70 & 1,5 & 19,29 \\
\hline $31 / 01 / 96$ & 26,8 & 72 & 1,6 & 15,62 \\
\hline $05 / 02 / 96$ & 25,0 & 85 & 1,7 & 11,44 \\
\hline $22 / 02 / 96$ & 25,6 & 77 & 1,7 & 13,76 \\
\hline $23 / 02 / 96$ & 25,4 & 79 & 1,4 & 12,73 \\
\hline $02 / 03 / 96$ & 24,4 & 82 & 2,1 & 10,18 \\
\hline $11 / 03 / 96$ & 22,8 & 75 & 2,0 & 11,64 \\
\hline $13 / 03 / 96$ & 23,1 & 87 & 1,6 & 13,23 \\
\hline $14 / 03 / 96$ & 23,6 & 88 & 1,4 & 10,43 \\
\hline $17 / 03 / 96$ & 23,2 & 90 & 1,3 & 8,78 \\
\hline $21 / 03 / 96$ & 23,5 & 84 & 2,2 & 9,62 \\
\hline $22 / 03 / 96$ & 23,6 & 82 & 1,8 & 10,31 \\
\hline $24 / 03 / 96$ & 24,3 & 85 & 1,4 & 12,93 \\
\hline $25 / 03 / 96$ & 24,4 & 81 & 1,6 & 14,26 \\
\hline $26 / 03 / 96$ & 25,4 & 79 & 1,4 & 14,18 \\
\hline $28 / 03 / 96$ & 24,5 & 85 & 1,2 & 11,06 \\
\hline $03 / 04 / 96$ & 25,8 & 74 & 1,6 & 12,29 \\
\hline $04 / 04 / 96$ & 25,7 & 75 & 1,6 & 11,27 \\
\hline 06/04/96 & 24,7 & 80 & 1,2 & 11,84 \\
\hline $07 / 04 / 96$ & 25,2 & 77 & 1,8 & 12,01 \\
\hline $10 / 04 / 96$ & 24,5 & 79 & 1,5 & 10,66 \\
\hline $13 / 04 / 96$ & 23,8 & 83 & 1,3 & 9,49 \\
\hline $15 / 04 / 96$ & 24,4 & 80 & 1,7 & 11,24 \\
\hline $18 / 04 / 96$ & 18,3 & 73 & 3,2 & 9,04 \\
\hline $19 / 04 / 96$ & 17,0 & 74 & 2,6 & 11,31 \\
\hline $20 / 04 / 96$ & 18,9 & 74 & 2,1 & 10,75 \\
\hline $26 / 04 / 96$ & 20,0 & 81 & 2,5 & 8,19 \\
\hline $27 / 04 / 96$ & 20,0 & 74 & 3,1 & 8,31 \\
\hline $29 / 04 / 96$ & 21,2 & 78 & 1,4 & 10,10 \\
\hline $30 / 04 / 96$ & 20,6 & 81 & 1,8 & 8,22 \\
\hline $04 / 05 / 96$ & 19,2 & 76 & 1,4 & 10,37 \\
\hline $17 / 05 / 96$ & 19,1 & 83 & 1,4 & 9,26 \\
\hline $24 / 05 / 96$ & 18,1 & 81 & 2,5 & 5,48 \\
\hline $02 / 08 / 96$ & 15,5 & 61 & 1,2 & 9,46 \\
\hline $03 / 08 / 96$ & 15,6 & 68 & 1,4 & 9,29 \\
\hline
\end{tabular}


Tabela 8. Continuação

\begin{tabular}{|c|c|c|c|c|}
\hline $04 / 08 / 96$ & 17,2 & 63 & 1,5 & 9,72 \\
\hline $05 / 08 / 96$ & 17,6 & 59 & 1,6 & 9,03 \\
\hline $06 / 08 / 96$ & 17,3 & 60 & 1,4 & 8,75 \\
\hline $07 / 08 / 96$ & 18,8 & 60 & 1,5 & 8,48 \\
\hline $08 / 08 / 96$ & 20,2 & 62 & 1,5 & 8,46 \\
\hline $09 / 08 / 96$ & 22,2 & 55 & 2,2 & 7,19 \\
\hline $11 / 08 / 96$ & 17,3 & 83 & 2,0 & 6,80 \\
\hline $12 / 08 / 96$ & 18,1 & 84 & 1,9 & 8,38 \\
\hline $13 / 08 / 96$ & 20,0 & 80 & 1,5 & 9,91 \\
\hline $15 / 08 / 96$ & 17,8 & 80 & 2,1 & 8,69 \\
\hline $16 / 08 / 96$ & 14,6 & 65 & 3,1 & 10,21 \\
\hline $17 / 08 / 96$ & 16,2 & 70 & 1,5 & 10,74 \\
\hline $18 / 08 / 96$ & 17,1 & 67 & 1,5 & 10,85 \\
\hline $19 / 08 / 96$ & 17,8 & 65 & 1,6 & 11,16 \\
\hline $21 / 08 / 96$ & 19,6 & 59 & 2,0 & 10,92 \\
\hline $22 / 08 / 96$ & 20,6 & 56 & 1,8 & 10,12 \\
\hline $23 / 08 / 96$ & 20,9 & 59 & 1,8 & 10,52 \\
\hline $24 / 08 / 96$ & 20,5 & 61 & 2,0 & 11,39 \\
\hline $25 / 08 / 96$ & 20,9 & 57 & 1,9 & 11,26 \\
\hline $26 / 08 / 96$ & 22,7 & 55 & 2,1 & 11,12 \\
\hline $27 / 08 / 96$ & 24,1 & 56 & 1,8 & 10,36 \\
\hline $28 / 08 / 96$ & 21,9 & 71 & 2,7 & 9,40 \\
\hline $29 / 08 / 96$ & 20,8 & 72 & 3,1 & 9,24 \\
\hline $30 / 08 / 96$ & 22,8 & 68 & 1,7 & 10,39 \\
\hline $31 / 08 / 96$ & 24,3 & 59 & 2,5 & 11,29 \\
\hline 02/09/96 & 20,2 & 71 & 1,6 & 11,54 \\
\hline $04 / 09 / 96$ & 19,7 & 80 & 1,4 & 7,94 \\
\hline 07/09/96 & 19,1 & 75 & 1,9 & 13,03 \\
\hline $12 / 09 / 96$ & 17,7 & 80 & 2,7 & 9,28 \\
\hline $13 / 09 / 96$ & 19,7 & 79 & 2,1 & 12,42 \\
\hline $14 / 09 / 96$ & 20,7 & 77 & 1,9 & 13,35 \\
\hline $15 / 09 / 96$ & 21,0 & 75 & 1,5 & 13,57 \\
\hline $17 / 09 / 96$ & 18,9 & 81 & 2,9 & 9,84 \\
\hline $18 / 09 / 96$ & 17,5 & 73 & 3,1 & 12,70 \\
\hline $19 / 09 / 96$ & 19,9 & 69 & 1,8 & 13,84 \\
\hline $20 / 09 / 96$ & 21,1 & 67 & 1,4 & 13,29 \\
\hline $22 / 09 / 96$ & 23,9 & 55 & 1,9 & 13,14 \\
\hline $23 / 09 / 96$ & 24,6 & 60 & 2,1 & 12,48 \\
\hline $24 / 09 / 96$ & 23,4 & 69 & 2,4 & 11,25 \\
\hline $26 / 09 / 96$ & 22,2 & 74 & 2,9 & 13,74 \\
\hline $27 / 09 / 96$ & 22,8 & 69 & 3,1 & 13,42 \\
\hline $28 / 09 / 96$ & 20,2 & 83 & 1,9 & 4,78 \\
\hline 29/09/96 & 22,3 & 76 & 1,6 & 11,68 \\
\hline $30 / 09 / 96$ & 22,3 & 72 & 2,5 & 13,96 \\
\hline $04 / 10 / 96$ & 21,1 & 79 & 1,9 & 15,20 \\
\hline $07 / 10 / 96$ & 20,4 & 85 & 2,8 & 12,53 \\
\hline $08 / 10 / 96$ & 20,4 & 77 & 2,9 & 12,01 \\
\hline $09 / 10 / 96$ & 22,3 & 74 & 2,4 & 14,26 \\
\hline $11 / 10 / 96$ & 23,8 & 85 & 1,6 & 12,67 \\
\hline
\end{tabular}


Tabela 8. Continuação...

\begin{tabular}{|c|c|c|c|c|}
\hline $15 / 10 / 96$ & 19,3 & 75 & 3,4 & 10,67 \\
\hline $16 / 10 / 96$ & 20,0 & 75 & 2,1 & 14,38 \\
\hline $17 / 10 / 96$ & 22,7 & 75 & 1,4 & 15,82 \\
\hline $18 / 10 / 96$ & 25,0 & 70 & 1,9 & 14,79 \\
\hline $19 / 10 / 96$ & 25,0 & 70 & 2,5 & 12,02 \\
\hline $21 / 10 / 96$ & 21,3 & 83 & 3,0 & 8,19 \\
\hline $22 / 10 / 96$ & 22,8 & 78 & 1,5 & 15,31 \\
\hline $23 / 10 / 96$ & 24,4 & 77 & 2,3 & 14,75 \\
\hline $24 / 10 / 96$ & 21,7 & 71 & 2,8 & 12,40 \\
\hline $28 / 10 / 96$ & 22,2 & 78 & 1,9 & 12,92 \\
\hline $29 / 10 / 96$ & 23,3 & 67 & 1,5 & 15,25 \\
\hline $30 / 10 / 96$ & 24,5 & 64 & 1,8 & 14,95 \\
\hline $31 / 10 / 96$ & 25,8 & 61 & 1,9 & 15,81 \\
\hline $04 / 11 / 96$ & 22,2 & 83 & 2,5 & 11,72 \\
\hline $05 / 11 / 96$ & 21,8 & 70 & 3,0 & 17,03 \\
\hline $06 / 11 / 96$ & 23,2 & 70 & 1,9 & 17,58 \\
\hline $07 / 11 / 96$ & 25,0 & 71 & 1,6 & 18,08 \\
\hline $08 / 11 / 96$ & 26,3 & 64 & 2,3 & 15,72 \\
\hline $09 / 11 / 96$ & 25,7 & 61 & 2,0 & 18,40 \\
\hline $10 / 11 / 96$ & 25,6 & 56 & 2,0 & 17,22 \\
\hline $11 / 11 / 96$ & 25,1 & 69 & 2,5 & 14,70 \\
\hline $12 / 11 / 96$ & 24,1 & 76 & 1,6 & 9,30 \\
\hline $22 / 11 / 96$ & 19,0 & 84 & 3,8 & 5,56 \\
\hline $23 / 11 / 96$ & 20,4 & 76 & 2,2 & 14,82 \\
\hline $24 / 11 / 96$ & 21,5 & 72 & 1,5 & 17,06 \\
\hline $25 / 11 / 96$ & 22,5 & 70 & 2,2 & 17,16 \\
\hline $26 / 11 / 96$ & 21,5 & 68 & 3,2 & 16,27 \\
\hline $27 / 11 / 96$ & 21,7 & 65 & 3,2 & 17,01 \\
\hline $28 / 11 / 96$ & 22,8 & 61 & 2,6 & 17,51 \\
\hline $29 / 11 / 96$ & 22,7 & 65 & 1,4 & 14,97 \\
\hline $30 / 11 / 96$ & 21,1 & 83 & 1,4 & 5,31 \\
\hline $05 / 12 / 96$ & 24,6 & 78 & 2,0 & 17,20 \\
\hline $06 / 12 / 96$ & 25,0 & 80 & 1,9 & 16,35 \\
\hline $08 / 12 / 96$ & 23,8 & 88 & 1,3 & 11,54 \\
\hline $09 / 12 / 96$ & 25,9 & 64 & 1,7 & 18,55 \\
\hline
\end{tabular}


Tabela 9. Evapotranspiração de referência medida em lisímetro (ETo-Lis) e estimada pelos métodos de Penman (ETo-P), Priestley-Taylor (ETo-PT) e PenmanMonteith (ETo-PM), com dados medidos na estação meteorológica convencional (EMC), em Piracicaba, SP.

\begin{tabular}{|c|c|c|c|c|c|c|c|c|c|}
\hline \multirow[t]{2}{*}{ Data } & ETo-Lis & ETo-P' & ETo-P $P^{2}$ & ETo-PT $^{3}$ & ETo-PT $^{+}$ & ETo-PM ${ }^{3}$ & ETo-PM ${ }^{6}$ & ETo-PM? & ETo-PM ${ }^{8}$ \\
\hline & \multicolumn{9}{|c|}{$\mathrm{mm} \cdot \mathrm{d}^{-1}$} \\
\hline $23 / 12 / 95$ & 4,5 & 5,6 & 5,8 & 5,5 & 4,4 & 4,9 & 5,1 & 4,1 & 4,3 \\
\hline $01 / 01 / 96$ & 2,1 & 3,1 & 2,8 & $3: 0$ & 2,4 & 2,7 & 2,4 & 2,7 & 2,4 \\
\hline $13 / 01 / 96$ & 4,8 & 5,1 & 5,3 & 5,4 & 4,2 & 4,5 & 4,7 & 4,1 & 4,2 \\
\hline 14/01/96 & 5,4 & 6,2 & 6,7 & 6,0 & 4,7 & 5,5 & 5,9 & 4,7 & 5,1 \\
\hline $18 / 01 / 96$ & 4,2 & 5,3 & 5,5 & 5,3 & 4,2 & 4,6 & 4,8 & 4,0 & 4,1 \\
\hline $22 / 01 / 96$ & 4,7 & 6,1 & 6,4 & 6.2 & 4,9 & 5,4 & 5,6 & 4,7 & 5,0 \\
\hline $25 / 01 / 96$ & 5,6 & 6,2 & 6,8 & 5.9 & 4,7 & 5,5 & 6,0 & 4,8 & 5,2 \\
\hline $26 / 01 / 96$ & 4,6 & 5.3 & 5,6 & 5,3 & 4,2 & 4.6 & 5,0 & 4,4 & 4,7 \\
\hline $28 / 01 / 96$ & 5,6 & 6.4 & 6,9 & 6,1 & 4,9 & 5,6 & 6,0 & 4,8 & 5,2 \\
\hline $31 / 01 / 96$ & 4.6 & 5,8 & 6,2 & 6.0 & 4.8 & 5,2 & 5,5 & 4,9 & 5,2 \\
\hline $05 / 02 / 96$ & 3,3 & 3,7 & 3,9 & 3,7 & 2,9 & 3,3 & 3,4 & 3,0 & 3,1 \\
\hline $22 / 02 / 96$ & 4,0 & 5,0 & 5,3 & 4,8 & 3,8 & 4,4 & 4,7 & 3,8 & 4,1 \\
\hline $23 / 02 / 96$ & 3,7 & 5,0 & 5,3 & 5,3 & 4,2 & 4,5 & 4,7 & 4,5 & 4,7 \\
\hline $02 / 03 / 96$ & 3,2 & 3,7 & 3,9 & 3,7 & 2,9 & 3,2 & 3,4 & 2,7 & 2,8 \\
\hline $11 / 03 / 96$ & 3,9 & 4,1 & 4,3 & 3,6 & 2,9 & 3,5 & 3,7 & 2,9 & 3,1 \\
\hline 13/03/96 & 3,4 & 4,0 & 4,1 & 4,2 & 3,4 & 3,5 & 3,7 & 3,3 & 3,4 \\
\hline $14 / 03 / 96$ & 2,8 & 3,8 & 4,0 & 4,2 & 3,3 & 3,5 & 3,6 & 3,4 & 3,5 \\
\hline $17 / 03 / 96$ & 2,5 & 3,0 & 3,0 & 3,3 & 2,6 & 2,7 & 2,7 & 2,5 & 2,4 \\
\hline $21 / 03 / 96$ & 3,1 & 3,7 & 3,8 & 3,4 & 2,7 & 3,2 & 3,3 & 2,4 & 2,5 \\
\hline $22 / 03 / 96$ & 2,9 & 4,3 & 4,5 & 4,4 & 3,5 & 3,7 & 4,0 & 3,2 & 3,4 \\
\hline $24 / 03 / 96$ & 3,4 & 4,2 & 4,5 & 4,4 & 3,5 & 3,7 & 4,0 & 3,6 & 3,8 \\
\hline $25 / 03 / 96$ & 4,1 & 4,7 & 5,0 & 4,7 & 3,8 & 4,1 & 4,4 & 3,5 & 3,8 \\
\hline 26/03/96 & 4,2 & 4,7 & 5,1 & 4,7 & 3,7 & 4,1 & 4,5 & 3,9 & 4,3 \\
\hline 28/03/96 & 3,1 & 4,1 & 4,4 & 4,3 & 3,4 & 3,7 & 3,9 & 3,6 & 3,8 \\
\hline 03/04/96 & 3,7 & 4,1 & 4,8 & 3,6 & 2,9 & 3,5 & 4,2 & 3,2 & 3,9 \\
\hline $04 / 04 / 96$ & 3,7 & 4,2 & 4,9 & 3,6 & 2,9 & 3,6 & 4,2 & 2,9 & 3,3 \\
\hline 06/04/96 & 3,2 & 3,6 & 4,1 & 3,5 & 2,8 & 3,1 & 3,6 & 3,1 & 3,6 \\
\hline $07 / 04 / 96$ & 3,5 & 3,9 & 4,5 & 3,5 & 2,8 & 3,4 & 3,9 & 2,9 & 3,4 \\
\hline $10 / 04 / 96$ & 2,9 & 3,6 & 4,2 & 3,3 & 2,6 & 3,1 & 3,6 & 2,9 & 3,4 \\
\hline $13 / 04 / 96$ & 2,6 & 3,0 & 3,2 & 2,9 & 2,3 & 2,6 & 2,8 & 2,4 & 2,7 \\
\hline $15 / 04 / 96$ & 3,4 & 3,6 & 4,0 & 3,4 & 2,7 & 3,1 & 3,5 & 2,8 & 3,2 \\
\hline 18/04/96 & 3,3 & 3,4 & 3,8 & 2,6 & 2,1 & 2,8 & 3,2 & 2,0 & 2,3 \\
\hline 19/04/96 & 3,0 & 3,3 & 3,8 & 2,5 & 2,0 & 2,7 & 3,1 & 1,8 & 2,1 \\
\hline $20 / 04 / 96$ & 2,8 & 3,3 & 3,9 & 2,8 & 2,2 & 2,8 & 3,3 & 2,2 & 2,6 \\
\hline $26 / 04 / 96$ & 2,1 & 3,3 & 3,6 & 2,7 & 2,1 & 2,8 & 3,0 & 2,0 & 2,2 \\
\hline $27 / 04 / 96$ & 2,2 & 3,4 & 3,7 & 2,4 & 1,9 & 2,9 & 3,1 & 2,0 & 2,2 \\
\hline 29/04/96 & 2,5 & 3,1 & 3,7 & 2,9 & 2,3 & 2,7 & 3,2 & 2,7 & 3,2 \\
\hline $30 / 04 / 96$ & 2,3 & 3,1 & 3,6 & 2,8 & 2,2 & 2,7 & 3,0 & 2,2 & 2,5 \\
\hline 04/05/96 & 2,6 & 2,4 & 3,3 & 2,0 & 1,6 & 2,0 & 2,8 & 1,9 & 2,6 \\
\hline $17 / 05 / 96$ & 2,6 & 2,3 & 3,0 & 2,1 & 1,7 & 2,0 & 2,6 & 1,9 & 2,5 \\
\hline $24 / 05 / 96$ & 1,5 & 2,4 & 2,7 & 1,8 & 1,4 & 2,0 & 2,2 & 1,4 & 1,6 \\
\hline $02 / 08 / 96$ & 3,0 & 2,5 & 3,3 & 1,8 & 1,9 & 2,0 & 2,7 & 2,0 & 2,7 \\
\hline 03/08/96 & 2,7 & 2,6 & 3,3 & 1,9 & 2,0 & 2,1 & 2,7 & 1,9 & 2,5 \\
\hline
\end{tabular}


Tabela 9. Continuação...

\begin{tabular}{|c|c|c|c|c|c|c|c|c|c|}
\hline $04 / 08 / 96$ & 4,0 & 2,9 & 3,9 & 1,8 & 1,9 & 2,3 & 3,2 & 2,1 & 3,0 \\
\hline $05 / 08 / 96$ & 3,5 & 2,9 & 3,9 & 1,9 & 2,0 & 2,3 & 3,2 & 2,1 & 2,9 \\
\hline $06 / 08 / 96$ & 3,3 & 2,8 & 3,7 & 1,9 & 2,0 & 2,3 & 3,1 & 2,1 & 2,8 \\
\hline $07 / 08 / 96$ & 3,0 & 2,7 & 3,6 & 2,1 & 2,2 & 2,2 & 3,0 & 2,2 & 3,0 \\
\hline $08 / 08 / 96$ & 3,3 & 3,0 & 3,8 & 2,3 & 2,4 & 2,5 & 3,2 & 2,4 & 3,0 \\
\hline $09 / 08 / 96$ & 3,3 & 3,4 & 4,0 & 1,9 & 2,0 & 2,9 & 3,4 & 2,3 & 2,8 \\
\hline $11 / 08 / 96$ & 2,7 & 1,9 & 1,7 & 1,7 & 1,8 & 1,6 & 1,4 & 1,3 & 1,2 \\
\hline $12 / 08 / 96$ & 3,0 & 2,4 & 2,7 & 2,1 & 2,2 & 2,0 & 2,2 & 1,8 & 2,1 \\
\hline $13 / 08 / 96$ & 3,1 & 2,7 & 3,2 & 2,6 & 2,7 & 2,3 & 2,8 & 2,1 & 2,5 \\
\hline $15 / 08 / 96$ & 3,1 & 2,6 & 3,0 & 2,3 & 2,4 & 2,2 & 2,5 & 1,6 & 1,8 \\
\hline $16 / 08 / 96$ & 4,1 & 2,6 & 3,1 & 1,9 & 2,1 & 2,1 & 2,5 & 1,5 & 1,8 \\
\hline $17 / 08 / 96$ & 3,8 & 2,6 & 3,3 & 2,0 & 2,1 & 2,1 & 2,7 & 1,9 & 2,5 \\
\hline $18 / 08 / 96$ & 3,6 & 2,8 & 3,7 & 2,0 & 2,1 & 2,3 & 3,0 & 2,0 & 2,8 \\
\hline 19/08/96 & 3,8 & 2,9 & 3,7 & 1,9 & 2,0 & 2,4 & 3,1 & 2,0 & 2,7 \\
\hline $21 / 08 / 96$ & 4.4 & 3,3 & 4,4 & 1,9 & 2,0 & 2,7 & 3,7 & 2,3 & 3,2 \\
\hline $22 / 08 / 96$ & 3,9 & 3,3 & 4,3 & 2,1 & 2,2 & 2,7 & 3,6 & 2,3 & 3,1 \\
\hline $23 / 08 / 96$ & 4.2 & 3,3 & 4,3 & 2,3 & 2,4 & 2,7 & 3,7 & 2,3 & 3,1 \\
\hline $24 / 08 / 96$ & 4,4 & 3,8 & 4,9 & 2,2 & 2,3 & 3,2 & 4,2 & 2,4 & 3,1 \\
\hline $25 / 08 / 96$ & 4,3 & 3,3 & 4,5 & 2,2 & 2,3 & 2,8 & 3,8 & 2,4 & 3,3 \\
\hline $26 / 08 / 96$ & 4,6 & 4,1 & 5,3 & 2,3 & 2,5 & 3,5 & 4,5 & 2,7 & 3,5 \\
\hline $27 / 08 / 96$ & 4,5 & 3,7 & 4,8 & 2,4 & 2,5 & 3,0 & 4,1 & 2,7 & 3,7 \\
\hline $28 / 08 / 96$ & 3,8 & 3,3 & 3,9 & 2,8 & 2,9 & 2,8 & 3,3 & 2,1 & 2,5 \\
\hline $29 / 08 / 96$ & 3,2 & 2,9 & 3,2 & 2,3 & 2,5 & 2,4 & 2,7 & 1,8 & 2,0 \\
\hline $30 / 08 / 96$ & 4,2 & 3,1 & 3,8 & 2,7 & 2,8 & 2,7 & 3,3 & 2,5 & 3,0 \\
\hline $31 / 08 / 96$ & 5,1 & 5,1 & 6,6 & 2,1 & 2,2 & 4,5 & 5,7 & 3,2 & 4,0 \\
\hline $02 / 09 / 96$ & 3,9 & 3,8 & 4,3 & 3,2 & 3,4 & 3,2 & 3,7 & 2,8 & 3,2 \\
\hline $04 / 09 / 96$ & 3,4 & 2,5 & 2,4 & 2,3 & 2,4 & 2,1 & 2,0 & 2,1 & 1,9 \\
\hline 07/09/96 & 4,7 & 3,7 & 4,2 & 3,1 & 3,3 & 3,1 & 3,5 & 2,4 & 2,7 \\
\hline $12 / 09 / 96$ & 3,7 & 3,1 & 3,1 & 2,5 & 2,7 & 2,5 & 2,5 & 1,8 & 1,8 \\
\hline $13 / 09 / 96$ & 4,0 & 3,6 & 3,9 & 3,5 & 3,7 & 3,1 & 3,4 & 2,7 & 3,0 \\
\hline $14 / 09 / 96$ & 4,8 & 3,6 & 4,1 & 3,5 & 3,7 & 3,1 & 3,5 & 2,9 & 3,3 \\
\hline $15 / 09 / 96$ & 4,7 & 3,5 & 4,1 & 3,3 & 3,5 & 3,0 & 3,5 & 2,6 & 3,1 \\
\hline $17 / 09 / 96$ & 4,2 & 3,4 & 3,5 & 2,8 & 3,0 & 2,8 & 2,9 & 2,0 & 2,0 \\
\hline $18 / 09 / 96$ & 4,8 & 3,5 & 3.8 & 2,9 & 3,1 & 2,9 & 3,1 & 2,1 & 2,2 \\
\hline $19 / 09 / 96$ & 5,2 & 3,7 & 4,3 & 3,2 & 3,3 & 3,1 & 3,6 & 2,9 & 3,4 \\
\hline $20 / 09 / 96$ & 4,8 & 4,0 & 4,8 & 3,1 & 3,3 & 3,3 & 4,0 & 3,0 & 3,7 \\
\hline $22 / 09 / 96$ & 5,5 & 4,4 & 5,6 & 3,1 & 3,2 & 3,6 & 4,7 & 3,4 & 4,4 \\
\hline $23 / 09 / 96$ & 5,2 & 4,2 & 4,9 & 3,5 & 3,7 & 3,6 & 4,2 & 3,2 & 3,7 \\
\hline $24 / 09 / 96$ & 4,4 & 4,0 & 4,5 & 3,4 & 3,6 & 3,4 & 3,8 & 2,8 & 3,2 \\
\hline $26 / 09 / 96$ & 5,1 & 4,4 & 5,0 & 3,4 & 3,6 & 3,8 & 4,2 & 2,8 & 3,1 \\
\hline $27 / 09 / 96$ & 5,3 & 4,3 & 4,9 & 3,5 & 3,7 & 3,7 & 4,2 & 2,9 & 3,3 \\
\hline $28 / 09 / 96$ & 2,5 & 2,3 & 2,0 & 2,1 & 2,3 & 1,9 & 1,7 & 1,7 & 1,5 \\
\hline 29/09/96 & 4,2 & 3,5 & 3,8 & 3,1 & 3,2 & 3,0 & 3.3 & 2,8 & 3,1 \\
\hline $30 / 09 / 96$ & 5,7 & 4,5 & 5,1 & 3,6 & 3,8 & 3,8 & 4,3 & 2,9 & 3,2 \\
\hline $04 / 10 / 96$ & 4,6 & 4,3 & 4,5 & 4,0 & 4,3 & 3,7 & 3,8 & 3,1 & 3,2 \\
\hline $07 / 10 / 96$ & 4,4 & 4,1 & 4,0 & 4,3 & 4,5 & 3,4 & 3,3 & 2,5 & 2,4 \\
\hline $08 / 10 / 96$ & 4,4 & 4,0 & 3,9 & 3,7 & 3,9 & 3,3 & 3,2 & 2,4 & 2,4 \\
\hline $09 / 10 / 96$ & 4,5 & 4,6 & 4,8 & 4,4 & 4,6 & 3,9 & 4,1 & 3,2 & 3,3 \\
\hline $11 / 10 / 96$ & 4,2 & 4,2 & 4,3 & 4,5 & 4,8 & 3,8 & 3,9 & 3,4 & 3,5 \\
\hline
\end{tabular}


Tabela 9. Continuação...

\begin{tabular}{|c|c|c|c|c|c|c|c|c|c|}
\hline $15 / 10 / 96$ & 4,5 & 4.1 & 4,0 & 3,6 & 3,8 & 3,4 & 3,3 & 2,4 & 2,4 \\
\hline $16 / 10 / 96$ & 5,3 & 4,1 & 4,3 & 4,0 & 4,2 & 3,5 & 3,7 & 3,1 & 3,2 \\
\hline $17 / 10 / 96$ & 5,9 & 4,7 & 5,0 & 4,6 & 4,9 & 4,1 & 4,4 & 4,1 & 4,4 \\
\hline $18 / 10 / 96$ & 6,3 & 5,2 & 5,7 & 4,8 & 5,1 & 4,5 & 5,0 & 4,1 & 4,5 \\
\hline $19 / 10 / 96$ & 4,7 & 4,6 & 4,9 & 3,9 & 4,1 & 3,9 & 4,2 & 3,0 & 3,2 \\
\hline $21 / 10 / 96$ & 3,7 & 3,4 & 3,3 & 3,4 & 3,6 & 2,9 & 2,8 & 2,1 & 2,1 \\
\hline $22 / 10 / 96$ & 5,1 & 4,4 & 4,6 & 4,6 & 4,9 & 3,9 & 4,1 & 3,5 & 3,7 \\
\hline $23 / 10 / 96$ & 5,4 & 5,0 & 5,3 & 4,7 & 5,0 & 4,3 & 4,5 & 3,3 & 3,5 \\
\hline $24 / 10 / 96$ & 4,7 & 4,3 & 4,4 & 4,1 & 4,3 & 3,6 & 3,7 & 2,9 & 2,9 \\
\hline $28 / 10 / 96$ & 5,0 & 4,4 & 4,7 & 4,0 & 4,2 & 3,7 & 4,0 & 3,4 & 3,7 \\
\hline $29 / 10 / 96$ & 5,6 & 4,7 & 5,3 & 4,1 & 4,3 & 4,0 & 4,5 & 3,9 & 4,4 \\
\hline $30 / 10 / 96$ & 6,0 & 5,0 & 5,6 & 4,3 & 4,5 & 4,2 & 4,8 & 3,8 & 4,3 \\
\hline $31 / 10 / 96$ & 6,2 & 5,5 & 6,3 & 4,6 & 4,9 & 4,8 & 5,4 & 4,0 & 4,5 \\
\hline $04 / 11 / 96$ & 4,4 & 4,0 & 3,9 & 3,9 & 4,1 & 3,4 & 3,3 & 2,5 & 2,4 \\
\hline $05 / 11 / 96$ & 6,4 & 5,7 & 5,9 & 5,1 & 5,4 & 4,8 & 5,0 & 3,5 & 3,6 \\
\hline $06 / 11 / 96$ & 6,5 & 5,1 & 5,3 & 5,1 & 5,4 & 4.5 & 4,7 & 4,3 & 4.5 \\
\hline $07 / 11 / 96$ & 6,1 & 5,7 & 6,2 & 5,4 & 5,7 & 5.0 & 5,4 & 4,5 & 4,9 \\
\hline $08 / 11 / 96$ & 6,5 & 5,5 & 6,0 & 4,9 & 5,2 & 4,7 & 5,2 & 4,2 & 4,6 \\
\hline $09 / 11 / 96$ & 6,9 & 6,1 & 7,0 & 5,3 & 5,6 & 5,3 & 6,0 & 4,7 & 5,4 \\
\hline $10 / 11 / 96$ & 6,9 & 6,1 & 7,0 & 4,8 & 5,1 & 5,2 & 6,0 & 4,4 & 5,1 \\
\hline $11 / 11 / 96$ & 5,3 & 4,5 & 4,7 & 4,5 & 4,8 & 3,9 & 4,1 & 3,8 & 4,0 \\
\hline $12 / 11 / 96$ & 3,5 & 3,2 & 3,2 & 3,3 & 3,5 & 2,8 & 2,9 & 2,7 & 2,8 \\
\hline $22 / 11 / 96$ & 2,7 & 2,5 & 1,9 & 2,4 & 2,6 & 1,9 & 1,5 & 1,3 & 1,0 \\
\hline $23 / 11 / 96$ & 5,0 & 4,2 & 4,1 & 4,1 & 4,3 & 3,6 & 3,5 & 3,0 & 2,9 \\
\hline $24 / 11 / 96$ & 6,4 & 5,1 & 5,5 & 4,8 & 5,0 & 4,4 & 4,7 & 4,2 & 4,6 \\
\hline $25 / 11 / 96$ & 6,0 & 5,5 & 5,7 & 5,2 & 5,5 & 4,7 & 4,9 & 3,8 & 3,9 \\
\hline $26 / 11 / 96$ & 5,5 & 6,0 & 6,4 & 5,1 & 5,4 & 5,0 & 5,2 & 3,4 & 3,6 \\
\hline $27 / 11 / 96$ & 6,3 & 6,2 & 6,7 & 4,9 & 5,2 & 5,2 & 5,6 & 3,7 & 3,9 \\
\hline $28 / 11 / 96$ & 6,1 & 5,7 & 6,2 & 5,0 & 5,3 & 4,9 & 5,3 & 4,0 & 4,3 \\
\hline $29 / 11 / 96$ & 5,2 & 4,6 & 4,9 & 4,3 & 4,5 & 3,9 & 4,2 & 3,5 & 3,7 \\
\hline $30 / 11 / 96$ & 2,2 & 2,6 & 2,2 & 2,7 & 2,9 & 2,3 & 2,0 & 2,0 & 1,8 \\
\hline $05 / 12 / 96$ & 5,8 & 5,4 & 5,6 & 5,4 & 5,7 & 4,7 & 4,8 & 3,9 & 4,0 \\
\hline $06 / 12 / 96$ & 5,7 & 4,7 & 4,8 & 4,9 & 5,2 & 4,1 & 4,2 & 3,6 & 3,7 \\
\hline $08 / 12 / 96$ & 3,9 & 3,3 & 3,3 & 3,8 & 4,0 & 3,1 & 3,0 & 2,7 & 2,7 \\
\hline $09 / 12 / 96$ & 7,0 & 6,0 & 6,7 & 5,4 & 5,7 & 5,1 & 5,8 & 4,9 & 5,5 \\
\hline
\end{tabular}

1 - Rn estimada por Angström-Brunt; 2 - Rn estimada pela equação $22 ; 3-\alpha=1,26 ; 4-\alpha=1,00$ no período úmido e $\alpha=1,33$ no período seco; $5-r_{c} / r_{a}$ da FAO e Rn estimada por Angström-Brunt; $6-r_{c} / r_{a}$ FAO e Rn estimada pela equação 22; $7-r_{c} / r_{a}$ Pereira et al. (1998) e Rn estimada por Angström-Brunt; 8 $\mathrm{r}_{\mathrm{c}} / \mathrm{r}_{\mathrm{a}}$ Pereira et al. (1998) e Rn estimada pela equação 22. 
Tabela 10. Evapotranspiração de referência medida em lisímetro (ETo-Lis) e estimada pelos métodos de Penman (ETo-P), Priestley-Taylor (ETo-PT) e PenmanMonteith (ETo-PM), com dados medidos na estação meteorológica automática (EMA), em Piracicaba, SP.

\begin{tabular}{|c|c|c|c|c|c|c|c|c|c|}
\hline Data & ETo-Lis & ETo-P & ETo-P $\mathrm{P}^{2}$ & $\mathrm{ETo} \mathrm{PT}^{3}$ & $\begin{array}{c}\text { ETo-PT } \\
\mathrm{mm} \cdot \mathrm{d}^{-1}\end{array}$ & ETo-PMS & $\mathrm{ETO}^{\mathrm{P}} \mathrm{PM}^{6}$ & ETo-PM & $\overline{\text { ETo-PM }}{ }^{8}$ \\
\hline $23 / 12 / 95$ & 4,5 & 6,5 & 6,6 & 6,5 & 5,1 & 5,6 & 5,7 & 4,6 & 4,6 \\
\hline $01 / 01 / 96$ & 2,1 & 3,3 & 3,3 & 3,1 & 2,5 & 2,8 & 2.8 & 2,6 & 2,6 \\
\hline $13 / 01 / 96$ & 4,8 & 5,7 & 5,1 & 6,4 & 5,1 & 5,1 & 4,5 & 4,7 & 4,2 \\
\hline 14/01/96 & 5,4 & 6,9 & 6,3 & 7,1 & 5,6 & 6,1 & 5.5 & 5,2 & 4,7 \\
\hline $18 / 01 / 96$ & 4,2 & 5,7 & 4.9 & 6,0 & 4,8 & 5,0 & 4,3 & 4,3 & 3.8 \\
\hline $22 / 01 / 96$ & 4,7 & 7,0 & 6,0 & 7,3 & 5,8 & 6,1 & 5.3 & 5,2 & 4,5 \\
\hline 25/01/96 & 5,6 & 7,0 & 6,1 & 7,1 & 5,6 & 6,2 & 5.4 & 5,6 & 4,9 \\
\hline $26 / 01 / 96$ & 4,6 & 6,4 & 5,8 & 6,4 & 5,1 & 5,6 & 5,1 & 4,9 & 4,4 \\
\hline $28 / 01 / 96$ & 5,6 & 7,2 & 6.4 & 7,4 & 5,9 & 6,4 & 5.7 & 5,8 & 5,1 \\
\hline $31 / 01 / 96$ & 4,6 & 6,1 & 5,6 & 6,0 & 4,8 & 5,3 & 4.9 & 4,8 & 4.4 \\
\hline 05/02/96 & 3,3 & 4,1 & 3,8 & 4,3 & 3,4 & 3,6 & 3,3 & 3,1 & 2,9 \\
\hline $22 / 02 / 96$ & 4,0 & 5,2 & 5,0 & 5,2 & 4,2 & 4,6 & 4,4 & 4,0 & 3,8 \\
\hline $23 / 02 / 96$ & 3,7 & 4,7 & 4,6 & 4,8 & 3,8 & 4,2 & 4,1 & 3,8 & 3,7 \\
\hline $02 / 03 / 96$ & 3,2 & 3,9 & 3,7 & 3,8 & 3,0 & 3,4 & 3,2 & 2,8 & 2,6 \\
\hline $11 / 03 / 96$ & 3,9 & 4,6 & 4,5 & 4,3 & 3,4 & 3,9 & 3,8 & 3,2 & 3,1 \\
\hline $13 / 03 / 96$ & 3,4 & 4,4 & 4,1 & 4,9 & 3,9 & 3,9 & 3,6 & 3,4 & 3,2 \\
\hline $14 / 03 / 96$ & 2,8 & 3,6 & 3,4 & 3,9 & 3,1 & 3,1 & 3,0 & 2,9 & 2,8 \\
\hline $17 / 03 / 96$ & 2,5 & 3,0 & 2,9 & 3,2 & 2,6 & 2,6 & 2,5 & 2,5 & 2,4 \\
\hline $21 / 03 / 96$ & 3,1 & 3,6 & 3,5 & 3,6 & 2,8 & 3,1 & 3,0 & 2,5 & 2,4 \\
\hline $22 / 03 / 96$ & 2,9 & 3,8 & 3,8 & 3,8 & 3,0 & 3,3 & 3,3 & 2,8 & 2,8 \\
\hline 24/03/96 & 3,4 & 4,5 & 4,1 & 4,8 & 3,8 & 4,0 & 3,6 & 3,6 & 3,3 \\
\hline $25 / 03 / 96$ & 4,1 & 5,1 & 4,8 & 5,3 & 4,2 & 4,5 & 4,2 & 3,9 & 3,7 \\
\hline $26 / 03 / 96$ & 4,2 & 5,2 & 4,9 & $5: 4$ & 4,3 & 4,6 & 4,3 & 4,2 & 3,9 \\
\hline 28/03/96 & 3,1 & 3,9 & 3,8 & 4,1 & 3,3 & 3,4 & 3,4 & 3,3 & 3,3 \\
\hline $03 / 04 / 96$ & 3,7 & 4,9 & 4,8 & 4,7 & 3,7 & 4,3 & 4,2 & 3,8 & 3,7 \\
\hline $04 / 04 / 96$ & 3,7 & 4,5 & 4,6 & 4.3 & 3,4 & 3,9 & 4,0 & 3,5 & 3,5 \\
\hline 06/04/96 & 3,2 & 4,3 & 4,2 & 4,4 & 3,5 & 3,8 & 3,7 & 3,7 & 3,6 \\
\hline $07 / 04 / 96$ & 3,5 & 4,7 & 4,6 & 4,5 & 3,6 & 4,1 & 4,0 & 3,5 & 3,4 \\
\hline $10 / 04 / 96$ & 2,9 & 4,1 & 4,0 & 4,0 & 3,2 & 3,5 & 3,5 & 3,2 & 3,1 \\
\hline $13 / 04 / 96$ & 2,6 & 3,5 & 3,4 & 3,5 & 2,8 & 3,0 & 2,9 & 2,9 & 2,8 \\
\hline $15 / 04 / 96$ & 3,4 & 4,2 & 3,9 & 4,2 & 3,3 & 3,7 & 3,4 & 3,2 & 2,9 \\
\hline $18 / 04 / 96$ & 3,3 & 3,9 & 4,2 & 3,1 & 2,5 & $3,2^{\circ}$ & 3,4 & 2,2 & 2,4 \\
\hline $19 / 04 / 96$ & 3,0 & 4,2 & 4,3 & 3,8 & 3,0 & 3,4 & 3,5 & 2,5 & 2,6 \\
\hline 20/04/96 & 2,8 & 4,1 & 4,2 & 3,7 & 2,9 & 3,4 & 3,5 & 2,7 & 2,8 \\
\hline $26 / 04 / 96$ & 2,1 & 3,2 & 3,2 & 2,9 & 2,3 & 2,7 & 2,6 & 2,0 & 2,0 \\
\hline $27 / 04 / 96$ & 2,2 & 3,8 & 3,8 & 2,9 & 2,3 & 3,1 & 3,1 & 2,2 & 2,2 \\
\hline 29/04/96 & 2,5 & 3,7 & 3,7 & 3,6 & 2,9 & 3,2 & 3,1 & 2,9 & 2,9 \\
\hline $30 / 04 / 96$ & 2,3 & 3,1 & 3,2 & 2,9 & 2,3 & 2,6 & 2,7 & 2,2 & 2,3 \\
\hline $04 / 05 / 96$ & 2,6 & 3,7 & 3,8 & 3,6 & 2,9 & 3,2 & 3,2 & 2,9 & 2,9 \\
\hline $17 / 05 / 96$ & 2,6 & 3,2 & 3,2 & 3,2 & 2,5 & 2,7 & 2,7 & 2,5 & 2.5 \\
\hline
\end{tabular}


Tabela 10. Continuação...

\begin{tabular}{|c|c|c|c|c|c|c|c|c|c|}
\hline $24 / 05 / 96$ & 1,5 & 2,4 & 2,6 & 1,9 & 1,5 & 2,0 & 2,1 & 1,5 & 1,6 \\
\hline $02 / 08 / 96$ & 3,0 & 3,6 & 3,8 & 3,1 & 3,3 & 3,0 & 3,2 & 2,8 & 3,0 \\
\hline $03 / 08 / 96$ & 2,7 & 3,4 & 3,5 & 3,1 & 3,2 & 2,8 & 2,9 & 2,6 & 2,6 \\
\hline $04 / 08 / 96$ & 4,0 & 3,9 & 4,0 & 3,3 & 3,5 & 3,2 & 3,3 & 2,8 & 2,9 \\
\hline $05 / 08 / 96$ & 3,5 & 3,9 & 4,1 & 3,1 & 3,2 & 3,2 & 3,4 & 2,8 & 2,9 \\
\hline $06 / 08 / 96$ & 3,3 & 3,7 & 3,9 & 3,0 & 3,1 & 3,0 & 3,2 & 2,8 & 2,9 \\
\hline $07 / 08 / 96$ & 3,0 & 3,8 & 4,0 & 2,9 & 3,1 & 3,1 & 3,3 & 2,8 & 2,9 \\
\hline $08 / 08 / 96$ & 3,3 & 3.8 & 4,0 & 3,0 & 3,1 & 3,2 & 3,3 & 2,8 & 2,9 \\
\hline 09/08/96 & 3,3 & 4,3 & 4,4 & 2,6 & 2,8 & 3,6 & 3,7 & 2,9 & 2,9 \\
\hline $11 / 08 / 96$ & 2,7 & 2,5 & 2,3 & 2,3 & 2,4 & 2,1 & 2,0 & 1,6 & 1,5 \\
\hline $12 / 08 / 96$ & 3.0 & 2,9 & 2,9 & 2,9 & 3,0 & 2,4 & 2,4 & 2,0 & 2,0 \\
\hline $13 / 08 / 96$ & 3,1 & 3,5 & 3,4 & 3,5 & 3,7 & 3,0 & 2,9 & 2,7 & 2,6 \\
\hline $15 / 08 / 96$ & 3,1 & 3,2 & 3,2 & 3,0 & 3,1 & 2,6 & 2,7 & 2,1 & 2,1 \\
\hline $16 / 08 / 96$ & 4,1 & 4,3 & 4,6 & 3,3 & 3,5 & 3,4 & 3,6 & 2,3 & 2,5 \\
\hline $17 / 08 / 96$ & 3,8 & 3,8 & 4,0 & 3,6 & 3,8 & 3,2 & 3,3 & 2,8 & 2,9 \\
\hline $18 / 08 / 96$ & 3,6 & 4,0 & 4,1 & 3,6 & 3,9 & 3,4 & 3,5 & 3,0 & 3,0 \\
\hline $19 / 08 / 96$ & 3,8 & 4,3 & 4,3 & 3,8 & 4,0 & 3,6 & 3,6 & 3,1 & 3,1 \\
\hline $21 / 08 / 96$ & 4,4 & 4,8 & 4,9 & 3,8 & 4,0 & 4,0 & 4,1 & 3,2 & 3,3 \\
\hline $22 / 08 / 96$ & 3,9 & 4,7 & 4,9 & 3,6 & 3,8 & 4,0 & 4,1 & 3,3 & 3.4 \\
\hline $23 / 08 / 96$ & 4,2 & 4,7 & 4,8 & 3,7 & 4,0 & 4,0 & 4,0 & 3,3 & 3,4 \\
\hline $24 / 08 / 96$ & 4,4 & 4.9 & 5,0 & 4,0 & 4,3 & 4,2 & 4,2 & 3,4 & 3,4 \\
\hline $25 / 08 / 96$ & 4,3 & 5,0 & 5,1 & 4,0 & 4,2 & 4,3 & 4,3 & 3,5 & 3,6 \\
\hline $26 / 08 / 96$ & 4,6 & 5,4 & 5,4 & 4,1 & 4,3 & 4,6 & 4,6 & 3,7 & 3,7 \\
\hline $27 / 08 / 96$ & 4,5 & 5,1 & 5,1 & 3,9 & 4,1 & 4,3 & 4,3 & 3,7 & 3,6 \\
\hline $28 / 08 / 96$ & 3,8 & 4,3 & 4,2 & 3,4 & 3,6 & 3,6 & 3,6 & 2,7 & 2,7 \\
\hline 29/08/96 & 3,2 & 4,2 & 4,1 & 3,3 & 3,5 & 3,5 & 3,5 & 2,5 & 2,5 \\
\hline $30 / 08 / 96$ & 4,2 & 4,4 & 4,3 & 3,8 & 4,0 & 3,8 & 3,6 & 3,2 & 3,1 \\
\hline $31 / 08 / 96$ & 5,1 & 5,6 & 5,6 & 4,2 & 4,4 & 4,8 & 4,8 & 3,7 & 3,7 \\
\hline $02 / 09 / 96$ & 3,9 & 4,4 & 4,3 & 4,1 & 4,3 & 3,7 & 3,6 & 3,2 & 3.1 \\
\hline 04/09/96 & 3,4 & 2,9 & 2,9 & 2,8 & 2,9 & 2,5 & 2,4 & 2,3 & 2.2 \\
\hline 07/09/96 & 4,7 & 4,6 & 4,3 & 4,5 & 4,8 & 3,9 & 3,6 & 3,2 & 3.0 \\
\hline $12 / 09 / 96$ & 3,7 & 3,5 & 3,4 & 3,1 & 3,3 & 2,8 & 2,8 & 2,0 & 2,0 \\
\hline $13 / 09 / 96$ & 4,0 & 4,4 & 4,2 & 4,3 & 4,6 & 3,7 & 3,6 & 2,9 & 2,8 \\
\hline $14 / 09 / 96$ & 4,8 & 4,8 & 4,6 & 4,7 & 5,0 & 4,1 & 3,9 & 3,3 & 3,2 \\
\hline $15 / 09 / 96$ & 4,7 & 4,8 & 4,5 & 4,8 & 5,1 & 4,2 & 3,9 & 3,7 & 3,5 \\
\hline $17 / 09 / 96$ & 4,2 & 3,7 & 3,3 & 3,4 & 3,6 & 3,0 & 2,7 & 2,1 & 1,9 \\
\hline $18 / 09 / 96$ & 4,8 & 4,8 & 4,8 & 4,3 & 4,5 & 3,9 & 3,8 & 2,7 & 2,7 \\
\hline $19 / 09 / 96$ & 5,2 & 5,1 & 5,0 & 4,9 & 5,1 & 4,4 & 4,2 & 3,6 & 3,5 \\
\hline $20 / 09 / 96$ & 4,8 & 5,0 & 4,9 & 4,7 & 5,0 & 4,3 & 4,2 & 3,9 & 3,8 \\
\hline $22 / 09 / 96$ & 5,5 & 6,0 & 5,9 & 4,9 & 5,2 & 5,1 & 5,0 & 4,3 & 4,2 \\
\hline $23 / 09 / 96$ & 5,2 & 5,7 & 5,6 & 4,7 & 4,9 & 4,9 & 4,8 & 4,0 & 3,9 \\
\hline $24 / 09 / 96$ & 4,4 & 4,9 & 4,8 & 4,1 & 4,4 & 4,2 & 4,1 & 3,3 & 3,2 \\
\hline $26 / 09 / 96$ & 5,1 & 5,5 & 5,2 & 5,0 & 5,3 & 4,6 & 4,3 & 3,3 & 3,1 \\
\hline $27 / 09 / 96$ & 5,3 & 5,8 & 5,5 & 4,9 & 5,2 & 4,8 & 4,6 & 3,5 & 3,3 \\
\hline 28/09/96 & 2,5 & 2,1 & 2,1 & 1,7 & 1,8 & 1,7 & 1,8 & 1,4 & 1,5 \\
\hline 29/09/96 & 4,2 & 4,4 & 4,1 & 4,2 & 4,5 & 3,8 & 3,6 & 3,3 & 3,1 \\
\hline
\end{tabular}


Tabela 10. Continuação...

\begin{tabular}{|c|c|c|c|c|c|c|c|c|c|}
\hline $30 / 09 / 96$ & 5,7 & 5,5 & 5,0 & 5,1 & 5,4 & 4,6 & 4,2 & 3,5 & 3,2 \\
\hline $04 / 10 / 96$ & 4,6 & 5,2 & 4,7 & 5,4 & 5,7 & 4,5 & 4,0 & 3,7 & 3,3 \\
\hline $07 / 10 / 96$ & 4,4 & 4,3 & 4,1 & 4,4 & 4,7 & 3,5 & 3,4 & 2,6 & 2,5 \\
\hline $08 / 10 / 96$ & 4,4 & 4,6 & 4,3 & 4,2 & 4,5 & 3,8 & 3,6 & 2,7 & 2,6 \\
\hline $09 / 10 / 96$ & 4,5 & 5,4 & 5,1 & 5,2 & 5,5 & 4,6 & 4,3 & 3,6 & 3,4 \\
\hline $11 / 10 / 96$ & 4,2 & 4,4 & 4,0 & 4,7 & 5,0 & 3,9 & 3,5 & 3,4 & 3,1 \\
\hline $15 / 10 / 96$ & 4,5 & 4,4 & 4,5 & 3,7 & 3,9 & 3,6 & 3,6 & 2,5 & 2,5 \\
\hline $16 / 10 / 96$ & 5,3 & 5,1 & 4,9 & 5,1 & 5,3 & 4,3 & 4,1 & 3,4 & 3,2 \\
\hline $17 / 10 / 96$ & 5,9 & 5,6 & 5,3 & 5,8 & 6,1 & 4,9 & 4,6 & 4,4 & 4,2 \\
\hline $18 / 10 / 96$ & 6,3 & 5,9 & 5,6 & 5,6 & 5,9 & 5,1 & 4,8 & 4,3 & 4,0 \\
\hline $19 / 10 / 96$ & 4,7 & 5,3 & 5,2 & 4,5 & 4,8 & 4,5 & 4,4 & 3,5 & 3,4 \\
\hline $21 / 10 / 96$ & 3,7 & 3,3 & 3,3 & 2,9 & 3,1 & 2,7 & 2,7 & 2,0 & 2,0 \\
\hline $22 / 10 / 96$ & 5,1 & 5,4 & 5,1 & 5,6 & 5,9 & 4,7 & 4,5 & 4,1 & 4,0 \\
\hline $23 / 10 / 96$ & 5,4 & 5,6 & 5,1 & 5,5 & 5,8 & 4,8 & 4,4 & 3,8 & 3.5 \\
\hline $24 / 10 / 96$ & 4,7 & 5,2 & 5,1 & 4,5 & 4,7 & 4,3 & 4,3 & 3,2 & 3,1 \\
\hline $28 / 10 / 96$ & 5,0 & 4,7 & 4,2 & 4,7 & 4,9 & 4,1 & 3,6 & 3,3 & 2,9 \\
\hline $29 / 10 / 96$ & 5,6 & 5,8 & 5,6 & 5,6 & 5,9 & 5,0 & 4,9 & 4,5 & 4,4 \\
\hline $30 / 10 / 96$ & 6,0 & 6,1 & 5,7 & 5,6 & 5,9 & 5,3 & 4,9 & 4,5 & 4,2 \\
\hline $31 / 10 / 96$ & 6,2 & 6,7 & 6,3 & 6,0 & 6,4 & 5,8 & 5,4 & 4,9 & 4,5 \\
\hline $04 / 11 / 96$ & 4,4 & 4,3 & 4,0 & 4,2 & 4,5 & 3,6 & 3,4 & 2,7 & 2,6 \\
\hline $05 / 11 / 96$ & 6,4 & 6,6 & 6,3 & 6,1 & 6,5 & 5,5 & 5,2 & 4,0 & 3,8 \\
\hline $06 / 11 / 96$ & 6,5 & 6,5 & 6,0 & 6,5 & 6,8 & 5,6 & 5,1 & 4,7 & 4,3 \\
\hline $07 / 11 / 96$ & 6,1 & 6,7 & 6,0 & 6,8 & 7,2 & 5,9 & 5,3 & 5,2 & 4,6 \\
\hline $08 / 11 / 96$ & 6,5 & 6,8 & 5,8 & 6,0 & 6,4 & 5,9 & 5,0 & 4,7 & 4,0 \\
\hline $09 / 11 / 96$ & 6,9 & 7,5 & 6,9 & 7,0 & 7,4 & 6,5 & 5,9 & 5,4 & 4,9 \\
\hline $10 / 11 / 96$ & 6,9 & 7,4 & 7,0 & 6,5 & 6,9 & 6,4 & 6,0 & 5,3 & 5,0 \\
\hline $11 / 11 / 96$ & 5,3 & 6,2 & 5,5 & 5,5 & 5,9 & 5,3 & 4,7 & 4,1 & 3,7 \\
\hline $12 / 11 / 96$ & 3,5 & 3,8 & 3,7 & 3,5 & 3,7 & 3,3 & 3,2 & 2,9 & 2,8 \\
\hline $22 / 11 / 96$ & 2,7 & 2,5 & 2,6 & 1,9 & 2,0 & 2,0 & 2,1 & 1,4 & 1,4 \\
\hline $23 / 11 / 96$ & 5,0 & 5,3 & 4,9 & 5,2 & 5,5 & 4,4 & 4,2 & 3,5 & 3,2 \\
\hline $24 / 11 / 96$ & 6,4 & 6,0 & 5,8 & 6,1 & 6,5 & 5,2 & 5,0 & 4,6 & 4,5 \\
\hline $25 / 11 / 96$ & 6,0 & 6,4 & 6,2 & 6,2 & 6,6 & 5,5 & 5,3 & 4,4 & 4,2 \\
\hline $26 / 11 / 96$ & 5,5 & 6,5 & 6,6 & 5,8 & 6,2 & 5,4 & 5,5 & 3,8 & 3,9 \\
\hline $27 / 11 / 96$ & 6,3 & 7,0 & 6,9 & 6,1 & 6,5 & 5,8 & 5,7 & 4,1 & 4,0 \\
\hline $28 / 11 / 96$ & 6,1 & 7,2 & 7,0 & 6,4 & 6,8 & 6,1 & 5,9 & 4,6 & 4,5 \\
\hline 29/11/96 & 5,2 & 5,8 & 5,5 & 5,5 & 5,8 & 5,0 & 4,7 & 4,5 & 4,3 \\
\hline $30 / 11 / 96$ & 2,2 & 2,2 & 2,1 & 1,9 & 2,0 & 1,8 & 1,8 & 1,7 & 1,6 \\
\hline $05 / 12 / 96$ & 5,8 & 6,2 & 5,8 & 6,4 & 6,8 & 5,4 & 5,0 & 4,4 & 4,1 \\
\hline $06 / 12 / 96$ & 5,7 & 5,9 & 5,2 & 6,2 & 6,5 & 5,1 & 4,5 & 4,3 & 3,8 \\
\hline $08 / 12 / 96$ & 3,9 & 3,9 & 3,6 & 4,3 & 4,5 & 3,5 & 3,2 & 3,3 & 3,0 \\
\hline $09 / 12 / 96$ & 7,0 & 7,3 & 6,7 & 7,1 & 7,5 & 6,4 & 5,8 & 5,6 & 5,1 \\
\hline
\end{tabular}

1 - Rn medida; 2 - Rn estimada pela equação $23 ; 3-\alpha=1,26 ; 4-\alpha=1,00$ no período úmido e $\alpha=1,33$ no período seco; $5-r_{d} / r_{a}$ da FAO e Rn medida; $6-r_{c} / r_{a}$ FAO e Rn estimada pela equação 23; $7-r_{d} / r_{a}$ Pereira et al. (1998) e Rn medida; $8-r_{d} / r_{a}$ Pereira et al. (1998) e Rn estimada pela equação 23. 


\section{REFERÊNCIAS BIBLIOGRÁFICAS}

ALLEN, R.G. A Penman for all seasons. Journal of Irrigation and Drainage Eng., v.112, n.4, p.348-368. 1986.

ALLEN, R.G.; JENSEN, M.E.; WRIGHT, J.; BURMAN, R.D. Operational estimates of reference evapotranspiration. Agronomy Journal, v.81, p.650-662, 1989.

ALVES, I.; PERRIER, A.; PEREIRA, L.S. Aerodynamic and surface resistances of complete cover crops: How good is the "Big Leaf"? Transactions of the ASAE, v.41, n.2, p.345-351, 1998.

ASSIS, F.N. O uso do evapotranspirômetro no estudo de algumas relações entre a evapotranspiração medida e estimada. Piracicaba, 1978. 73p. Dissertação (M.S.) Escola Superior de Agricultura "Luiz de Queiroz", Universidade de São Paulo.

AZEVEDO, P.V.; RAO, T.V.R.; LEITÃO, M.M.V.B.R.; AMORIM, M.S.; PEREIRA, J.R.C.; ESPINOLA, J. Avaliação da radiação atmosférica sobre uma área cultivada com algodão. In: CONGRESSO BRASILEIRO DE AGROMETEOROLOGIA, 7, Viçosa, 1991. Resumos. Viçosa: Sociedade Brasileira de Agrometeorologia, 1991. p. $280-282$.

BARBIERI, V. Medidas e estimativas de consumo hídrico em cana-de-açúcar (Saccharum spp). Piracicaba, 1981. 82p. Dissertação (M.S.) - Escola Superior de Agricultura "Luiz de Queiroz", Universidade de São Paulo. 
BAUSCH, W.C. Sensor height effects on calculated reference evapotranspiration. Transactions of the ASAE, v.33, n.3, p.791-798, 1990.

BERGAMASCHI, H.; ROSA, L.M.G.; SANTOS, A.O.; BERGONCI, J.I. Automação de um lisímetro de pesagem através de estação meteorológica, a campo. In: CONGRESSO BRASILEIRO DE AGROMETEOROLOGIA, 10, Piracicaba, 1997. Anais. Piracicaba: Sociedade Brasileira de Agrometeorologia, 1997. p.222-224.

BERLATO, M.A.; MOLION, L.C.B. Evaporação e evapotranspiração. Porto Alegre: IPAGRO, 1981. 96p. (Boletim Técnico, 7).

BRUTSAERT, W. Evaporation into the atmosphere: theory, history and aplications. Dordrecht: Kluwer Academic, 1982. 229p. (Environment Fluid Mechanics, 1).

CAMARGO, A.P. Contribuição para a determinação da evapotranspiração potencial no Estado de São Paulo. Bragantia, v.21, n.12, p.163-213, 1962.

CAMARGO, A.P. Balanço hídrico no Estado de São Paulo. Campinas: IAC, 1971. 28p. (Boletim Técnico, 116).

CAMARGO, A.P; PEREIRA, A.R. Prescrição de rega por modelo climatológico. Campinas: Fundação Cargill, 1990. 27p.

CAMARGO, A.P; SENTELHAS, P.C. Avaliação do desempenho de diferentes métodos de estimativa da evapotranspiração potencial no Estado de São Paulo. Rev. Bras. de Agrometeorologia, v.5, n.1, p.89-97, 1997. 
CAMPBELL, E.C.; TANNER, B.D. Structured design in automated weather stations. In: WEISS, A. Computer techniques and meteorological data applied to problems of agriculture and forestry: a workshop. Anaheim, 1981. p.5-18.

CAMPECHE, L.F.S.M. Estimativa da resistência de dossel (rc) da grama com o uso da termometria ao infravermelho. Piracicaba, 1997. 52p. Dissertação (M.S.) - Escola Superior de Agricultura "Luiz de Queiroz", Universidade de São Paulo.

COCKERHAM, S.T.; ORTEGA, T.R. Remote data acquisition for agricultural experiment station management. Applied Agricultural Research, v.4, n.2, p.144$147,1989$.

CRUZ, R.F.R. Comparação do desempenho de dois tipos de lisímetro na determinação da evapotranspiração máxima da cultura da ervilha (Pisum sativum, L.). Piracicaba, 1995. 55p. Dissertação (M.S.) - Escola Superior de Agricultura "Luiz de Queiroz", Universidade de São Paulo.

CUNHA, G.R.; BERGAMASCHI, H. Coeficientes das equações de Makkink e Priestley-Taylor para a estimativa da evapotranspiração máxima da alfafa. Rev. Bras. de Agrometeorologia, v.2, n.1, p.33-36, 1994.

CURRY, R.B.; KLINK, J.C.; HOLMAN, J.R.; SCIARINI, M.J. Development of an automated weather station network in Ohio. St. Joseph: ASAE, 1981 (ASAE Paper, 81-4502).

DOORENBOS, J..; PRUITT, W.O. Guidelines for predicting crop water requirements. FAO Irrigation and Drainage paper 24, 2nd ed., Rome, 179p. 1977. 
DOORENBOS, J.; KASSAM, A.H. Efeito da água no rendimento das culturas. Estudos FAO, Irrigação e Drenagem 33. Tradução Gheyi, H.R. e outros, UFPB, Campina Grande. FAO. 306p. 1994.

ELTINK, M.G.; PEREIRA, F.A.C.; FOLEGATTI, M.V. Comparação entre métodos de estimativa de evapotranspiração de referência. In: SIMPÓSIO DE INICIAÇÃO CIENTÍFICA DA UNIVERSIDADE DE SÃO PAULO, 5, Piracicaba, 1997. Resumos. São Paulo: Universidade de São Paulo, 1997, p.517.

FERNANDES, A.L.T. Monitoramento da cultura do crisântemo em estufa através do uso de lisímetro e estação agrometeorológica automatizados. Piracicaba, 1996. 96p. Dissertação (M.S.) - Escola Superior de Agricultura "Luiz de Queiroz", Universidade de São Paulo.

FISCH, G.; SANTOS, J.M. Comparações entre observações meteorológicas convencionais e automáticas na região do Vale do Paraíba, SP. In: CONGRESSO BRASILEIRO DE AGROMETEOROLOGIA, 10, Piracicaba, 1997. Anais. Piracicaba: Sociedade Brasileira de Agrometeorologia, 1997. p.246-248.

FOLEGATTI, M.V.; SCATOLINI, M.E.; PAZ, V.P.S et al. Efeitos da cobertura plástica sobre os elementos meteorológicos e evapotranspiração da cultura em crisântemo em estufa. Rev. Bras. de Agrometeorologia, v.5, n.2, p.155-163, 1997.

FUCHS, M.; COHEN, Y.; MORESHET, S. Determining transpiration from meteorological data and crop characteristics for irrigation management. Irrigation Science, v.8, p.91-99, 1987. 
FUNARI, F.L.; TARIFA, J.L.; SIMPSON, J.G.P. Estudo comparativo entre as equações de Brunt-Penman (1949) e a de Linacre (1967) para estimativa da radiação líquida. In: CONGRESSO BRASILEIRO DE AGROMETEOROLOGIA, 4, Londrina, 1985. Anais. Londrina: Sociedade Brasileira de Agrometeorologia, 1985. p.129131.

GENERE, B. Tropicalisation of automatic weather stations and initial results for improved irrigation water management in Reunion Island. Agricultural Water Management, v.17, p.141-149, 1990.

GOMIDE, R.L.; OLIVEIRA, C.S.G.; FACCIOLI, G.G. Protótipo de um lisímetro de pesagem automático para estudos em casa de vegetação. Rev. Bras. de Agrometeorologia, v.4, n.1, p.61-68, 1996.

HASHEMI, F.; DECKER, W. Using climatic information and weather forecast for decisions in economizing irrigation water. Agricultural Meteorology, v.6, p.245$257,1969$.

HASHEMI, F.; HABIBIAN, M.T. Limitations of temperature-based methods in estimating crop evapotranspiration in arid-zone agricultural development projects. Agricultural Meteorology, v.20, p.237-247, 1979.

HUBBARD, K.G.; ROSENBERG, N.J.; NIELSEN, D.C. Automated weather data network for agriculture. Journal of Water Resources Planning and Management, v.109, n.3, p.213-222, 1983. 
HUBBARD, K.G.; KLOCKE, N.L. Climate and irrigation in Nebraska. In: CONFERENCE ON CLIMATE AND WATER MANAGEMENT: A CRITICAL ERA AND CONFERENCE ON THE HUMAN CONSEQUENCE OF 1985's CLIMATE. Asheville, NC, 1986. Boston: Americam Meteorological Society. 1986. p.33-35.

JENSEN, M.E. Consumptive use of water and irrigation water requirements. New York: American Society of Civil Eng., 215p. 1973.

JENSEN, M.E.; WRIGHT, J.L. The role of evapotranspiration models in irrigation scheduling. Transactions of the ASAE, v.21, p.82-87, 1978.

KUSTAS, W.P.; PRUEGER, J.H.; HIPPS, L.E.; HATFIELD, J.L.; MEEK, D. Inconsistencies in net radiation estimates from use of several models of instruments in a desert environment. Agricultural and Forest Meteorology, v.90, p.257-263, 1998.

LINACRE, E.T. Estimating the net-radiation flux. Agricultural Meteorology, v.5, p.4963. 1967.

MAGGIOTTO, S.R. Estimativa da evapotranspiração de referência pelo uso da termometria ao infravermelho. Piracicaba, 1996. 71p. Dissertação (M.S.) - Escola Superior de Agricultura "Luiz de Queiroz", Universidade de São Paulo.

MEDEIROS, S.L.P. Avaliação de métodos de estimativa da evapotranspiração de referência para a região mesoclimática de Santa Maria, RS. Rev. Bras. de Agrometeorologia, v.6, n.1, p.105-109, 1998. 
MEYER, S.J.; HUBBARD, K.G. Non federal automated weather stations and networks in the United States and Canada: a preliminary survey. Bulletin American Meteorological Society, v.73, n.4, p.449-457, 1992.

MOHAMMAD, F.S.; AL-AMOUD, A.I. Water conservation through irrigation scheduling under arid climatic conditions. Agricultural Water Management, v.24, p. 251-264, 1993.

MONTEITH, J.L. Evaporation and environment. Symp. Soc. Expl. Biol., v.19, p.205$234,1965$.

MONTEITH, J.L. Evaporation and surface temperature. Quarterly Journal of the Royal Meteorological Society, v.107, n.451, p.1-27, 1981.

OMETTO, J.C. Estudo das relações entre radiação solar global, radiação líquida e insolação. Piracicaba, 1968. 64p. Tese (Doutorado) - Escola Superior de Agricultura "Luiz de Queiroz", Universidade de São Paulo.

OMETTO, J.C. Bioclimatologia Vegetal. São Paulo: Ed. Agronômica Ceres. 1981. 440p.

OMETTO, J.C. Registro e estimativas dos parâmetros meteorológicos da região de Piracicaba. Piracicaba: FEALQ, 1991. 76p.

OMETTO , J.P.H.B. Medidas e estimativas do balanço de ondas longas para a região de Piracicaba, SP. Piracicaba, 1995. 87p. Dissertação (M.S.) - Escola Superior de Agricultura "Luiz de Queiroz", Universidade de São Paulo. 
PENMAN, H.L. Natural evaporation from open water, bare soil and grass. Proc. R. Soc. London, v.A193, p.120-146, 1948.

PENMAN, H.L. Evaporation: an introductory survey. Neth. J. Agric. Sci., v.4, p.9-29, 1956.

PENMAN, H.L. Vegetation and hydrology. Commonwealth Agric. Bureaux, Famham Royal. 124p. 1963 (Tech. Commun., 53).

PEREIRA, A.B.; VILLA NOVA, N.A.; TUON, R.L.; BARBIERI, V. Estimativa da evapotranspiração máxima da batata nas condições edafoclimáticas de Botucatu, SP, Brasil. Rev. Bras. de Agrometeorologia, v.3, n. 1, p.53-58, 1995a.

PEREIRA, A.B.; PEDRAS, J.F.; VILLA NOVA, N.A.; CURY, D.M. Consumo d'água e coeficiente de cultura da batata (Solanum tuberosum, L., cv. Itararé) em plantio de inverno no município de Botucatu, SP. Rev. Bras. de Agrometeorologia, v.3, n.1, p.59-62, $1995 b$.

PEREIRA, A .B. Modelo de estimativa do potencial de energia solar à superfície. Botucatu, 1997. 92p. Tese (Doutorado) - Faculdade de Ciências Agronômicas, Universidade Estadual Paulista.

PEREIRA, A.R.; VILLA NOVA, N.A. Analysis of the Priestley-Taylor parameter. Agricultural and Forest Meteorology, v.61, p.1-9, 1992.

PEREIRA, A.R.; VILLA NOVA, N.A.; PEREIRA, A.S.; BARBIERI, V. A model for the class A pan coefficient. Agricultural and Forest Meteorology, v.76, p.75-82, 1995. 
PEREIRA, A.R.; MANIERO, M.A.; VILLA NOVA, N.A.; BARBIERI, V. Penman's wind function for a tropical humid climate. Rev. Bras. de Agrometeorologia, v.4, n.1, p.69-75, 1996.

PEREIRA, A.R.; VILLA NOVA, N.A.; SEDIYAMA, G.C. Evapo(transpi)ração. Piracicaba: FEALQ, 1997a. 183p.

PEREIRA, A.R.; VILLA NOVA, N.A.; SENTELHAS, P.C. O parâmetro de PriestleyTaylor para a estimativa da evapotranspiraçào de referência na escala mensal. Rev. Bras. de Agrometeorologia, v.5, n.1, p.83-87, 1997 b.

PEREIRA, A.R.; PEREIRA, F.A.C.; MAGGIOTTO, S.R.; VILlA NOVA, N.A.; FOLEGATTI, M.V. Penman-Monteith reference evapotranspiration in a tropical climate. In: CONFERENCE ON AGRICULTURAL AND FOREST METEOROLOGY, 23, Albuquerque, 1998. Albuquerque: American Meteorological Society, 1998, P2.16.

PEREIRA, F.A.C. Desempenho do modelo de Penman-Monteith e de dois evaporímetros na estimativa da evapotranspiração de referência (ETo) em relação a um lisímetro de pesagem. Piracicaba, 1998. 87p. Tese (Doutorado) - Escola Superior de Agricultura "Luiz de Queiroz", Universidade de São Paulo.

PERES, J.G.; PEREIRA, A.R.; FRIZZONE, J.A.; VILLA NOVA, N.A. Determinação da resistência do dossel da grama para as condições de evapotranspiração potencial. Rev. Bras. de Agrometeorologia, v.4, n.1, p.55-60, 1996.

PERES, J.G.; PEREIRA, A.R.; FRIZZONE, J.A.; VILLA NOVA, N.A. Calibração do modelo de Priestley-Taylor para estimar a evapotranspiração potencial da cana-deaçúcar. Rev. Bras. de Agrometeorologia, v.5, n.1, p.77-82, 1997. 
PRIESTLEY, C.H.B.; TAYLOR, R.J. On the assessment of surface heat flux and evaporation using large-scale parameters. Monthly Weather Rev., v.100, p.81-92, 1972.

REICHARDT, K. Dinâmica da matéria e da energia em ecossistemas. Piracicaba: DFM/ESALQ/USP. 2ed. 1996. 505p.

ROSENBERG, N.J.; BLAD, B.L.; VERMA, S.B. Microclimate: the biological environment. 2ed. New York: John Wiley and Sons, Inc. 1983. 495p.

SAMANI, Z.A.; PESSARAKLI, M. Estimating potential crop evapotranspiration with minimum data in Arizona. Transactions of the ASAE, v.29, n.2, p.522-524, 1986.

SANTOS, A.O.; BERGAMASCHI, H.; CUNHA, G.R. Necessidades hídricas da alfafa: coeficientes de cultura (Kc) no período pós corte. Rev. Bras. de Agrometeorologia, v.4, n.1, p.37-40, 1996.

SEDIYAMA, G.C. Estimativa da evapotranspiração: histórico, evolução e análise crítica. Rev. Bras. de Agrometeorologia, v.4, n.1, p.i-xii, 1996.

SENTELHAS, P.C. Ocorrência de helmintosporiose (Helminthosporium sativum) e de oídio (Erysiphe graminis) na cultura do trigo (Triticum aestivum, L.) sob diferentes condições microclimáticas. Piracicaba, 1992. 103p. Dissertação (M.S.) - Escola Superior de Agricultura "Luiz de Queiroz", Universidade de São Paulo.

SENTELHAS, P.C.; CAMARGO, A.P. Equação para a estimativa da evapotranspiração potencial no Estado de São Paulo, baseada no método de Hargreaves - 1974. Rev. Bras. de Agrometeorologia, v.4, n.1, p.77-81, 1996. 
SENTELHAS, P.C.; MORAES, S.O.; PIEDADE, S.M.S; PEREIRA, A.R.; ANGELOCCI, L.R.; MARIN, F.R. Análise comparativa de dados meteorológicos obtidos por estações convencional e automática. Rev. Bras. de Agrometeorologia, v.5, n.2, p.215-221, 1997.

SENTELHAS, P.C.; MARIN, F.R.; PEREIRA, A.R.; ANGELOCCI, L.R.; VILLA NOVA, N.A.; BARBIERI, V. Análise dos dados climáticos e do balanço hídrico climatológico de Piracicaba (1917-1997). Piracicaba: DFM/ESALQ/USP. 1998. $81 \mathrm{p}$.

SERRARENS, D.A.; PEREIRA, F.A.C.; SILVA, F.C.; FOLEGATTI, M.V.; FRIZZONE, J.A. Performance de campo de estações meteorológicas automáticas portáteis comparadas a uma estação meteorológica automática padrão. In: SIMPÓSIO DE INICIAÇÃO CIENTÍFICA DA UNIVERSIDADE DE SÃO PAULO, 5, Piracicaba, 1997. Resumos. São Paulo: Universidade de São Paulo, 1997, p.515.

SILVA, F.C. Uso de dispositivos lisimétricos para medida da evapotranspiração de referência. Piracicaba, 1996. 68p. Dissertação (M.S.) - Escola Superior de Agricultura "Luiz de Queiroz", Universidade de São Paulo.

SMITH, M. Report on expert consultation on procedures fro revision of FAO methodologies for crop water requirements. Rome: FAO, 1991. 45p.

SORIANO, B.M.A.; PEREIRA, A.R. Estimativa da evapotranspiração de referência para a sub-região de Nhecolândia, pantanal mato-grossense. Rev. Bras. de Agrometeorologia, v.1, n.1, p.123-129, 1993.

STANHILL, G. A comparison of methods of calculating potential evapotranspiration from climatic data. Israel J. Agric. Res., v.11, p.159-171, 1961. 
TANNER, B.D. Automated weather stations. Remote Sensing Reviews, v.51, p.73-98, 1990.

TESTOLIN, R. An automated system for irrigation trial management. Acta Horticulturae, v.228, p.53-60, 1988.

THOM, A.S.; OLIVER, H.R. On Penman's equation for estimating regional evaporation. Quarterly Journal of the Royal Meteorological Society, v.103, p.345$357,1977$.

THORNTHWAITE, C.W. The moisture factor in climate. Am. Geophys Union Trans., v. 27, p. $41-48,1946$.

THORNTHWAITE, C.W. An approach toward a rational classification of climate. Geogr. Rev, v.38, p.55-94, 1948.

THORNTHWAITE, C.W.; MATHER, J.R. The water balance. Publications in Climatology. New Jersey: Drexel Institute of Technology, 104p. 1955.

VILLAGRA, M.M.; BACCHI, O.O.S.; TUON, R.L.; REICHARDT, K. Difficulties of estimating evapotranspiration from the water balance equation. Agricultural and Forest Meteorology, v.72, p.317-325, 1995.

VILLA NOVA, N.A.; REICHARDT, K. Evaporação/Evapotranspiração de um ecossistema e suas relações com o meio ambiente. Engenharia Hidrológica, Coleção ABRH de Recursos Hídricos, Vol. 2, p.145-197, 1989. 
VILLANUEVA, J.G. Estudo do coeficiente de transparência do vapor d'água sobre a cultura do feijão. Piracicaba, 1987. 58p. Dissertação (M.S.) - Escola Superior de Agricultura "Luiz de Queiroz", Universidade de São Paulo.

VISWANADHAM, Y.; SILVA FILHO, V.P.; ANDRE, R.G.B. The Priestley-Taylor parameter $\alpha$ for the Amazon forest. Forest Ecology Management, v.38, p.211-225, 1991.

WILSON, R.G.; ROUSE, W.R. Moisture and temperature limits of the equilibrium evapotranspiration model. Journal of Applied Meteorology, v.11, p.436-442, 1972.

WMO. Automatic weather stations. Geneva: World Meteorological Organization, 1967. 364p. (Technical Note $n^{\circ} .82$ ).

WMO. Guide to meteorological instruments and methods of observation. Geneva: World Meteorological Organization, 1983.230p. (nº.8, 5th edition).

WOODS, C. Weather network operating: FAWN went on-line Jan. 14. Citrus Industry, v.79, n.2, p.35-37, 1998. 